\title{
Orally Active CCR5 Antagonists as Anti-HIV-1 Agents: Synthesis and Biological Activity of 1-Benzothiepine 1,1-Dioxide and 1-Benzazepine Derivatives Containing a Tertiary Amine Moiety
}

\author{
Masaki Seto, ${ }^{*, a}$ Yoshio Aramaki, ${ }^{a}$ Tomohiro Okawa, ${ }^{a}$ Naoki MiYamoto, ${ }^{a}$ Katsuji Aikawa, ${ }^{a}$ \\ Naoyuki Kanzaki, ${ }^{b}$ Shin-ichi Niwa, ${ }^{c}$ Yuji IIzawa, ${ }^{d}$ Masanori Baba, ${ }^{e}$ and Mitsuru ShiRAishi ${ }^{a}$ \\ ${ }^{a}$ Medicinal Chemistry Research Laboratries, Pharmaceutical Research Division, Takeda Chemical Industries Ltd.; \\ ${ }^{b}$ Pharmaceutical Discovery Center, Pharmaceutical Research Division, Takeda Chemical Industries Ltd.; ${ }^{c}$ Drug Analysis \\ \& Pharmacokinetics Research Laboratories, Pharmaceutical Research Division, Takeda Chemical Industries Ltd.; \\ ${ }^{d}$ Pharmacology Research Laboratories I, Pharmaceutical Research Division, Takeda Chemical Industries Ltd.; 2-17-85 \\ Jusohonmachi, Yodogawa-ku, Osaka 532-8686, Japan: and ${ }^{e}$ Division of Antiviral Chemotherapy, Center for Chronic Viral \\ Diseases, Faculty of Medicine, Kagoshima University; 8-35-1, Sakuragaoka, Kagoshima 890-8520, Japan. \\ Received January 5, 2004; accepted February 24, 2004; published online February 25, 2004
}

The search for orally active CCR5 antagonists was performed by chemical modification of the 1-benzothiepine 1,1-dioxide 3 and 1-benzazepine 4 lead compounds containing a tertiary amine moiety. Replacement of methyl group with a 2-( $\mathrm{C}_{2-4}$ alkoxy)ethoxy group at the 4-position on the 7-phenyl group of the 1-benzothiepine ring resulted in both enhanced activity and significant improvement in the pharmacokinetic properties upon oral administration in rats. Introduction of $\mathrm{C}_{2-4}$ alkyl, phenyl or (hetero)arylmethyl groups as the 1-substituent on the 1-benzazepine ring together with the 2-(butoxy)ethoxy group led to further increase of activity. Among the 1benzazepine derivatives, the isobutyl (6i), benzyl (6o) or 1-methylpyrazol-4-ylmethyl (6s) compounds were found to exhibit highly potent inhibitory effects, equivalent to the injectable CCR5 antagonist 1, in the HIV-1 envelopemediated membrane fusion assay. In particular, compound 6 s showed the most potent CCR5 antagonistic activity $\left(\mathrm{IC}_{50}=2.7 \mathrm{nM}\right)$ and inhibitory effect $\left(\mathrm{IC}_{50}=1.2 \mathrm{nM}\right)$ on membrane fusion, together with good pharmacokinetic properties in rats. The synthesis of 1-benzothiepine 1,1-dioxide and 1-benzazepine derivatives and their biological activity are described.

Key words CCR5 antagonist; HIV-1; 1-benzazepine; 1-benzothiepine 1,1-dioxide; 2-(alkoxy)ethoxy group

In 1996, it was found that the CC chemokine receptor 5 (CCR5) is a coreceptor for the entry of macrophage-tropic (CCR5-using or R5) human immunodeficiency virus type 1 (HIV-1) into host cells. ${ }^{1-5)}$ CCR5 is a member of the G-protein coupled seven-transmembrane domain receptors and its natural ligands [regulated on activation normal T-cell expressed and secreted (RANTES), macrophage inflammatory protein (MIP)- $1 \alpha$ and MIP-1 $\beta$ ] are known to block R5 HIV-1 infection. ${ }^{6}$ It has been found that individuals with a 32-basepair deletion in the CCR5 coding region (CCR5 432 ) are highly resistant to R5 HIV-1 infection, and interestingly, these individuals don't appear to have any significant health problems. $^{7-9)}$

Recently, combination chemotherapy using HIV-1 protease inhibitors and reverse transcriptase inhibitors, called highly active antiretroviral therapy (HAART), has achieved high level and long-term suppression of viral replication in HIV-1 infected individuals. ${ }^{10)}$ However, eradication of HIV-1 is impossible even by HAART, ${ }^{11)}$ and there are several problems with HAART, such as the emergence of drug resistance, sideeffect profiles and difficult dosing regimens. ${ }^{12,13)}$ Therefore, the discovery of novel anti-HIV-1 agents with new mechanisms of action is still needed and CCR5 antagonists as HIV1 entry inhibitors are considered to be a new and attractive target. ${ }^{14,15)}$

We previously discovered a small-molecule, nonpeptide CCR5 antagonist 1 as an anti-HIV-1 agent for injection. ${ }^{16,17)}$ Benzocycloheptene compound $\mathbf{1}$ exhibited highly potent CCR5 antagonistic and anti-HIV activities but poor oral absorption because of its polar quaternary ammonium moiety. We then reported that replacement of the benzocycloheptene ring in the tertiary amine compound 2 (the chemical precursor of 1) with the 1-benzothiepine 1,1-dioxide (3) or 1-benzoazepine (4) ring moieties enhanced the activity. ${ }^{18)} \mathrm{We}$ selected the orally active 1-benzothiepine 1,1-dioxide (3) and 1-benzazepine (4) compounds as new leads, and carried out their chemical modification in order to enhance the activity and to improve the pharmacokinetic profiles. In this paper, we describe the design, synthesis and structure-activity relationships (SAR) of the 1-benzothiepine 1,1-dioxide (5) and 1-benzazepine (6) derivatives.

\section{Chemistry}

The syntheses of the target compounds $(\mathbf{5}, \mathbf{6})$ are shown in Charts 1 and 2. Coupling reaction of the carboxylic acids 7 with 4-[ $N$-methyl- $N$-(tetrahydropyran-4-yl)aminomethyl]aniline $\mathbf{8}^{17)}$ afforded the desired compounds $(\mathbf{5}, \mathbf{6})$ (Chart 1 , Method A). An alternative synthetic method is outlined in Chart 2. The target compounds $(\mathbf{5}, \mathbf{6})$ were prepared by the Suzuki coupling reaction of the anilide derivatives 9 with the phenylboronic acids 10 (Chart 2, Method B).

The 1-benzothiepine-4-carboxylic acid key intermediates $7 \mathbf{a}-\mathbf{e}$ were synthesized according to Chart 3. Methoxycarbonylation of the ketone $\mathbf{1 1}^{18)}$ gave the $\beta$-keto ester, which was then transformed by reduction and subsequent dehydration via methanesulfonylation to afford the 1-benzothiepine4-carboxylate 12. The 1-benzothiepine 1,1-dioxide 13a was obtained by oxidation of $\mathbf{1 2}$ using $30 \%$ aqueous $\mathrm{H}_{2} \mathrm{O}_{2}$. The carboxylic acids $7 \mathbf{a}-\mathbf{e}$ were prepared by the Suzuki coupling reaction of the 7-bromide 13a followed by acid or alkaline hydrolysis.

The syntheses of the 1-benzazepines $13 \mathbf{c}-\mathbf{f}$ are illustrated 


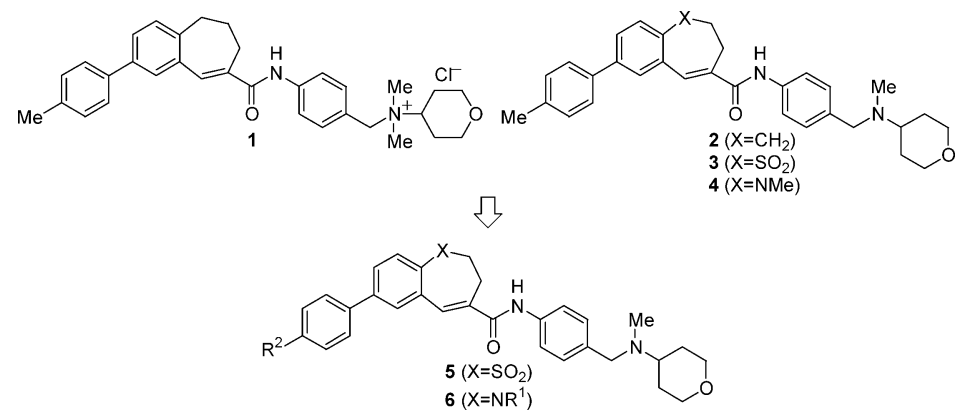

Fig. 1. Compound $\mathbf{1}$ and Lead Compounds of Orally Active CCR5 Antagonists

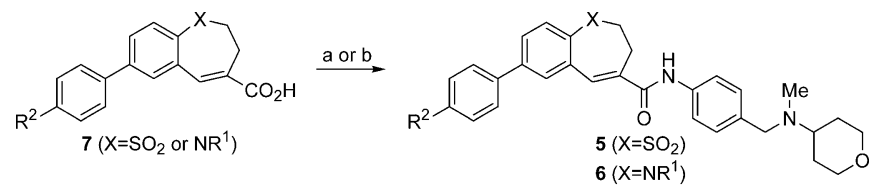

Reagents: (a) (1) $(\mathrm{COCl})_{2}$ or $\mathrm{SOCl}_{2}$, cat. DMF, THF, (2) 8, $\mathrm{Et}_{3} \mathrm{~N}$, THF; (b) 8, EDC, HOBt, $\mathrm{Et}_{3} \mathrm{~N}, \mathrm{DMF}$.

Chart 1

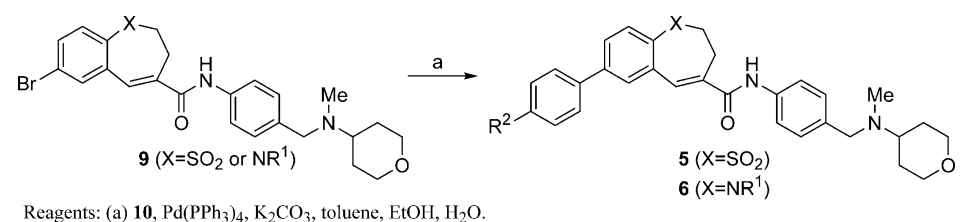

Reagents: (a) 10, $\mathrm{Pd}\left(\mathrm{PPh}_{3}\right)_{4}, \mathrm{~K}_{2} \mathrm{CO}_{3}$, toluene, $\mathrm{EtOH}, \mathrm{H}_{2} \mathrm{O}$.

Chart 2

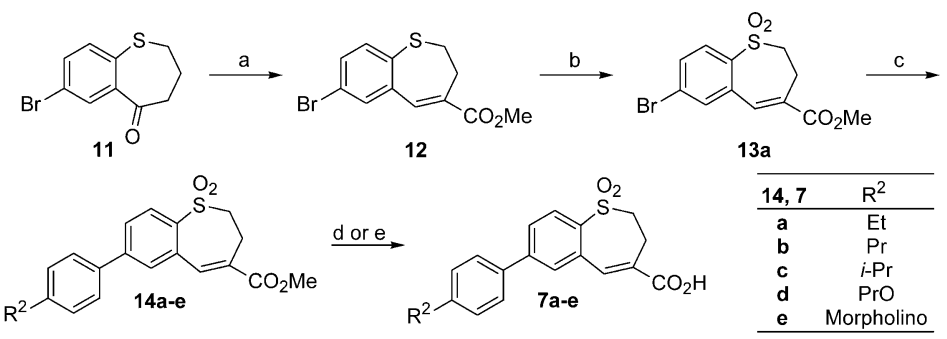

Reagents: (a) (1) NaOMe, (MeO) 2 CO, (2) $\mathrm{NaBH}_{4}, \mathrm{MeOH}, \mathrm{THF}$, (3) $\mathrm{MsCl}_{3} \mathrm{Et}_{3} \mathrm{~N}$, THF, then DBU; (b) $30 \%$ aq. $\mathrm{H}_{2} \mathrm{O}_{2}, \mathrm{AcOH}$; (c) 10, $\mathrm{Pd}\left(\mathrm{PPh}_{3}\right)_{4}, \mathrm{~K}_{2} \mathrm{CO}_{3}$, toluene, $\mathrm{EtOH}, \mathrm{H}_{2} \mathrm{O}$; (d) $6 \mathrm{~N} \mathrm{HCl}$, 1,2-dimethoxyethane; (e) $1 \mathrm{~N}$ $\mathrm{NaOH}, \mathrm{EtOH}, \mathrm{THF}$.

Chart 3

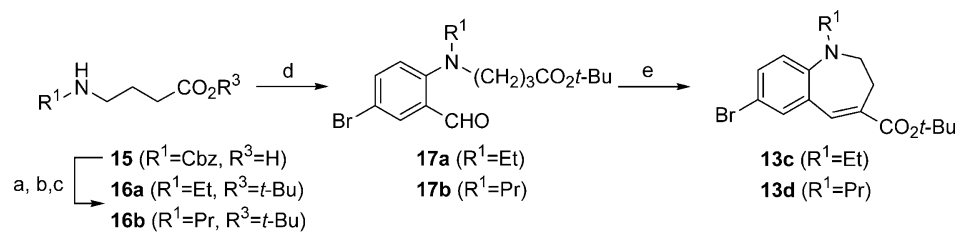

Reagents: (a) EtI or PrI, NaH, THF; (b) $\mathrm{Boc}_{2} \mathrm{O}$, DMAP, $t$-BuOH; (c) $10 \% \mathrm{Pd}-\mathrm{C}, \mathrm{H}_{2}$, conc. $\mathrm{HCl}$, MeOH; (d) 5-bromo-2-fluorobenzaldehyde, $\mathrm{K}_{2} \mathrm{CO}_{3}$, DMF; (e) $t$ - $\mathrm{BuOK}, t$ - $\mathrm{BuOH}$.

Chart 4

in Charts 4 and 5. $N$-Alkylation of the $N$-Cbz protected 4aminobutyric acid 15 , esterification ${ }^{19)}$ and subsequent removal of the $\mathrm{Cbz}$ group afforded the tert-butyl 4-(alkylamino)butyrates 16a, $\mathbf{b}$. Reaction of the amines $\mathbf{1 6 a}, \mathbf{b}$ with 5-bromo-2-fluorobenzaldehyde gave the cyclization precursors 17a,b. The synthesis of 1-benzazepine derivatives 13c, d was accomplished by the intramolecular ClaisenSchmidt type cyclization reaction of $\mathbf{1 7} \mathbf{a}, \mathbf{b}$ using potassium tert-butoxide. The 1-benzazepines $\mathbf{1 3 e}, \mathbf{f}$ were prepared by an alternative method (Chart 5). The 1-benzazepine-5-one $\mathbf{1 9}$ was obtained by the one-pot alkylation of $\mathbf{1 8}^{20)}$ with ethyl 4bromobutyrate and Dieckmann-type condensation, followed by removal of the tosyl group and decarboxylation reaction using sulfuric acid and acetic acid. ${ }^{21)}$ The 1-benzazepine-4carboxylate $\mathbf{2 0}$ was synthesized by a synthetic method similar to that used for 1-benzothiepine-4-carboxylate $\mathbf{1 2}$ after $\mathrm{N}$ Boc protection of 19. Removal of the $N$-Boc group of $\mathbf{2 0}$ gave the 1-unsubstituted 1-benzazepine 21. Reductive amina- 
tion of $\mathbf{2 1}$ with appropriate aldehydes afforded the 1-alkyl-1benzazepines 13e, $\mathbf{f}^{22)}$

The key imtermediates $\mathbf{7 f}-\mathbf{o}$ were prepared according to Chart 6. Suzuki coupling reaction of $\mathbf{2 1}$ and subsequent reductive amination of $\mathbf{2 2}$ with appropriate aldehydes gave $\mathbf{1 4 g}-\mathbf{i}, \mathbf{1 4} \mathbf{k}-\mathbf{o}^{22)}$ The 1-phenyl-1-benzazepine $14 \mathbf{j}$ was synthesized by phenylation of $\mathbf{2 2}$ using triphenylbismuth diacetate and copper(II) pivalate. ${ }^{23)}$ The ester $\mathbf{1 4 f}$ was obtained by the Suzuki coupling reaction of 13e. The 1-benzazepine-4carboxylic acids $\mathbf{7 f}-\mathbf{0}$ were prepared by alkaline hydrolysis of the esters 14f $-\mathbf{0}$.

The synthetic route to the 1-acetyl-1-benzazepine-4-carboxylic acid $\mathbf{7 p}$ is shown in Chart 7. Suzuki coupling reaction of $\mathbf{2 0}$ and subsequent deprotection of the $N$-Boc group
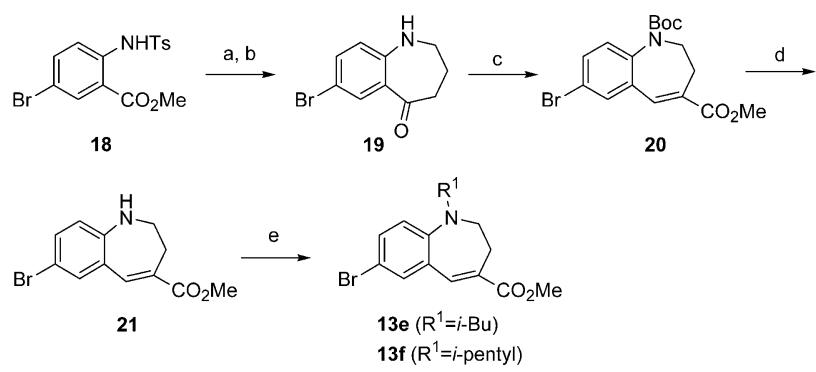

Reagents:(a) (1) $\mathrm{NaH}, \mathrm{NaI}, \mathrm{Br}\left(\mathrm{CH}_{2}\right)_{3} \mathrm{CO}_{2} \mathrm{Et}$, DMF, then $\mathrm{NaH}$; (b) $\mathrm{H}_{2} \mathrm{SO}_{4}, \mathrm{AcOH}$; (c) (1) $\mathrm{Boc}_{2} \mathrm{O}$ DMAP, THF, (2) MeONa, (MeO) 2 CO, (3) $\mathrm{NaBH}_{4}, \mathrm{MeOH}$, THF, (4) $\mathrm{MsCl}, \mathrm{Et} 33 \mathrm{~N}$, THF then DBU; (d) $6 \mathrm{~N} \mathrm{HCl}$, EtOAc; (e) appropriate aldehyde, $\mathrm{NaBH}(\mathrm{OAc})_{3}, 1,2$-dichloroethane. gave the 1-benzazepine $\mathbf{2 4}$. The carboxylic acid $\mathbf{7 p}$ was prepared by acetylation of $\mathbf{2 4}$ and subsequent alkaline hydrolysis.

The other key intermediates, the anilide derivatives $9 \mathbf{a}-\mathbf{e}$, were prepared according to Chart 8 . Acid or alkaline hydrolysis of the compounds 13a - $\mathbf{d}, \mathbf{1 3 f}$ provided the corresponding carboxylic acids 25a-e. Conversion of the carboxylic acids $25 \mathbf{a}-\mathbf{e}$ into the acid chlorides and subsequent condensation with the aniline 8 gave the key intermediates $9 \mathbf{a}-\mathbf{e}$.

The requisite phenylboronic acids $\mathbf{1 0}$ utilized in the Suzuki coupling reaction were available commercially or synthesized according to Chart 9 . The alkoxybromobenzenes $27 \mathbf{a}-\mathbf{f}$ were obtained by alkylation of the 4-bromophenol (26a) or 2-(4bromophenoxy)ethanol (26b). Reaction of the Grignard reagents, generated by reaction of magnesium metal and the corresponding bromobenzenes $\mathbf{2 7} \mathbf{b}-\mathbf{f}$, or phenyllithium, generated by halogen-metal exchange reaction of the bromobenzene 27a, with trimethyl borate gave the 4-substituted phenylboronic acids 10a- $\mathbf{f}$.

The target compounds $(\mathbf{5 a}-\mathbf{d}, \mathbf{6 e}, \mathbf{6} \mathbf{i}, \mathbf{6} \mathbf{k}-\mathbf{s})$ were prepared by condensation of the acid chlorides, generated from the carboxylic acids $(\mathbf{7 a}-\mathbf{d}, \mathbf{7} \mathbf{f}-\mathbf{p})$, with the aniline $\mathbf{8}$ in the presence of triethylamine $\left(\mathrm{Et}_{3} \mathrm{~N}\right)($ Chart 1, Method A). The compound 5e was synthesized by an activated-ester method using 1-ethyl-3-(3-dimethylaminopropyl)carbodiimide hydrochloride (EDC) and 1-hydroxybenzotriazole (HOBt) (Chart 1, Method A). The other target compounds $(\mathbf{5 f}-\mathbf{k}$, $\mathbf{6 a}-\mathbf{d}, \mathbf{6} \mathbf{f}-\mathbf{h}, \mathbf{6 j}$ ) were prepared by the Suzuki coupling re-

Chart 5

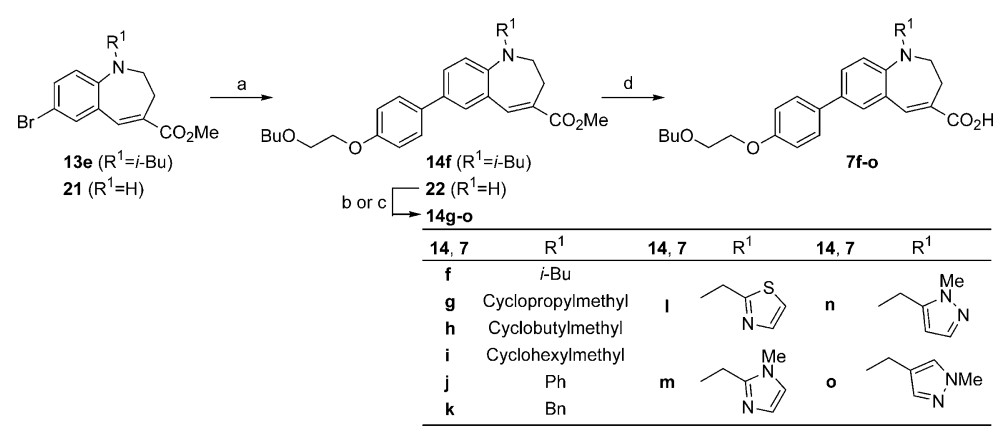

Reagents: (a) 10d, $\mathrm{K}_{2} \mathrm{CO}_{3}$, toluene, EtOH, $\mathrm{H}_{2} \mathrm{O}$; (b) appropriate aldehyde, $\mathrm{NaBH}(\mathrm{OAc})_{3}$, 1,2-dichloroethane; (c) $\mathrm{Ph}_{3} \mathrm{Bi}(\mathrm{OAc})_{2}$, cat. $\mathrm{Cu}(\mathrm{OPiv})_{2}, \mathrm{CH}_{2} \mathrm{Cl}_{2}$; (d) $1 \mathrm{~N} \mathrm{NaOH}, \mathrm{MeOH}$, THF.

Chart 6

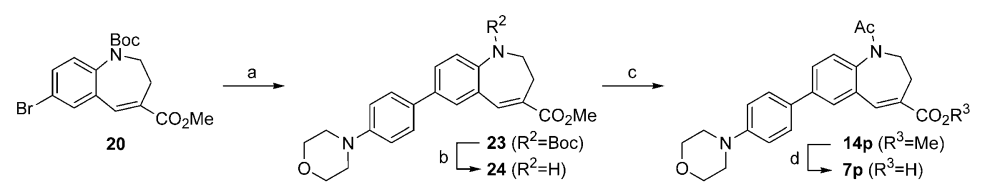

Reagents: (a) 4-(morpholino)phenylboronic acid, $\mathrm{K}_{2} \mathrm{CO}_{3}$, toluene, $\mathrm{EtOH}, \mathrm{H}_{2} \mathrm{O}$; (b) $6 \mathrm{~N} \mathrm{HCl}$, EtOAc; (c) AcCl, pyridine, THF; (d) $1 \mathrm{~N} \mathrm{NaOH}$, MeOH, THF.

Chart 7

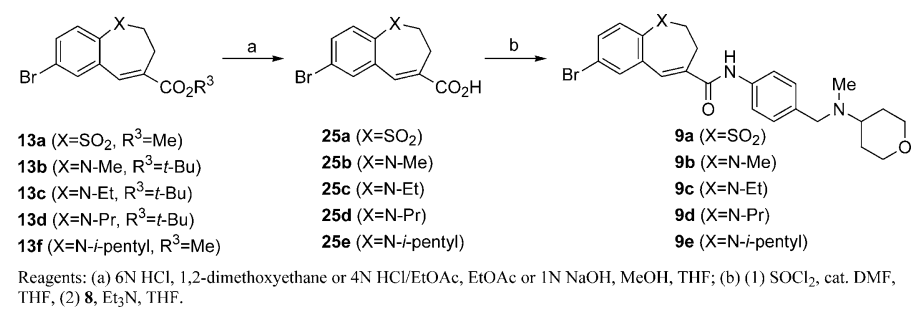


action of the bromides $9 \mathbf{a}-\mathbf{e}$ with the phenylboronic acids 10 (Chart 2, Method B).

\section{Biological Results and Discussion}

The compounds prepared were evaluated for their inhibitory effects on chemokine binding to CCR5-expressing $\mathrm{CHO}$ cells. Binding reactions were performed in the presence of $\left[{ }^{125} \mathrm{I}\right]$ RANTES and various concentrations of the test compounds. The results are summarized in Tables 1 and 2 as $\mathrm{IC}_{50}$ values. The compounds with potent binding inhibitory activity were further evaluated for their inhibitory effects on an HIV-1 envelope (Env)-mediated membrane fusion. The membrane fusion assay was carried out using R5 HIV-1 (JRFL strain) Env-expressing COS-7 cells and CCR5-expressing MOLT- 4 cells. The results are summarized in Table 3 as $\mathrm{IC}_{50}$ values.

First, keeping the 1,1-dioxo-1-benzothiepine moiety in the lead compound $\mathbf{3}$, the effect of the substituent at the 4-position on the 7-phenyl group was investigated (Table 1). As the size of the alkyl group was increased, the activity was found to become more potent $(\mathbf{5 a}, \mathbf{b})$. Thus, the propyl compound 5b had about 6 times greater activity than the methyl one 3 . Replacement of the propyl group (5b) with the propoxy group (5d) retained activity, but substitution with the bulkier isopropyl group (5c) decreased the activity compared with 5b. These results suggested that the linear alkyl or alkoxy group was necessary for potent activity. Interestingly, the

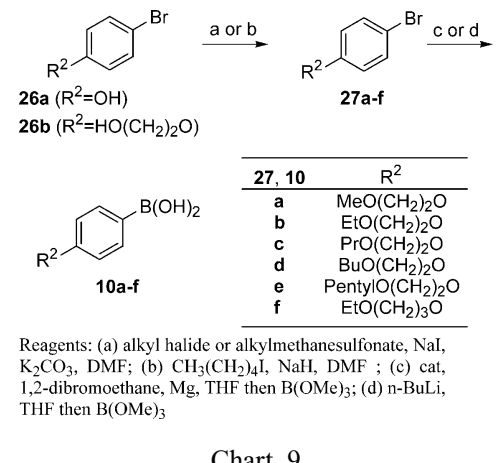

Chart 9 bulky morpholino-substituted compound 5e exhibited relatively potent activity. Therefore, we examined the inhibitory effect of compound 5g with the linear 2-(ethoxy)ethoxy group, which represents a ring-opened morpholino group after replacing the nitrogen atom with oxygen atom. The 2(ethoxy)ethoxy-substituted compound $\mathbf{5 g}$ was as highly active as compound 5d. Furthermore, we investigated the effects of several alkoxyalkoxy groups in place of the 2(ethoxy)ethoxy group. Replacement of the 2-(ethoxy)ethoxy group (5g) with the 2-(propoxy)ethoxy (5h) or 2(butoxy)ethoxy (5i) group retained activity, whereas substitution of the smaller 2-(methoxy)ethoxy (5f) or longer 2(pentyloxy)ethoxy $(\mathbf{5 j})$ group resulted in a relative decrease of activity. Replacement of the 2-(propoxy)ethoxy group (5h) with the 3-(ethoxy)propoxy group (5k) decreased the activity by about half. From these results, it was suggested that the length of alkoxyalkoxy group and position of the oxygen atom were important to exhibit potent activity. Secondly, we examined the inhibitory effects of the potent compounds $\mathbf{5 h}$, $\mathbf{i}$ in the binding assay on the HIV-1 Env-mediated membrane fusion. As shown in Table 3, their inhibitory effects were greatly weaker than their binding inhibitory activities $\left(\mathrm{IC}_{50}=420,410 \mathrm{~nm}\right.$, respectively).

As described in our previous paper, ${ }^{18)}$ change at the 5-position (X) of the benzocycloheptene ring was considered to influence the activity (Fig. 1). Therefore, we targeted another lead compound, 1-benzazepine derivative 4 , in order to enhance the activity. On the basis of the above-mentioned results in the 1-benzothiepine 1,1-dioxides, we mainly modified the 1-substituent on the 1-benzazepine ring. The effect of the 4-substituent on the 7-phenyl group was verified, keeping the 1-methyl-1-benzazepine moiety $(\mathbf{6 a -}-\mathbf{c})$, and the 2(butoxy)ethoxy-substituted compound $\mathbf{6 c}$ was found to exhibit the most potent activity, followed by the 1-benzothiepine derivative 5i. Replacement of the 1-methyl group of $\mathbf{6 a}$ with the 1-ethyl group (6d) retained activity whereas the 1acetyl-1-benzazepine derivative $\mathbf{6 e}$, which was considered as an introduction of an oxygen atom at the 1-position of the ethyl group of $\mathbf{6 d}$, decreased the activity. The 1-ethyl-1-benzazepines with the 2-(propoxy)ethoxy (6f) and 2-(butoxy)-

Table 1. Physical Properties and Inhibitory Effects of Compounds 5 on Chemokine Binding to CCR5-Expressing CHO Cells

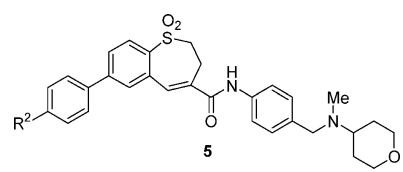

\begin{tabular}{ccccccccc}
\hline \hline Compd. & $\mathrm{R}^{2}$ & $\mathrm{IC}_{50}{ }^{a)}(\mathrm{nm})$ & $\mathrm{mp}\left({ }^{\circ} \mathrm{C}\right)$ & Recrystln. solvent $^{b)}$ & Method & Yield (\%) & Formula & Anal. ${ }^{c)}$ \\
\hline $\mathbf{3}$ & $\mathrm{Me}$ & 200 & & & & & & \\
$\mathbf{5 a}$ & $\mathrm{Et}$ & 60 & $257-260$ & $\mathrm{ET}$ & $\mathrm{A}$ & 61 & $\mathrm{C}_{32} \mathrm{H}_{36} \mathrm{~N}_{2} \mathrm{O}_{4} \mathrm{~S}$ & $\mathrm{CHN}$ \\
$\mathbf{5 b}$ & $\mathrm{Pr}$ & 33 & $247-250$ & $\mathrm{ET}$ & $\mathrm{A}$ & 69 & $\mathrm{C}_{33} \mathrm{H}_{38} \mathrm{~N}_{2} \mathrm{O}_{4} \mathrm{~S}$ & $\mathrm{CHN}$ \\
$\mathbf{5 c}$ & $i-\mathrm{Pr}$ & 120 & $240-247$ & $\mathrm{ET}$ & $\mathrm{A}$ & 67 & $\mathrm{C}_{33} \mathrm{H}_{38} \mathrm{~N}_{2} \mathrm{O}_{4} \mathrm{~S}$ & $\mathrm{CHN}$ \\
$\mathbf{5 d}$ & $\mathrm{PrO}$ & 35 & $244-247$ & $\mathrm{ET}$ & $\mathrm{A}$ & 56 & $\mathrm{C}_{33} \mathrm{H}_{38} \mathrm{~N}_{2} \mathrm{O}_{5} \mathrm{~S}$ & $\mathrm{CHN}$ \\
$\mathbf{5 e}$ & $\mathrm{Morpholino}$ & 70 & $280-282$ & ET-E & $\mathrm{A}$ & 24 & $\mathrm{C}_{34} \mathrm{H}_{39} \mathrm{~N}_{3} \mathrm{O}_{5} \mathrm{~S} \cdot 1.5 \mathrm{H}_{2} \mathrm{O}$ & $\mathrm{CHN}$ \\
$\mathbf{5 f}$ & $\mathrm{MeO}\left(\mathrm{CH}_{2}\right)_{2} \mathrm{O}$ & 140 & $227-231$ & $\mathrm{ET}$ & $\mathrm{B}$ & 72 & $\mathrm{C}_{33} \mathrm{H}_{38} \mathrm{~N}_{2} \mathrm{O}_{6} \mathrm{~S}$ & $\mathrm{CHN}$ \\
$\mathbf{5 g}$ & $\mathrm{EtO}\left(\mathrm{CH}_{2}\right)_{2} \mathrm{O}$ & 34 & $215-217$ & $\mathrm{ET}$ & $\mathrm{B}$ & 75 & $\mathrm{C}_{34} \mathrm{H}_{40} \mathrm{~N}_{2} \mathrm{O}_{6} \mathrm{~S}$ & $\mathrm{CHN}$ \\
$\mathbf{5 h}$ & $\mathrm{PrO}\left(\mathrm{CH}_{2}\right)_{2} \mathrm{O}$ & 35 & $195-197$ & $\mathrm{ET}$ & $\mathrm{B}$ & 45 & $\mathrm{C}_{35} \mathrm{H}_{42} \mathrm{~N}_{2} \mathrm{O}_{6} \mathrm{~S}$ & $\mathrm{CHN}$ \\
$\mathbf{5 i}$ & $\mathrm{BuO}\left(\mathrm{CH}_{2}\right)_{2} \mathrm{O}$ & 27 & $194-196$ & $\mathrm{ET}$ & $\mathrm{B}$ & 68 & $\mathrm{C}_{36} \mathrm{H}_{44} \mathrm{~N}_{2} \mathrm{O}_{6} \mathrm{~S}$ & $\mathrm{CHN}$ \\
$\mathbf{5 j}$ & $\mathrm{PentylO}\left(\mathrm{CH}_{2}\right)_{2} \mathrm{O}$ & 720 & $188-189$ & $\mathrm{ET}$ & $\mathrm{B}$ & 49 & $\mathrm{C}_{37} \mathrm{H}_{46} \mathrm{~N}_{2} \mathrm{O}_{6} \mathrm{~S}$ & $\mathrm{CHN}$ \\
$\mathbf{5 k}$ & $\mathrm{EtO}\left(\mathrm{CH}_{2}\right)_{3} \mathrm{O}$ & 68 & $214-215$ & $\mathrm{ET}$ & $\mathrm{B}$ & 29 & $\mathrm{C}_{35} \mathrm{H}_{42} \mathrm{~N}_{2} \mathrm{O}_{6} \mathrm{~S}$ & $\mathrm{CHN}$ \\
\hline
\end{tabular}

a) The concentration required to inhibit the binding of $\left[{ }^{125} \mathrm{I}\right] \mathrm{RANTES}$ to CCR5-expressing CHO cells by $50 \%$. b) $\mathrm{ET}=\mathrm{ethanol}$, E= diethyl ether. c) All compounds gave satisfactory elemental analysis $( \pm 0.4 \%)$ for $\mathrm{C}, \mathrm{H}$ and $\mathrm{N}$. 
Table 2. Physical Properties and Inhibitory Effects of Compounds 6 on Chemokine Binding to CCR5-expressing CHO Cells

\begin{tabular}{|c|c|c|c|c|c|c|c|c|c|}
\hline Compd. & $\mathrm{R}^{1}$ & $\mathrm{R}^{2}$ & $\mathrm{IC}_{50}{ }^{a)}(\mathrm{nM})$ & $\mathrm{mp}\left({ }^{\circ} \mathrm{C}\right)$ & Recrystln. solvent ${ }^{b)}$ & Method & Yield (\%) & Formula & Anal. $^{c)}$ \\
\hline 4 & $\mathrm{Me}$ & $\mathrm{Me}$ & 130 & & & & & & \\
\hline $6 a$ & $\mathrm{Me}$ & Morpholino & 49 & $209-211$ & ET & $\mathrm{B}$ & 86 & $\mathrm{C}_{35} \mathrm{H}_{42} \mathrm{~N}_{4} \mathrm{O}_{3}$ & $\mathrm{CHN}$ \\
\hline $6 \mathbf{b}$ & $\mathrm{Me}$ & $\mathrm{PrO}\left(\mathrm{CH}_{2}\right)_{2} \mathrm{O}$ & 68 & $136-138$ & ET & $\mathrm{B}$ & 35 & $\mathrm{C}_{36} \mathrm{H}_{45} \mathrm{~N}_{3} \mathrm{O}_{4} \cdot 0.25 \mathrm{H}_{2} \mathrm{O}$ & $\mathrm{CHN}$ \\
\hline $6 c$ & $\mathrm{Me}$ & $\mathrm{BuO}\left(\mathrm{CH}_{2}\right)_{2} \mathrm{O}$ & 21 & $107-110$ & EA-IPE & B & 53 & $\mathrm{C}_{37} \mathrm{H}_{47} \mathrm{~N}_{3} \mathrm{O}_{4} \cdot 0.1 \mathrm{H}_{2} \mathrm{O}$ & $\mathrm{CHN}$ \\
\hline $6 d$ & Et & Morpholino & 51 & $193-194$ & ET & $\mathrm{B}$ & 37 & $\mathrm{C}_{36} \mathrm{H}_{44} \mathrm{~N}_{4} \mathrm{O}_{3}$ & $\mathrm{CHN}$ \\
\hline $6 e$ & Ac & Morpholino & 200 & $141-145$ & EA-H & A & 21 & $\mathrm{C}_{36} \mathrm{H}_{42} \mathrm{~N}_{4} \mathrm{O}_{4}$ & $\mathrm{CHN}$ \\
\hline $6 f$ & Et & $\mathrm{PrO}\left(\mathrm{CH}_{2}\right)_{2} \mathrm{O}$ & 17 & $106-108$ & EA-IPE & $\mathrm{B}$ & 46 & $\mathrm{C}_{37} \mathrm{H}_{47} \mathrm{~N}_{3} \mathrm{O}_{4} \cdot 0.25 \mathrm{H}_{2} \mathrm{O}$ & $\mathrm{CHN}$ \\
\hline $6 \mathrm{~g}$ & Et & $\mathrm{BuO}\left(\mathrm{CH}_{2}\right)_{2} \mathrm{O}$ & 5.6 & $102-106$ & EA-IPE & $\mathrm{B}$ & 42 & $\mathrm{C}_{38} \mathrm{H}_{49} \mathrm{~N}_{3} \mathrm{O}_{4} \cdot 0.2 \mathrm{H}_{2} \mathrm{O}$ & $\mathrm{CHN}$ \\
\hline $6 \mathrm{~h}$ & $\operatorname{Pr}$ & $\mathrm{BuO}\left(\mathrm{CH}_{2}\right)_{2} \mathrm{O}$ & 3.5 & $118-121$ & EA-IPE & $\mathrm{B}$ & 50 & $\mathrm{C}_{39} \mathrm{H}_{51} \mathrm{~N}_{3} \mathrm{O}_{4}$ & $\mathrm{CHN}$ \\
\hline $6 \mathbf{i}$ & $i-\mathrm{Bu}$ & $\mathrm{BuO}\left(\mathrm{CH}_{2}\right)_{2} \mathrm{O}$ & 3.6 & $74-75$ & EA-H & A & 56 & $\mathrm{C}_{40} \mathrm{H}_{53} \mathrm{~N}_{3} \mathrm{O}_{4}$ & $\mathrm{CHN}$ \\
\hline $6 \mathbf{j}$ & $i$-Pentyl & $\mathrm{BuO}\left(\mathrm{CH}_{2}\right)_{2} \mathrm{O}$ & 32 & Amorphous & - & $\mathrm{B}$ & 9 & $\mathrm{C}_{41} \mathrm{H}_{55} \mathrm{~N}_{3} \mathrm{O}_{4}$ & $\mathrm{CHN}$ \\
\hline $6 \mathbf{k}$ & & $\mathrm{BuO}\left(\mathrm{CH}_{2}\right)_{2} \mathrm{O}$ & 4.5 & $92-94$ & EA-H & A & 86 & $\mathrm{C}_{40} \mathrm{H}_{51} \mathrm{~N}_{3} \mathrm{O}_{4}$ & $\mathrm{CHN}$ \\
\hline 61 & & $\mathrm{BuO}\left(\mathrm{CH}_{2}\right)_{2} \mathrm{O}$ & 12 & Amorphous & - & A & 61 & $\mathrm{C}_{41} \mathrm{H}_{53} \mathrm{~N}_{3} \mathrm{O}_{4} \cdot 2 \mathrm{HCl} \cdot 1.5 \mathrm{H}_{2} \mathrm{O}$ & $\mathrm{CHN}$ \\
\hline $6 \mathrm{~m}$ & & $\mathrm{BuO}\left(\mathrm{CH}_{2}\right)_{2} \mathrm{O}$ & 14 & $115-117$ & E-EA-H & A & 78 & $\mathrm{C}_{43} \mathrm{H}_{57} \mathrm{~N}_{3} \mathrm{O}_{4}$ & $\mathrm{CHN}$ \\
\hline $6 n$ & $\mathrm{Ph}$ & $\mathrm{BuO}\left(\mathrm{CH}_{2}\right)_{2} \mathrm{O}$ & 5.6 & Amorphous & - & A & 58 & $\mathrm{C}_{42} \mathrm{H}_{49} \mathrm{~N}_{3} \mathrm{O}_{4} \cdot 0.25 \mathrm{H}_{2} \mathrm{O}$ & $\mathrm{CHN}$ \\
\hline 60 & $\mathrm{Bn}$ & $\mathrm{BuO}\left(\mathrm{CH}_{2}\right)_{2} \mathrm{O}$ & 5.3 & $127-131$ & EA-H & A & 61 & $\mathrm{C}_{43} \mathrm{H}_{51} \mathrm{~N}_{3} \mathrm{O}_{4} \cdot 0.25 \mathrm{H}_{2} \mathrm{O}$ & $\mathrm{CHN}$ \\
\hline $6 p$ & & $\mathrm{BuO}\left(\mathrm{CH}_{2}\right)_{2} \mathrm{O}$ & 12 & Amorphous & - & A & 57 & $\mathrm{C}_{40} \mathrm{H}_{48} \mathrm{~N}_{4} \mathrm{O}_{4} \mathrm{~S}$ & $\mathrm{CHN}$ \\
\hline $6 q$ & & $\mathrm{BuO}\left(\mathrm{CH}_{2}\right)_{2} \mathrm{O}$ & 12 & Amorphous & - & A & 33 & $\mathrm{C}_{41} \mathrm{H}_{51} \mathrm{~N}_{5} \mathrm{O}_{4} \cdot 0.5 \mathrm{H}_{2} \mathrm{O}$ & $\mathrm{CHN}$ \\
\hline $6 \mathbf{r}$ & & $\mathrm{BuO}\left(\mathrm{CH}_{2}\right)_{2} \mathrm{O}$ & 10 & Amorphous & - & A & 21 & $\mathrm{C}_{41} \mathrm{H}_{51} \mathrm{~N}_{5} \mathrm{O}_{4} \cdot 0.25 \mathrm{H}_{2} \mathrm{O}$ & $\mathrm{CHN}$ \\
\hline $6 s$ & & $\mathrm{BuO}\left(\mathrm{CH}_{2}\right)_{2} \mathrm{O}$ & 2.7 & $113-115$ & EA-H & A & 13 & $\mathrm{C}_{41} \mathrm{H}_{51} \mathrm{~N}_{5} \mathrm{O}_{4}$ & $\mathrm{CHN}$ \\
\hline
\end{tabular}

a) The concentration required to inhibit the binding of $\left[{ }^{125} \mathrm{I}\right] \mathrm{RANTES}$ to CCR5-expressing CHO cells by $50 \%$. b) $\mathrm{ET}=\mathrm{ethanol}$, EA=ethyl acetate, IPE $=$ diisopropyl ether, $\mathrm{H}=$ hexane, $\mathrm{E}=$ diethyl ether. c) All compounds gave satisfactory elemental analysis $( \pm 0.4 \%)$ for $\mathrm{C}, \mathrm{H}$ and $\mathrm{N}$.

ethoxy $(\mathbf{6 g})$ groups were more active than the corresponding 1-methyl-1-benzazepines $\mathbf{6 b}$ and $\mathbf{6 c}$. These results suggested that the 2-(butoxy)ethoxy group was optimal as the 4-substituent on the 7-phenyl group and that enlarging the size of the 1-alkyl group led to enhancement of activity. Therefore, we investigated the effects of various alkyl groups at the 1position on the 1-benzazepine ring, while retaining the 2-(butoxy)ethoxy group $(\mathbf{6} \mathbf{h}-\mathbf{m})$. Introduction of the propyl $(\mathbf{6 h})$ or isobutyl (6i) group further increased the binding inhibitory activity. However, replacement with the bulkier isopentyl group $(\mathbf{6 j})$ resulted in a relative reduction of activity. The cyclopropylmethyl compound $\mathbf{6 k}$, which represents a cyclized isobutyl group, retained the potent activity. Enlarging the ring size from cyclopropylmethyl group (6k) to cyclobutylmethyl (6l) or cyclohexylmethyl (6m) groups decreased the activity by about a third. In addition, we determined the effects of 1-phenyl and 1-(substituted)methyl groups such as benzyl and 5-membered heteroarylmethyl groups, considering the propyl, isobutyl and cyclopropylmethyl groups with appropriate bulkiness were most active $(\mathbf{6 n}-\mathbf{s})$. The phenyl (6n), benzyl (6o) and 1-methylpyrazol4-ylmethyl (6s) compounds were as highly active as the isobutyl (6i) and cyclopropylmethyl (6k) compounds, whereas the thiazol-2-ylmethyl (6p), 1-methylimidazol-2-ylmethyl (6q) and 1-methylpyrazol-5-ylmethyl (6r) compounds, the isomer of $\mathbf{6 s}$, exhibited relatively weak activity. Among the 1-benzazepine derivatives 6, the propyl $(\mathbf{6 h})$, isobutyl (6i) and 1-methylpyrazol-4-ylmethyl (6s) compounds showed most potent CCR5 antagonistic activity, comparable to compound $\mathbf{1}$. From the results of the SAR study, it was suggested that there might be 3 pockets in the binding
Table 3. Inhibitory Effects of Compounds $\mathbf{4}$ and $\mathbf{5}$ on HIV-1 Env-Mediated Membrane Fusion

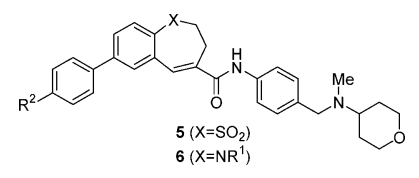

\begin{tabular}{ccrcc}
\hline \hline & & & RANTES & Fusion \\
\cline { 4 - 5 } Compd. & $\mathrm{X}$ & $\mathrm{R}^{2}$ & & \\
& & & $\mathrm{IC}_{50}{ }^{a)}(\mathrm{nM})$ & $\mathrm{IC}_{50}{ }^{b)}(\mathrm{nM})$ \\
\hline $\mathbf{1}$ & - & - & 1.4 & 1.4 \\
$\mathbf{5 h}$ & $\mathrm{SO}_{2}$ & $\mathrm{PrO}\left(\mathrm{CH}_{2}\right)_{2} \mathrm{O}$ & 35 & 420 \\
$\mathbf{5 i}$ & $\mathrm{SO}_{2}$ & $\mathrm{BuO}\left(\mathrm{CH}_{2}\right)_{2} \mathrm{O}$ & 27 & 410 \\
$\mathbf{6 g}$ & $\mathrm{N}-\mathrm{Et}$ & $\mathrm{BuO}\left(\mathrm{CH}_{2}\right)_{2} \mathrm{O}$ & 5.6 & 1000 \\
$\mathbf{6 h}$ & $\mathrm{N}-\mathrm{Pr}$ & $\mathrm{BuO}\left(\mathrm{CH}_{2}\right)_{2} \mathrm{O}$ & 3.5 & 54 \\
$\mathbf{6 i}$ & $\mathrm{N}-i-\mathrm{Bu}$ & $\mathrm{BuO}\left(\mathrm{CH}_{2}\right)_{2} \mathrm{O}$ & 3.6 & 1.7 \\
$\mathbf{6 k}$ & $\mathrm{N}-\nabla$ & $\mathrm{BuO}\left(\mathrm{CH}_{2}\right)_{2} \mathrm{O}$ & 4.5 & 150 \\
$\mathbf{6 n}$ & $\mathrm{N}-\mathrm{Ph}$ & $\mathrm{BuO}\left(\mathrm{CH}_{2}\right)_{2} \mathrm{O}$ & 5.6 & 19 \\
$\mathbf{6 0}$ & $\mathrm{N}-\mathrm{Bn}$ & $\mathrm{BuO}\left(\mathrm{CH}_{2}\right)_{2} \mathrm{O}$ & 5.3 & 2.3 \\
$\mathbf{6 s}$ & $\mathrm{N}^{\mathrm{N}}-\mathrm{N}_{\mathrm{N}-\mathrm{Me}}$ & $\mathrm{BuO}\left(\mathrm{CH}_{2}\right)_{2} \mathrm{O}$ & 2.7 & 1.2 \\
\hline
\end{tabular}

a) The concentration required to inhibit the binding of $\left[{ }^{125} \mathrm{I}\right] \mathrm{RANTES}$ to CCR5 expressing $\mathrm{CHO}$ cells by $50 \%$. b) The concentration required to inhibit the membrane fusion between HIV-1 Env-expressing COS-7 cells and CCR5-expressing MOLT-4 cells by $50 \%$.

sites on CCR5 [for the tertiary amine moiety, the 1-substituent and the 7-(4-substitutedphenyl) group on the 1-benzazepine ring] and that the shape of molecules was essential for optimal CCR5 antagonistic activity.

We finally evaluated the inhibitory effects of the highly potent 1-benzazepines in the RANTES binding assay on the HIV-1 Env-mediated membrane fusion (Table 3). The effects 
of the isobutyl (6i), benzyl (6o) and 1-methylpyrazol-4-ylmethyl (6s) compounds in the fusion assay were similar to those in the receptor binding assay. Additionally, the compounds $(\mathbf{6} \mathbf{i}, \mathbf{0}, \mathbf{s})$ greatly increased the anti-HIV-1 potency as compared with the ethyl (6g) and cyclopropylmethyl (6k) compounds, which remarkably reduced activity. The propyl (6h) and phenyl (6n) compounds showed moderate activity. From these results, it was found that isobutyl or (hetero)arylmethyl groups with suitable bulkiness, such as benzyl or 1methylpyrazol-4-ylmtehyl, were necessary as the 1-substituent on the 1-benzazepine ring for highly potent inhibitory activity in the membrane fusion assay.

\section{Pharmacokinetic Studies}

Preliminary pharmacokinetic studies of typical compounds with potent activity were investigated in rats. The compounds were orally administered at $10 \mathrm{mg} / \mathrm{kg}$ to $\mathrm{SD}$ (IGS) rats and the results are summarized in Table 4. The 1benzothiepine 1,1-dioxide 5d with a propoxy group showed about 6 times higher plasma level than the methyl-substituted compound 3, whereas plasma level of the ethyl compound 5a was similar to that of 3 . Reduction of the molecular lipophilicity was considered to lead to the improvement in the pharmacokinetic profiles. However, introduction of the polar morpholino group (5e) resulted in only slight improvement of pharmacokinetic profiles in comparison with compound 3 owing to its probably low solubility. Surprisingly, replacing the rigid morpholino group with the flexible 2(alkoxy)ethoxy group (5g-i) brought about remarkable improvement in the pharmacokinetic profiles together with increase of activity. Especially, the 2-(propoxy)ethoxy (5h) and 2-(butoxy)ethoxy (5i) compounds had significantly increased oral plasma levels. Thus, the 2-(butoxy)ethoxy compound $\mathbf{5 i}$ showed about 75 -fold $C_{\max }$ and 160 -fold $A U C$ values, when compared with the methyl compound 3. Next, the 1-benzazepine derivatives with the 2-(butoxy)ethoxy group were examined. The 1-propyl-1-benzazepine $\mathbf{6 h}$ exhibited about 10 times higher plasma level after oral administration compared with the lead compound 4. On the other hand, the plasma level of the 1-isobutyl compound 6i was not very high, probably due to its high lipophilicity. The 1-methylpyrazol-4-ylmethyl compound $\mathbf{6 s}$ had reduced lipophilicity and exhibited a $c a$. 5-fold increase in both $C_{\max }$ and $A U C$ values when compared with the lead compound 4.

\section{Conclusion}

The search for orally active CCR5 antagonists was performed by chemical modification of the 1-benzothiepine 1,1dioxide $\mathbf{3}$ and 1-benzazepine $\mathbf{4}$ lead compounds containing a tertiary amine moiety. Replacement of the methyl group with a 2-(butoxy)- or 2-(propoxy)ethoxy group at the 4-position on the 7-phenyl group of the 1-benzothiepine ring, not only resulted in enhanced activity but also significantly improved the pharmacokinetic properties upon oral administration in rats. Introduction of $\mathrm{C}_{2-4}$ alkyl, phenyl or (hetero)arylmethyl groups as the 1-substituent on the 1-benzazepine ring together with the 2-(butoxy)ethoxy group led to further increase in activity. Among the 1-benzazepine derivatives, the isobutyl (6i), benzyl (6o) or 1-methylpyrazol-4-ylmethyl (6s) compounds exhibited highly potent inhibitory effects, equivalent to the injectable CCR5 antagonist 1, in the HIV-1 Env-
Table 4. Pharmacokinetic Parameters of Compounds 5 and 6 in Rats

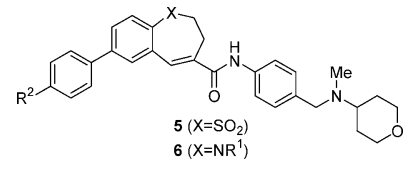

Oral administration ${ }^{a)}$

\begin{tabular}{|c|c|c|c|c|c|}
\hline \multirow[b]{2}{*}{ Compd. } & \multirow[b]{2}{*}{$X$} & \multirow[b]{2}{*}{$\mathrm{R}^{2}$} & \multirow[b]{2}{*}{$\begin{array}{c}C_{\max }^{b)} \\
(\mu \mathrm{g} / \mathrm{ml})\end{array}$} & \multirow[b]{2}{*}{$\begin{array}{c}T_{\max }^{c)} \\
\text { (h) }\end{array}$} & \multirow[b]{2}{*}{$\begin{array}{c}\left.A U C_{0-24 \mathrm{~h}}{ }^{d}\right) \\
(\mu \mathrm{gh} / \mathrm{ml})\end{array}$} \\
\hline & & & & & \\
\hline 3 & $\mathrm{SO}_{2}$ & $\mathrm{Me}$ & 0.16 & 3.3 & 1.55 \\
\hline 4 & $\mathrm{~N}-\mathrm{Me}$ & $\mathrm{Me}$ & 0.11 & 4.0 & 1.56 \\
\hline 5a & $\mathrm{SO}_{2}$ & Et & 0.17 & 5.3 & 2.23 \\
\hline $5 d$ & $\mathrm{SO}_{2}$ & $\mathrm{PrO}$ & 1.02 & 5.3 & 13.0 \\
\hline $5 \mathbf{e}^{e)}$ & $\mathrm{SO}_{2}$ & Morpholino & 0.26 & 1.7 & 2.55 \\
\hline $5 g$ & $\mathrm{SO}_{2}$ & $\mathrm{EtO}\left(\mathrm{CH}_{2}\right)_{2} \mathrm{O}$ & 4.48 & 5.3 & 64.1 \\
\hline $5 h$ & $\mathrm{SO}_{2}$ & $\mathrm{PrO}\left(\mathrm{CH}_{2}\right)_{2} \mathrm{O}$ & 13.6 & 4.0 & 213 \\
\hline $5 i$ & $\mathrm{SO}_{2}$ & $\mathrm{BuO}\left(\mathrm{CH}_{2}\right)_{2} \mathrm{O}$ & 11.8 & 10.7 & 244 \\
\hline $6 h$ & $\mathrm{~N}-\mathrm{Pr}$ & $\mathrm{BuO}\left(\mathrm{CH}_{2}\right)_{2} \mathrm{O}$ & 1.15 & 5.3 & 17.2 \\
\hline $6 \mathbf{i}$ & $\mathrm{N}-i-\mathrm{Bu}$ & $\mathrm{BuO}\left(\mathrm{CH}_{2}\right)_{2} \mathrm{O}$ & 0.08 & 5.3 & 1.03 \\
\hline $6 s$ & ${ }^{\mathrm{N}} \overbrace{\mathrm{N}}^{\mathrm{N}-\mathrm{Me}}$ & $\mathrm{BuO}\left(\mathrm{CH}_{2}\right)_{2} \mathrm{O}$ & 0.59 & 5.3 & 8.35 \\
\hline
\end{tabular}

a) Compounds $(10 \mathrm{mg} / \mathrm{kg})$ suspended in $0.5 \%$ methylcellulose were orally administered to SD (IGS) rats (male, 8 weeks old, $n=3$ ). b) Maximum plasma concentration after $10 \mathrm{mg} / \mathrm{kg}$ oral dosing. $c$ ) Time to $C_{\text {a }} . \quad d$ ) Area under the concentration time curve for $0-24 \mathrm{~h}$ after $10 \mathrm{mg} / \mathrm{kg}$ oral dosing. e) 5e hydrochloride was used.

mediated membrane fusion assay. In particular, compound $\mathbf{6 s}$ showed the most potent CCR5 antagonistic activity $\left(\mathrm{IC}_{50}=2.7 \mathrm{~nm}\right)$ and inhibitory effect $\left(\mathrm{IC}_{50}=1.2 \mathrm{nM}\right)$ on the membrane fusion, together with good pharmacokinetic properties in rats.

\section{Experimental}

Melting points were determined on a Yanagimoto micro melting point apparatus, and are uncorrected. Proton nuclear magnetic resonance ( $\left.{ }^{1} \mathrm{H}-\mathrm{NMR}\right)$ spectra were recorded on a Varian Gemini-200 $(200 \mathrm{MHz})$ spectrometer. Chemical shifts are given in parts per million (ppm) with tetramethylsilane as an internal standard, and coupling constants ( $J$ values) are given in Hertz $(\mathrm{Hz})$. Elemental analyses were carried out by Takeda Analytical Research Laboratories, Ltd., and results obtained were within $\pm 0.4 \%$ of the theoretical values. Column chromatography was carried out on a silica gel column (Kieselgel 60, 63-200 mesh, Merck). Yields were not optimized.

Methyl 7-Bromo-2,3-dihydro-1-benzothiepine-4-carboxylate (12) To a solution of $\left.11^{18}\right)(96.0 \mathrm{~g}, 373 \mathrm{mmol})$ in dimethyl carbonate $(684 \mathrm{ml})$ was added sodium methoxide $(101 \mathrm{~g}, 1870 \mathrm{mmol})$ at room temperature, and the mixture was refluxed for $5 \mathrm{~h}$ under a nitrogen atmosphere. The mixture was acidified using $3 \mathrm{~N} \mathrm{HCl}$ under ice cooling, and the mixture was extracted with EtOAc. The organic layer was washed with brine, dried over $\mathrm{MgSO}_{4}$, and concentrated in vacuo to give $103 \mathrm{~g}(88 \%)$ of methyl 7-bromo-5-oxo2,3,4,5-tetrahydro-1-benzothiepine-4-carboxylate as a pale brown solid. To a solution of methyl 7-bromo-5-oxo-2,3,4,5-tetrahydro-1-benzothiepine-4-carboxylate $(71.2 \mathrm{~g}, 226 \mathrm{mmol})$ in tetrahydrofuran (THF) was added $\mathrm{NaBH}_{4}$ $(8.15 \mathrm{~g}, 215 \mathrm{mmol})$ at $-40^{\circ} \mathrm{C}$. $\mathrm{MeOH}(100 \mathrm{ml})$ was added to the mixture at $-40^{\circ} \mathrm{C}$, and the mixture was stirred at $-10--20^{\circ} \mathrm{C}$ for $1 \mathrm{~h}$. Water was added to the reaction mixture and the mixture was extracted with EtOAc. The organic layer was washed with brine, dried over $\mathrm{MgSO}_{4}$, and concentrated in vacuo. To a solution of the residue and $\mathrm{Et}_{3} \mathrm{~N}(60.0 \mathrm{ml}, 430 \mathrm{mmol})$ in THF $(500 \mathrm{ml})$ was added methanesulfonyl chloride $(\mathrm{MsCl})(25.0 \mathrm{ml}$, $323 \mathrm{mmol}$ ) under ice cooling. The mixture was stirred under ice cooling for $0.5 \mathrm{~h}$ and at room temperature for $1 \mathrm{~h}$. To the mixture was added 1,8-diazabicyclo[5,4,0]undec-7-ene (DBU) $(51.6 \mathrm{~g}, 339 \mathrm{mmol})$ at room temperature. After being stirred at room temperature for $10 \mathrm{~min}$, water was added to the mixture, and the mixture was extracted with EtOAc. The organic layer was washed with water and brine, dried over $\mathrm{MgSO}_{4}$, and concentrated in vacuo. The residue was purified by column chromatography (hexane $:$ EtOAc $=4: 1$ ) to give $37.2 \mathrm{~g}(55 \%)$ of $\mathbf{1 2}$ as pale yellow crystals, mp $94-95{ }^{\circ} \mathrm{C} .{ }^{1} \mathrm{H}-\mathrm{NMR}$ $\left(\mathrm{CDCl}_{3}\right) \delta 2.94-3.00(2 \mathrm{H}, \mathrm{m}), 3.15-3.21(2 \mathrm{H}, \mathrm{m}), 3.83(3 \mathrm{H}, \mathrm{s}), 7.28$ $7.33(2 \mathrm{H}, \mathrm{m}), 7.51(1 \mathrm{H}, \mathrm{d}, J=1.2 \mathrm{~Hz}), 7.70(1 \mathrm{H}, \mathrm{s})$. Anal. Calcd for $\mathrm{C}_{12} \mathrm{H}_{11} \mathrm{BrO}_{2} \mathrm{~S}: \mathrm{C}, 48.17$; H, 3.71. Found: C, 48.37; H, 3.77. 
Methyl 7-Bromo-2,3-dihydro-1-benzothiepine-4-carboxylate 1,1-Dioxide (13a) To a mixture of $12(3.00 \mathrm{~g}, 10.0 \mathrm{mmol})$ and acetic acid $(30 \mathrm{ml})$ was added $30 \%$ aqueous $\mathrm{H}_{2} \mathrm{O}_{2}(4.50 \mathrm{ml})$ at room temperature. After being refluxed for $1 \mathrm{~h}$, the reaction mixture was poured into water. The precipitated colorless crystals were collected by filtration, washed with water and diisopropyl ether $\left(i-\mathrm{Pr}_{2} \mathrm{O}\right)$ to give $3.06 \mathrm{~g}(90 \%)$ of $\mathbf{1 3 a}$ as colorless crystals, $\mathrm{mp}$ $162-164^{\circ} \mathrm{C} .{ }^{1} \mathrm{H}-\mathrm{NMR}\left(\mathrm{CDCl}_{3}\right) \delta 3.11(2 \mathrm{H}, \mathrm{t}, J=6.5 \mathrm{~Hz}), 3.62(2 \mathrm{H}, \mathrm{t}$ $J=6.5 \mathrm{~Hz}), 3.87(3 \mathrm{H}, \mathrm{s}), 7.64-7.76(3 \mathrm{H}, \mathrm{m}), 8.03(1 \mathrm{H}, \mathrm{d}, J=8.4 \mathrm{~Hz})$. Anal. Calcd for $\mathrm{C}_{12} \mathrm{H}_{11} \mathrm{BrO}_{4} \mathrm{~S}$ : C, 43.52; H, 3.35. Found: C, 43.52; H, 3.18.

Methyl 7-(4-Ethylphenyl)-2,3-dihydro-1-benzothiepine-4-carboxylate 1,1-Dioxide (14a) A mixture of 13a $(0.80 \mathrm{~g}, 2.42 \mathrm{mmol})$, 4-ethylphenylboronic acid $(0.40 \mathrm{~g}, 2.67 \mathrm{mmol})$ and $\mathrm{K}_{2} \mathrm{CO}_{3}(0.67 \mathrm{~g}, 4.85 \mathrm{mmol})$ in toluene $(30 \mathrm{ml}), \mathrm{EtOH}(3.0 \mathrm{ml})$ and water $(3.0 \mathrm{ml})$ was stirred at room temperature under an argon atmosphere for $1 \mathrm{~h}$. Tetrakis(triphenylphosphine)palladium $\left(\mathrm{Pd}\left(\mathrm{PPh}_{3}\right)_{4}\right)(0.14 \mathrm{~g}, 0.12 \mathrm{mmol})$ was added, and the mixture was refluxed for $15 \mathrm{~h}$ under an argon atmosphere. The reaction mixture was extracted with EtOAc. The organic layer was washed with brine, dried over $\mathrm{MgSO}_{4}$, and concentrated in vacuo. The residue was purified by column chromatography (hexane : EtOAc $=1: 1)$ to give $732 \mathrm{mg}(85 \%)$ of $\mathbf{1 4 a}$ as pale yellow crystals, mp $173-176^{\circ} \mathrm{C} .{ }^{1} \mathrm{H}-\mathrm{NMR}\left(\mathrm{CDCl}_{3}\right) \delta 1.29(3 \mathrm{H}, \mathrm{t}, J=7.5 \mathrm{~Hz}), 2.72(2 \mathrm{H}, \mathrm{q}$, $J=7.5 \mathrm{~Hz}), 3.11-3.18(2 \mathrm{H}, \mathrm{m}), 3.62-3.68(2 \mathrm{H}, \mathrm{m}), 3.87(3 \mathrm{H}, \mathrm{s}), 7.33(2 \mathrm{H}$, d, $J=8.1 \mathrm{~Hz}), 7.54(2 \mathrm{H}, \mathrm{d}, J=8.1 \mathrm{~Hz}), 7.66-7.74(2 \mathrm{H}, \mathrm{m}), 7.92(1 \mathrm{H}, \mathrm{br} \mathrm{s})$, $8.21(1 \mathrm{H}, \mathrm{d}, J=8.4 \mathrm{~Hz})$. Anal. Calcd for $\mathrm{C}_{20} \mathrm{H}_{20} \mathrm{O}_{4} \mathrm{~S}: \mathrm{C}, 67.39 ; \mathrm{H}, 5.66$. Found: C, 67.36; H, 5.63.

The following compounds $(\mathbf{1 4} \mathbf{b}-\mathbf{e})$ were prepared from 13a by a method similar to that described for $\mathbf{1 4 a}$.

Methyl 7-(4-Propylphenyl)-2,3-dihydro-1-benzothiepine-4-carboxylate 1,1-Dioxide (14b) Yield 62\%, mp 155-156 ${ }^{\circ} \mathrm{C} .{ }^{1} \mathrm{H}-\mathrm{NMR}\left(\mathrm{CDCl}_{3}\right) \delta 0.98$ $(3 \mathrm{H}, \mathrm{t}, J=7.4 \mathrm{~Hz}), 1.63-1.77(2 \mathrm{H}, \mathrm{m}), 2.66(2 \mathrm{H}, \mathrm{t}, J=7.6 \mathrm{~Hz}), 3.11-3.18$ $(2 \mathrm{H}, \mathrm{m}), 3.61-3.68(2 \mathrm{H}, \mathrm{m}), 3.87(3 \mathrm{H}, \mathrm{s}), 7.30(2 \mathrm{H}, \mathrm{d}, J=8.4 \mathrm{~Hz}), 7.54$ $(2 \mathrm{H}, \mathrm{d}, J=8.4 \mathrm{~Hz}), 7.69-7.73(2 \mathrm{H}, \mathrm{m}), 7.92(1 \mathrm{H}, \mathrm{brs}), 8.22(1 \mathrm{H}, \mathrm{d}$, $J=8.8 \mathrm{~Hz}$ ). Anal. Caled for $\mathrm{C}_{21} \mathrm{H}_{22} \mathrm{O}_{4} \mathrm{~S}: \mathrm{C}, 68.08 ; \mathrm{H}, 5.99$. Found: C, 68.13; $\mathrm{H}, 5.89$.

Methyl 7-(4-Isopropylphenyl)-2,3-dihydro-1-benzothiepine-4-carboxylate 1,1-Dioxide (14c) Yield $86 \%, \mathrm{mp} 142-144{ }^{\circ} \mathrm{C} .{ }^{1} \mathrm{H}-\mathrm{NMR}\left(\mathrm{CDCl}_{3}\right) \delta$ $1.30(6 \mathrm{H}, \mathrm{d}, J=6.6 \mathrm{~Hz}), 2.90-3.06(1 \mathrm{H}, \mathrm{m}), 3.12-3.18(2 \mathrm{H}, \mathrm{m}), 3.62-$ $3.68(2 \mathrm{H}, \mathrm{m}), 3.87(3 \mathrm{H}, \mathrm{s}), 7.36(2 \mathrm{H}, \mathrm{d}, J=8.2 \mathrm{~Hz}), 7.55(2 \mathrm{H}, \mathrm{d}, J=8.2 \mathrm{~Hz})$, $7.69-7.73(2 \mathrm{H}, \mathrm{m}), 7.92(1 \mathrm{H}, \mathrm{br} \mathrm{s}), 8.22(1 \mathrm{H}, \mathrm{d}, J=8.8 \mathrm{~Hz})$. Anal. Calcd for $\mathrm{C}_{21} \mathrm{H}_{22} \mathrm{O}_{4} \mathrm{~S}: \mathrm{C}, 68.08 ; \mathrm{H}, 5.99$. Found: $\mathrm{C}, 68.04 ; \mathrm{H}, 6.15$.

Methyl 7-(4-Propoxyphenyl)-2,3-dihydro-1-benzothiepine-4-carboxylate 1,1-Dioxide (14d) Yield $76 \%$, mp $153-155{ }^{\circ} \mathrm{C} .{ }^{1} \mathrm{H}-\mathrm{NMR}\left(\mathrm{CDCl}_{3}\right) \delta$ $1.07(3 \mathrm{H}, \mathrm{t}, J=7.5 \mathrm{~Hz}), 1.76-1.93(2 \mathrm{H}, \mathrm{m}), 3.11-3.17(2 \mathrm{H}, \mathrm{m}), 3.61-$ $3.68(2 \mathrm{H}, \mathrm{m}), 3.87(3 \mathrm{H}, \mathrm{s}), 3.99(2 \mathrm{H}, \mathrm{t}, J=6.6 \mathrm{~Hz}), 7.01(2 \mathrm{H}, \mathrm{d}, J=9.0 \mathrm{~Hz})$, $7.55(2 \mathrm{H}, \mathrm{d}, J=9.0 \mathrm{~Hz}), 7.66-7.70(2 \mathrm{H}, \mathrm{m}), 7.91(1 \mathrm{H}, \mathrm{br} \mathrm{s}), 8.20(1 \mathrm{H}, \mathrm{d}$, $J=8.4 \mathrm{~Hz}$ ). Anal. Calcd for $\mathrm{C}_{21} \mathrm{H}_{22} \mathrm{O}_{5} \mathrm{~S}: \mathrm{C}, 65.27 ; \mathrm{H}, 5.74$. Found: $\mathrm{C}, 65.35$; $\mathrm{H}, 5.63$.

Methyl 7-(4-Morpholinophenyl)-2,3-dihydro-1-benzothiepine-4-carboxylate 1,1-Dioxide (14e) Yield $71 \%$, mp 215-217 ${ }^{\circ} \mathrm{C} .{ }^{1} \mathrm{H}-\mathrm{NMR}$ $\left(\mathrm{CDCl}_{3}\right) \delta 3.10-3.17(2 \mathrm{H}, \mathrm{m}), 3.23-3.28(4 \mathrm{H}, \mathrm{m}), 3.61-3.67(2 \mathrm{H}, \mathrm{m})$, $3.87(3 \mathrm{H}, \mathrm{s}), 3.84-3.95(4 \mathrm{H}, \mathrm{m}), 7.00(2 \mathrm{H}, \mathrm{d}, J=8.8 \mathrm{~Hz}), 7.56(2 \mathrm{H}, \mathrm{d}$, $J=8.8 \mathrm{~Hz}), 7.66-7.74(2 \mathrm{H}, \mathrm{m}), 7.91(1 \mathrm{H}, \mathrm{s}), 8.18(1 \mathrm{H}, \mathrm{d}, J=8.8 \mathrm{~Hz})$. Anal. Calcd for $\mathrm{C}_{22} \mathrm{H}_{23} \mathrm{NO}_{5} \mathrm{~S}$ : C, 63.90; H, 5.61; N, 3.39. Found: C, 63.89; H, 5.74; $\mathrm{N}, 3.51$.

7-(4-Ethylphenyl)-2,3-dihydro-1-benzothiepine-4-carboxylic Acid 1,1Dioxide (7a) To a solution of $14 \mathrm{a}(600 \mathrm{mg}, 1.68 \mathrm{mmol})$ in 1,2 dimethoxyethane $(20 \mathrm{ml})$ was added $6 \mathrm{~N} \mathrm{HCl}(10 \mathrm{ml})$ at room temperature, and the mixture was refluxed for $24 \mathrm{~h}$. The mixture was extracted with EtOAc. The organic layer was washed with brine, dried over $\mathrm{MgSO}_{4}$, and concentrated in vacuo. The precipitated crystals were collected by filtration, washed with hexane to give $501 \mathrm{mg}(87 \%)$ of $7 \mathrm{a}$ as pale yellow crystals, $\mathrm{mp}$ $263-265^{\circ} \mathrm{C} .{ }^{1} \mathrm{H}-\mathrm{NMR}\left(\mathrm{CDCl}_{3}\right) \delta 1.29(3 \mathrm{H}, \mathrm{t}, J=7.6 \mathrm{~Hz}), 2.73(2 \mathrm{H}, \mathrm{q}$, $J=7.6 \mathrm{~Hz}), 3.17(2 \mathrm{H}, \mathrm{t}, J=6.6 \mathrm{~Hz}), 3.67(2 \mathrm{H}, \mathrm{t}, J=6.6 \mathrm{~Hz}), 7.34(2 \mathrm{H}, \mathrm{d}$, $J=8.4 \mathrm{~Hz}), 7.55(2 \mathrm{H}, \mathrm{d}, J=8.4 \mathrm{~Hz}), 7.70-7.78(2 \mathrm{H}, \mathrm{m}), 8.02(1 \mathrm{H}, \mathrm{s}), 8.24$ $(1 \mathrm{H}, \mathrm{d}, J=8.8 \mathrm{~Hz})$. Anal. Calcd for $\mathrm{C}_{19} \mathrm{H}_{18} \mathrm{O}_{4} \mathrm{~S}: \mathrm{C}, 66.65 ; \mathrm{H}, 5.30$. Found: $\mathrm{C}$, 66.47; H, 5.41 .

The following compounds $(\mathbf{7 b}-\mathbf{d})$ were prepared from the corresponding esters $(\mathbf{1 4 b}-\mathbf{d})$ by a method similar to that described for $\mathbf{7 a}$.

7-(4-Propylphenyl)-2,3-dihydro-1-benzothiepine-4-carboxylic Acid 1,1-Dioxide (7b) Yield 90\%. ${ }^{1} \mathrm{H}-\mathrm{NMR} \quad\left(\right.$ DMSO- $\left.d_{6}\right) \quad \delta \quad 0.92 \quad(3 \mathrm{H}, \mathrm{t}$, $J=7.3 \mathrm{~Hz}), 1.58-1.69(2 \mathrm{H}, \mathrm{m}), 2.58-2.66(2 \mathrm{H}, \mathrm{m}), 2.93-3.01(2 \mathrm{H}, \mathrm{m})$, $3.72-3.79(2 \mathrm{H}, \mathrm{m}), 7.34(2 \mathrm{H}, \mathrm{d}, J=8.2 \mathrm{~Hz}), 7.74(2 \mathrm{H}, \mathrm{d}, J=8.2 \mathrm{~Hz}), 7.88$ $7.93(2 \mathrm{H}, \mathrm{m}), 8.06-8.09(2 \mathrm{H}, \mathrm{m})$.

7-(4-Isopropylphenyl)-2,3-dihydro-1-benzothiepine-4-carboxylic Acid 1,1-Dioxide (7c) Yield $96 \%$, mp $281-282^{\circ} \mathrm{C}$ (dec.). ${ }^{1} \mathrm{H}-\mathrm{NMR}\left(\mathrm{CDCl}_{3}\right) \delta$
$1.30(6 \mathrm{H}, \mathrm{d}, J=7.0 \mathrm{~Hz}), 2.92-3.05(1 \mathrm{H}, \mathrm{m}), 3.13-3.20(2 \mathrm{H}, \mathrm{m}), 3.63-$ $3.70(2 \mathrm{H}, \mathrm{m}), 7.36(2 \mathrm{H}, \mathrm{d}, J=8.5 \mathrm{~Hz}), 7.56(2 \mathrm{H}, \mathrm{d}, J=8.2 \mathrm{~Hz}), 7.69-7.78$ $(2 \mathrm{H}, \mathrm{m}), 8.01(1 \mathrm{H}$, br s $), 8.24(1 \mathrm{H}, \mathrm{d}, J=8.8 \mathrm{~Hz})$. Anal. Calcd for $\mathrm{C}_{20} \mathrm{H}_{20} \mathrm{O}_{4} \mathrm{~S} \cdot 0.2 \mathrm{H}_{2} \mathrm{O}: \mathrm{C}, 66.72 ; \mathrm{H}, 5.71$. Found: $\mathrm{C}, 66.63 ; \mathrm{H}, 5.79$.

7-(4-Propoxyphenyl)-2,3-dihydro-1-benzothiepine-4-carboxylic Acid 1,1-Dioxide (7d) Yield 90\%, mp 270-273 ${ }^{\circ} \mathrm{C} .{ }^{1} \mathrm{H}-\mathrm{NMR}$ (DMSO- $d_{6}$ ) $\delta$ $1.00(3 \mathrm{H}, \mathrm{t}, J=7.5 \mathrm{~Hz}), 1.65-1.86(2 \mathrm{H}, \mathrm{m}), 2.93-3.00(2 \mathrm{H}, \mathrm{m}), 3.71-$ $3.78(2 \mathrm{H}, \mathrm{m}), 4.00(2 \mathrm{H}, \mathrm{t}, J=6.6 \mathrm{~Hz}), 7.06(2 \mathrm{H}, \mathrm{d}, J=8.7 \mathrm{~Hz}), 7.78(2 \mathrm{H}, \mathrm{d}$, $J=8.7 \mathrm{~Hz}), 7.83-7.93(2 \mathrm{H}, \mathrm{m}), 8.03-8.07(2 \mathrm{H}, \mathrm{m})$. Anal. Calcd for $\mathrm{C}_{20} \mathrm{H}_{20} \mathrm{O}_{5} \mathrm{~S}: \mathrm{C}, 64.50 ; \mathrm{H}, 5.41$. Found: $\mathrm{C}, 64.34 ; \mathrm{H}, 5.48$.

7-(4-Morpholinophenyl)-2,3-dihydro-1-benzothiepine-4-carboylic Acid 1,1-Dioxide (7e) To a solution of $\mathbf{1 4 e}(550 \mathrm{mg}, 1.33 \mathrm{mmol})$ in $\mathrm{EtOH}$ $(15 \mathrm{ml})$ and THF $(15 \mathrm{ml})$ was added $1 \mathrm{~N} \mathrm{NaOH}(1.6 \mathrm{ml}, 1.6 \mathrm{mmol})$ at room temperature. After being stirred at room temperature for $18 \mathrm{~h}, 1 \mathrm{~N} \mathrm{HCl}$ $(1.6 \mathrm{ml}, 1.6 \mathrm{mmol})$ was added to the reaction mixture at room temperature. The mixture was evaporated in vacuo. The precipitated crystals were collected by filtration, washed with 2-propanol and $i-\mathrm{Pr}_{2} \mathrm{O}$ to give $269 \mathrm{mg}$ $(51 \%)$ of $7 \mathbf{e}$ as pale yellow crystals. ${ }^{1} \mathrm{H}-\mathrm{NMR}$ (DMSO- $\left.d_{6}\right) \delta 2.89-3.02$ $(2 \mathrm{H}, \mathrm{m}), 3.15-3.26(4 \mathrm{H}, \mathrm{m}), 3.68-3.82(6 \mathrm{H}, \mathrm{m}), 7.06(2 \mathrm{H}, \mathrm{d}, J=9.0 \mathrm{~Hz})$, $7.74(2 \mathrm{H}, \mathrm{d}, J=9.0 \mathrm{~Hz}), 7.83-7.91(2 \mathrm{H}, \mathrm{m}), 7.99-8.08(2 \mathrm{H}, \mathrm{m})$. Anal. Calcd for $\mathrm{C}_{21} \mathrm{H}_{21} \mathrm{NO}_{5} \mathrm{~S}: \mathrm{C}, 61.75 ; \mathrm{H}, 5.43 ; \mathrm{N}, 3.43$. Found: $\mathrm{C}, 61.60 ; \mathrm{H}, 5.65$; $\mathrm{N}, 3.50$.

tert-Butyl 4-(Ethylamino)butanoate (16a) To a solution of $\mathbf{1 5}(25.4 \mathrm{~g}$, $107 \mathrm{mmol})$ and EtI $(50.0 \mathrm{~g}, 321 \mathrm{mmol})$ in THF $(350 \mathrm{ml})$ was added $\mathrm{NaH}$ (60\% dispersion in mineral oil, $12.8 \mathrm{~g}, 320 \mathrm{mmol})$ under ice cooling. The mixture was stirred at $75^{\circ} \mathrm{C}$ for $13 \mathrm{~h}$ under a nitrogen atmosphere. Water was added to the reaction mixture, and the mixture was extracted with EtOAc. The aqueous layer was acidified using $1 \mathrm{~N} \mathrm{HCl}$ under ice cooling. The mixture was extracted with EtOAc. The organic layer was washed with aqueous $\mathrm{Na}_{2} \mathrm{~S}_{2} \mathrm{O}_{3}$ and brine, dried over $\mathrm{MgSO}_{4}$, and concentrated in vacuo to give $25.1 \mathrm{~g}(87 \%)$ of $4-\{[($ benzyloxy)carbonyl](ethyl)amino\}butanoic acid as a yellow oil. To a solution of 4-\{[(benzyloxy)carbonyl](ethyl)amino\}butanoic acid $(8.24 \mathrm{~g}, 31.3 \mathrm{mmol})$ and di-tert-butyl dicarbonate $\left(\mathrm{Boc}_{2} \mathrm{O}\right)$ $(14.3 \mathrm{ml}, 62.2 \mathrm{mmol})$ in tert-BuOH $(300 \mathrm{ml})$ was added 4 - $(N, N$-dimethylamino)pyridine (DMAP) $(390 \mathrm{mg}, 9.34 \mathrm{mmol})$ at room temperature. After being stirred at room temperature for $4 \mathrm{~h}$, the mixture was concentrated in vacuo. The residue was purified by column chromatography (hexane : $\mathrm{EtOAc}=4: 1)$ to give $4.20 \mathrm{~g}(42 \%)$ of tert-butyl $4-\{[($ benzyloxy)carbonyl](ethyl)amino $\}$ butanoate as a pale yellow oil. A mixture of tertbutyl 4 -\{[(benzyloxy)carbonyl](ethyl)amino\} butanoate $(3.38 \mathrm{~g}, 10.5 \mathrm{mmol})$, conc. $\mathrm{HCl}(1$ drop) and $10 \% \mathrm{Pd}-\mathrm{C}(50 \%$ wet, $0.34 \mathrm{~g})$ in $\mathrm{MeOH}(35 \mathrm{ml})$ was stirred at room temperature for $3 \mathrm{~h}$ under a hydrogen atmosphere. The catalyst was removed by filtration and the filtrate was concentrated in vacuo to give $2.30 \mathrm{~g}$ (quant.) of $\mathbf{1 6 a}$ as a pale yellow oil. ${ }^{1} \mathrm{H}-\mathrm{NMR}\left(\mathrm{CDCl}_{3}\right) \delta 1.12$ $(3 \mathrm{H}, \mathrm{t}, J=7.2 \mathrm{~Hz}), 1.44(9 \mathrm{H}, \mathrm{s}), 1.78(2 \mathrm{H}$, quintet, $J=7.2 \mathrm{~Hz}), 2.27(2 \mathrm{H}, \mathrm{t}$, $J=7.2 \mathrm{~Hz}), 2.65(2 \mathrm{H}, \mathrm{t}, J=7.2 \mathrm{~Hz}), 2.67(2 \mathrm{H}, \mathrm{q}, J=7.2 \mathrm{~Hz})$.

tert-Butyl 4-(Propylamino)butanoate (16b) This compound was prepared in $34 \%$ yield from $\mathbf{1 5}$ by a method similar to that described for 16a. ${ }^{1} \mathrm{H}-\mathrm{NMR}\left(\mathrm{CDCl}_{3}\right) \delta 0.92(3 \mathrm{H}, \mathrm{t}, J=7.1 \mathrm{~Hz}), 1.45(9 \mathrm{H}, \mathrm{s}), 1.47-1.67(4 \mathrm{H}$, m), $1.70-1.85(2 \mathrm{H}, \mathrm{m}), 2.25(2 \mathrm{H}, \mathrm{q}, J=7.9 \mathrm{~Hz}), 2.60(2 \mathrm{H}, \mathrm{dt}, J=11.6$, $7.2 \mathrm{~Hz}), 3.21(1 \mathrm{H}, \mathrm{m})$.

tert-Butyl 4-[(4-Bromo-2-formylphenyl)(ethyl)amino]butanoate (17a) A mixture of $16 \mathrm{a}(2.30 \mathrm{~g}, 10.5 \mathrm{mmol}), 5$-bromo-2-fluorobenzaldehyde $(2.13 \mathrm{~g}, 10.5 \mathrm{mmol})$ and $\mathrm{K}_{2} \mathrm{CO}_{3}(1.74 \mathrm{~g}, 12.6 \mathrm{mmol})$ in $N, N$-dimethylformamide (DMF) $(20 \mathrm{ml})$ was stirred at $70-80{ }^{\circ} \mathrm{C}$ for $73 \mathrm{~h}$. Water was added to the reaction mixture, and the mixture was extracted with EtOAc. The organic layer was washed with brine, dried over $\mathrm{MgSO}_{4}$, and concentrated in vacuo. The residue was purified by column chromatography (hexane : EtOAc $=10: 1)$ to give $1.46 \mathrm{~g}(38 \%)$ of $\mathbf{1 7 a}$ as a yellow oil. ${ }^{1} \mathrm{H}-$ NMR $\left(\mathrm{CDCl}_{3}\right) \delta 1.05(3 \mathrm{H}, \mathrm{t}, J=7.1 \mathrm{~Hz}), 1.42(9 \mathrm{H}, \mathrm{s}), 1.77(2 \mathrm{H}$, quintet, $J=7.2 \mathrm{~Hz}), 2.21(2 \mathrm{H}, \mathrm{t}, J=7.1 \mathrm{~Hz}), 3.15(2 \mathrm{H}, \mathrm{t}, J=7.3 \mathrm{~Hz}), 3.18(2 \mathrm{H}, \mathrm{q}$, $J=7.1 \mathrm{~Hz}), 7.07(1 \mathrm{H}, \mathrm{d}, J=8.8 \mathrm{~Hz}), 7.58(1 \mathrm{H}, \mathrm{dd}, J=8.8,2.6 \mathrm{~Hz}), 7.91(1 \mathrm{H}$, d, $J=2.6 \mathrm{~Hz}), 10.25(1 \mathrm{H}, \mathrm{s})$.

tert-Butyl 4-[(4-Bromo-2-formylphenyl)(propyl)amino]butanoate (17b) This compound was prepared in $52 \%$ yield from $\mathbf{1 6 b}$ by a method similar to that described for 17a. ${ }^{1} \mathrm{H}-\mathrm{NMR}\left(\mathrm{CDCl}_{3}\right) \delta 0.84(3 \mathrm{H}, \mathrm{t}, J=7.8 \mathrm{~Hz}), 1.45$ $(9 \mathrm{H}, \mathrm{s}), 1.42-1.63(2 \mathrm{H}, \mathrm{m}), 1.81(2 \mathrm{H}$, quintet, $J=7.4 \mathrm{~Hz}), 2.19(2 \mathrm{H}, \mathrm{t}$, $J=7.5 \mathrm{~Hz}), 3.09(2 \mathrm{H}, \mathrm{t}, J=7.6 \mathrm{~Hz}), 3.17(2 \mathrm{H}, \mathrm{t}, J=7.5 \mathrm{~Hz}), 7.06(1 \mathrm{H}, \mathrm{d}$, $J=8.8 \mathrm{~Hz}), 7.56(1 \mathrm{H}, \mathrm{dd}, J=8.7,2.5 \mathrm{~Hz}), 7.90(1 \mathrm{H}, \mathrm{d}, J=2.6 \mathrm{~Hz}), 10.24(1 \mathrm{H}$ s).

tert-Butyl 7-Bromo-1-ethyl-2,3-dihydro-1H-1-benzazepine-4-carboxylate (13c) A mixture of $17 \mathbf{a}(1.44 \mathrm{~g}, 3.89 \mathrm{mmol})$ and potassium tert-butoxide $(480 \mathrm{mg}, 4.28 \mathrm{mmol})$ in toluene $(80 \mathrm{ml})$ and tert-BuOH $(8.0 \mathrm{ml})$ was stirred at $90^{\circ} \mathrm{C}$ for $3 \mathrm{~h} .1 \mathrm{~N} \mathrm{HCl}(6.0 \mathrm{ml})$ was added to the reaction mixture 
under ice cooling and the mixture was extracted with EtOAc. The organic layer was washed with brine, dried over $\mathrm{MgSO}_{4}$, and concentrated in vacuo. The residue was purified by column chromatography (hexane: EtOAc= $20: 1)$ to give $964 \mathrm{mg}(70 \%)$ of $\mathbf{1 3 c}$ as a yellow oil. ${ }^{1} \mathrm{H}-\mathrm{NMR}\left(\mathrm{CDCl}_{3}\right) \delta 1.26$ $(3 \mathrm{H}, \mathrm{t}, J=7.1 \mathrm{~Hz}), 1.53(9 \mathrm{H}, \mathrm{s}), 2.76(2 \mathrm{H}, \mathrm{td}, J=4.9,1.4 \mathrm{~Hz}), 3.19(2 \mathrm{H}, \mathrm{t}$, $J=4.9 \mathrm{~Hz}), 3.34(2 \mathrm{H}, \mathrm{q}, J=7.1 \mathrm{~Hz}), 6.69(1 \mathrm{H}, \mathrm{d}, J=9.0 \mathrm{~Hz}), 7.23(1 \mathrm{H}, \mathrm{dd}$, $J=9.0,2.4 \mathrm{~Hz}), 7.40(1 \mathrm{H}, \mathrm{d}, J=2.4 \mathrm{~Hz}), 7.47(1 \mathrm{H}, \mathrm{s})$.

tert-Butyl 7-Bromo-1-propyl-2,3-dihydro-1H-1-benzazepine-4-carboxylate (13d) This compound was prepared in $60 \%$ yield from $\mathbf{1 7 b}$ by a method similar to that described for 13c. ${ }^{1} \mathrm{H}-\mathrm{NMR}\left(\mathrm{CDCl}_{3}\right) \delta 0.95(3 \mathrm{H}, \mathrm{t}$, $J=7.5 \mathrm{~Hz}), 1.53(9 \mathrm{H}, \mathrm{s}), 1.68(2 \mathrm{H}$, sextet, $J=7.6 \mathrm{~Hz}), 2.75(2 \mathrm{H}, \mathrm{t}$, $J=4.4 \mathrm{~Hz}), 3.18-3.26(4 \mathrm{H}, \mathrm{m}), 6.67(1 \mathrm{H}, \mathrm{d}, J=9.2 \mathrm{~Hz}), 7.22(1 \mathrm{H}, \mathrm{dd}$, $J=8.8,2.6 \mathrm{~Hz}), 7.39(1 \mathrm{H}, \mathrm{d}, J=2.6 \mathrm{~Hz}), 7.46(1 \mathrm{H}, \mathrm{s})$.

Methyl 5-Bromo-2-\{[(4-methylphenyl)sulfonyl]amino\}benzoate (18) To a silution of methyl 5-bromo-2-aminobenzoate $(28.2 \mathrm{~g}, 123 \mathrm{mmol})$ in pyridine $(70 \mathrm{ml})$ was added $p$-toluenesulfonyl chloride $(35.1 \mathrm{~g}, 184 \mathrm{mmol})$ at room temperature. After being stirred at $55^{\circ} \mathrm{C}$ for $1 \mathrm{~h}$, the mixture was concentrated in vacuo, poured into water, and extracted with EtOAc. The organic layer was washed with water, $1 \mathrm{~N} \mathrm{HCl}$, and brine, dried over $\mathrm{MgSO}_{4}$, and concentrated in vacuo to give $41.5 \mathrm{~g}(88 \%)$ of $\mathbf{1 8}$ as colorless crystals, $\mathrm{mp} 123-124{ }^{\circ} \mathrm{C} .{ }^{1} \mathrm{H}-\mathrm{NMR}\left(\mathrm{CDCl}_{3}\right) \delta 2.38(3 \mathrm{H}, \mathrm{s}), 3.89(3 \mathrm{H}, \mathrm{s}), 7.24(2 \mathrm{H}$, d, $J=8.6 \mathrm{~Hz}), 7.53(1 \mathrm{H}, \mathrm{dd}, J=9.2,2.0 \mathrm{~Hz}), 7.61(1 \mathrm{H}, \mathrm{d}, J=9.2 \mathrm{~Hz}), 7.73$ $(2 \mathrm{H}, \mathrm{d}, J=8.6 \mathrm{~Hz}), 8.03(1 \mathrm{H}, \mathrm{d}, J=2.0 \mathrm{~Hz}), 10.52(1 \mathrm{H}, \mathrm{s})$. Anal. Calcd for $\mathrm{C}_{15} \mathrm{H}_{14} \mathrm{BrNO}_{4} \mathrm{~S}: \mathrm{C}, 46.89 ; \mathrm{H}, 3.67 ; \mathrm{N}, 3.65$. Found: C, 46.93; H, 3.53; N, 3.67 .

7-Bromo-1,2,3,4-tetrahydro-5 $\boldsymbol{H}$-1-benzazepin-5-one (19) To a solution of $18(38.1 \mathrm{~g}, 99.3 \mathrm{mmol})$ in DMF $(100 \mathrm{ml})$ was added $\mathrm{NaH}(60 \%$ dispersion in mineral oil, $4.76 \mathrm{~g}, 119 \mathrm{mmol})$ and DMF $(35 \mathrm{ml})$ under ice cooling. The mixture was stirred at room temperature for $1 \mathrm{~h}$ under a nitrogen atmosphere. NaI (14.9 g, $99.3 \mathrm{mmol})$ and ethyl 4-bromobutyrate $(21.3 \mathrm{~g}$, $109 \mathrm{mmol}$ ) were added, and then the mixture was stirred at $80^{\circ} \mathrm{C}$ for $14 \mathrm{~h}$ under a nitrogen atmosphere. $\mathrm{NaH}(60 \%$ dispersion in mineral oil, $4.76 \mathrm{~g}$, $119 \mathrm{mmol})$ and DMF $(25 \mathrm{ml})$ were added to the mixture under ice cooling. The mixture was stirred at $80^{\circ} \mathrm{C}$ for $15 \mathrm{~h}$ under a nitrogen atmosphere. The reaction mixture was concentrated in vacuo, and the residue was diluted with EtOAc. The mixture was washed successively with water and brine, dried over $\mathrm{MgSO}_{4}$, and concentrated in vacuo. The residue was purified by column chromatography (hexane: $\mathrm{EtOAc}=9: 1 \rightarrow 4: 1$ ) to give $25.1 \mathrm{~g}$ of white crystals. A mixture of the crystals $(25.1 \mathrm{~g})$, conc. $\mathrm{H}_{2} \mathrm{SO}_{4}(90 \mathrm{ml})$ and acetic acid $(150 \mathrm{ml})$ was stirred at $90{ }^{\circ} \mathrm{C}$ for $2.5 \mathrm{~h}$. The reaction mixture was poured into ice. The mixture was neutralized using $12 \mathrm{~N} \mathrm{NaOH}$ under ice cooling. Water was added to the mixture and the mixture was extracted with EtOAc. The organic layer was washed with brine, dried over $\mathrm{MgSO}_{4}$, and concentrated in vacuo. The residue was purified by column chromatography (hexane : EtOAc $=3: 1)$ to give $5.01 \mathrm{~g}(21 \%)$ of 19 as yellow crystals. ${ }^{1} \mathrm{H}$ NMR $\left(\mathrm{CDCl}_{3}\right) \delta 2.18(2 \mathrm{H}$, quintet, $J=7.1 \mathrm{~Hz}), 2.82(2 \mathrm{H}, \mathrm{t}, J=7.2 \mathrm{~Hz}), 3.25$ $(2 \mathrm{H}, \mathrm{t}, J=6.6 \mathrm{~Hz}), 4.65(1 \mathrm{H}, \mathrm{br}), 6.65(1 \mathrm{H}, \mathrm{d}, J=8.6 \mathrm{~Hz}), 7.20(1 \mathrm{H}, \mathrm{dd}$, $J=8.6,2.2 \mathrm{~Hz}), 7.82(1 \mathrm{H}, \mathrm{d}, J=2.2 \mathrm{~Hz})$

Methyl 7-Bromo-1-(tert-butoxycarbonyl)-2,3-dihydro-1H-1-benzazepine-4-carboxylate (20) To a solution of $19(4.31 \mathrm{~g}, 18.0 \mathrm{mmol})$ and $\mathrm{Boc}_{2} \mathrm{O}(13.8 \mathrm{~g}, 63.2 \mathrm{mmol})$ in THF $(36 \mathrm{ml})$ was added DMAP $(2.19 \mathrm{~g}$, $17.9 \mathrm{mmol})$ at room temperature. The mixture was refluxed for $1.5 \mathrm{~h}$. Water was added to the reaction mixture, and the mixture was extracted with EtOAc. The organic layer was washed with water and brine, dried over $\mathrm{MgSO}_{4}$, and concentrated in vacuo. The residue was purified by column chromatography (hexane $:$ EtOAc $=9: 1$ ) to give a yellow oil. To a solution of the oil in dimethyl carbonate $(100 \mathrm{ml})$ was added sodium methoxide $(4.86 \mathrm{~g}$, $90.0 \mathrm{mmol}$ ) at room temperature, and the mixture was refluxed for $2.5 \mathrm{~h}$. The reaction mixture was poured into ice water. To the mixture was added $1 \mathrm{~m}$ citric acid $(100 \mathrm{ml})$ and the mixture was extracted with EtOAc. The organic layer was washed with water and brine, dried over $\mathrm{MgSO}_{4}$, and concentrated in vacuo. The residue was purified by column chromatography (hexane $:$ EtOAc $=9: 1 \rightarrow 4: 1$ ) to give $3.89 \mathrm{~g}$ of $\beta$-keto ester as a pale yellow amorphous. To a mixture of $\beta$-keto ester $(3.89 \mathrm{~g})$ and $\mathrm{NaBH}_{4}(0.38 \mathrm{~g}$, $10 \mathrm{mmol})$ in THF $(100 \mathrm{ml})$ was added $\mathrm{MeOH}(10 \mathrm{ml})$ at $-40^{\circ} \mathrm{C}$. The mixture was stirred at $-15^{\circ} \mathrm{C}$ for $1 \mathrm{~h}$. To the reaction mixture was added $1 \mathrm{~m}$ citric acid $(20 \mathrm{ml})$ and water at $-40^{\circ} \mathrm{C}$, and the mixture was extracted with EtOAc. The organic layer was washed with water and brine, dried over $\mathrm{MgSO}_{4}$, and concentrated in vacuo. To a solution of the residue and $\mathrm{Et}_{3} \mathrm{~N}$ $(4.1 \mathrm{ml}, 29.4 \mathrm{mmol})$ in THF $(750 \mathrm{ml})$ was added $\mathrm{MsCl}(1.15 \mathrm{ml}, 14.9 \mathrm{mmol})$ under ice cooling. After being stirred at room temperature for $14 \mathrm{~h}, \mathrm{DBU}$ $(7.30 \mathrm{ml}, 48.9 \mathrm{mmol})$ was added to the reaction mixture at room temperature. The mixture was refluxed for $10 \mathrm{~min}$. Water was added to the reaction mixture, and the mixture was extracted with EtOAc. The organic layer was washed with water and brine, and dried over $\mathrm{MgSO}_{4}$, and concentrated in vacuo. The residue was purified by column chromatography (hexane $: \mathrm{EtOAc}=4: 1)$ to give $2.53 \mathrm{~g}(37 \%)$ of $\mathbf{2 0}$ as colorless crystals. ${ }^{1} \mathrm{H}$ NMR $\left(\mathrm{CDCl}_{3}\right) \delta 1.47(9 \mathrm{H}, \mathrm{s}), 2.89(2 \mathrm{H}, \mathrm{t}, J=4.8 \mathrm{~Hz}), 3.61(2 \mathrm{H}, \mathrm{br} \mathrm{s}), 3.83$ $(3 \mathrm{H}, \mathrm{s}), 7.27(1 \mathrm{H}, \mathrm{brs}), 7.39(1 \mathrm{H}, \mathrm{dd}, J=8.4,1.8 \mathrm{~Hz}), 7.54-7.55(2 \mathrm{H}, \mathrm{m})$.

Methyl 7-Bromo-2,3-dihydro-1 H-1-benzazepine-4-carboxylate (21) To a solution of $20(5.04 \mathrm{~g}, 13.2 \mathrm{mmol})$ in EtOAc $(250 \mathrm{ml})$ was added $6 \mathrm{~N}$ $\mathrm{HCl}(80 \mathrm{ml})$ at room temperature. The mixture was stirred at $80^{\circ} \mathrm{C}$ for $0.5 \mathrm{~h}$. To the reaction mixture was added $1 \mathrm{~N} \mathrm{NaOH}(400 \mathrm{ml})$ and saturated aqueous $\mathrm{Na}_{2} \mathrm{CO}_{3}(300 \mathrm{ml})$. The mixture was extracted with EtOAc. The organic layer was washed with saturated aqueous $\mathrm{NaHCO}_{3}$, water and brine, dried over $\mathrm{MgSO}_{4}$, and concentrated in vacuo to give $3.72 \mathrm{~g}$ (quant) of 21 as yellow crystals. ${ }^{1} \mathrm{H}-\mathrm{NMR}\left(\mathrm{CDCl}_{3}\right) \delta 2.86(2 \mathrm{H}, \mathrm{t}, J=5.2 \mathrm{~Hz}), 3.36(2 \mathrm{H}, \mathrm{t}, J=5.2 \mathrm{~Hz})$, $3.80(3 \mathrm{H}, \mathrm{s}), 4.57(1 \mathrm{H}, \mathrm{brs}), 6.49(1 \mathrm{H}, \mathrm{d}, J=8.4 \mathrm{~Hz}), 7.15(1 \mathrm{H}, \mathrm{dd}, J=8.4$, $2.2 \mathrm{~Hz}), 7.38(1 \mathrm{H}, \mathrm{d}, J=2.2 \mathrm{~Hz}), 7.53(1 \mathrm{H}, \mathrm{s})$.

Methyl 7-Bromo-1-isobutyl-2,3-dihydro-1 H-1-benzazepine-4-carboxylate (13e) To a solution of $21(2.00 \mathrm{~g}, 7.09 \mathrm{mmol})$ and isobutyraldehyde $(3.22 \mathrm{ml}, 35.4 \mathrm{mmol})$ in 1,2-dichloroethane $(70 \mathrm{ml})$ was added triacetoxyborohydride $(5.36 \mathrm{~g}, 24.8 \mathrm{mmol})$ under ice cooling. After being stirred at room temperature for $12 \mathrm{~h}, 1 \mathrm{~N} \mathrm{NaOH}$ was added to the reaction mixture, and the mixture was extracted with EtOAc. The organic layer was washed with water and brine, dried over $\mathrm{MgSO}_{4}$, and concentrated in vacuo. The residue was purified by column chromatography (hexane: EtOAc $=6: 1$ ) to give $1.82 \mathrm{~g}(76 \%)$ of $13 \mathrm{e}$ as a yellow solid. ${ }^{1} \mathrm{H}-\mathrm{NMR}\left(\mathrm{CDCl}_{3}\right) \delta 0.92(6 \mathrm{H}, \mathrm{d}$, $J=6.6 \mathrm{~Hz}), 2.03(1 \mathrm{H}, \mathrm{m}), 2.77-2.82(2 \mathrm{H}, \mathrm{m}), 3.10(2 \mathrm{H}, \mathrm{d}, J=7.4 \mathrm{~Hz})$, $3.21-3.26(2 \mathrm{H}, \mathrm{m}), 3.80(3 \mathrm{H}, \mathrm{s}), 6.71(1 \mathrm{H}, \mathrm{d}, J=8.8 \mathrm{~Hz}), 7.19-7.26(1 \mathrm{H}$, $\mathrm{m}), 7.42(1 \mathrm{H}, \mathrm{d}, J=2.6 \mathrm{~Hz}), 7.58(1 \mathrm{H}, \mathrm{s})$.

Methyl 7-Bromo-1-(3-methylbutyl)-2,3-dihydro-1H-1-benzazepine-4carboxylate (13f) This compound was prepared in $87 \%$ yield from 21 by a method similar to that described for 13e. ${ }^{1} \mathrm{H}-\mathrm{NMR}\left(\mathrm{CDCl}_{3}\right) \delta 0.95(6 \mathrm{H}, \mathrm{d}$, $J=6.2 \mathrm{~Hz}), 1.48-1.62(3 \mathrm{H}, \mathrm{m}), 2.79(2 \mathrm{H}, \mathrm{t}, J=4.4 \mathrm{~Hz}), 3.21(2 \mathrm{H}, \mathrm{t}$, $J=4.4 \mathrm{~Hz}), 3.24-3.33(2 \mathrm{H}, \mathrm{m}), 3.80(3 \mathrm{H}, \mathrm{s}), 6.68(1 \mathrm{H}, \mathrm{d}, J=8.8 \mathrm{~Hz})$, $7.20-7.26(1 \mathrm{H}, \mathrm{m}), 7.41(1 \mathrm{H}, \mathrm{d}, J=2.2 \mathrm{~Hz}), 7.56(1 \mathrm{H}, \mathrm{s})$.

The following compounds $(\mathbf{1 4 f}, \mathbf{2 2})$ were prepared from the corresponding bromides $(\mathbf{1 3 e}, \mathbf{2 1})$ by a method similar to that described for $\mathbf{1 4 a}$.

Methyl 7-\{4-[2-(Butoxy)ethoxy]phenyl\}-1-isobutyl-2,3-dihydro-1 H-1benzazepine-4-carboxylate (14f) Yield 62\%. ${ }^{1} \mathrm{H}-\mathrm{NMR}\left(\mathrm{CDCl}_{3}\right) \delta 0.93$ $(3 \mathrm{H}, \mathrm{t}, J=7.2 \mathrm{~Hz}), 0.95(6 \mathrm{H}, \mathrm{d}, J=6.6 \mathrm{~Hz}), 1.37-1.67(4 \mathrm{H}, \mathrm{m}), 1.99-2.16$ $(1 \mathrm{H}, \mathrm{m}), 2.82(2 \mathrm{H}, \mathrm{t}, J=4.8 \mathrm{~Hz}), 3.17(2 \mathrm{H}, \mathrm{d}, J=7.4 \mathrm{~Hz}), 3.30(2 \mathrm{H}, \mathrm{t}$, $J=4.8 \mathrm{~Hz}), 3.55(2 \mathrm{H}, \mathrm{t}, J=6.6 \mathrm{~Hz}), 3.77-3.83(5 \mathrm{H}, \mathrm{m}), 4.13-4.18(2 \mathrm{H}$, $\mathrm{m}), 6.89(1 \mathrm{H}, \mathrm{d}, J=8.4 \mathrm{~Hz}), 6.97(2 \mathrm{H}, \mathrm{d}, J=8.8 \mathrm{~Hz}), 7.36-7.52(4 \mathrm{H}, \mathrm{m})$, $7.77(1 \mathrm{H}, \mathrm{s})$.

Methyl 7-\{4-[2-(Butoxy)ethoxy]phenyl\}-2,3-dihydro-1H-1-benzazepine4-carboxylate (22) Yield 56\%. ${ }^{1} \mathrm{H}-\mathrm{NMR} \quad\left(\mathrm{CDCl}_{3}\right) \quad \delta \quad 0.93 \quad(3 \mathrm{H}, \mathrm{t}$, $J=7.3 \mathrm{~Hz}), 1.29-1.48(2 \mathrm{H}, \mathrm{m}), 1.51-1.69(2 \mathrm{H}, \mathrm{m}), 2.88(2 \mathrm{H}, \mathrm{t}$, $J=4.6 \mathrm{~Hz}), 3.37-3.44(2 \mathrm{H}, \mathrm{m}), 3.55(2 \mathrm{H}, \mathrm{t}, J=6.6 \mathrm{~Hz}), 3.78-3.83(2 \mathrm{H}$, $\mathrm{m}), 4.16(2 \mathrm{H}, \mathrm{t}, J=5.0 \mathrm{~Hz}), 4.5-4.64(1 \mathrm{H}, \mathrm{m}), 6.67(1 \mathrm{H}, \mathrm{d}, J=8.2 \mathrm{~Hz}), 6.97$ $(2 \mathrm{H}, \mathrm{d}, J=8.8 \mathrm{~Hz}), 7.33(1 \mathrm{H}, \mathrm{dd}, J=8.2,2.2 \mathrm{~Hz}), 7.43-7.48(3 \mathrm{H}, \mathrm{m}), 7.71$ $(1 \mathrm{H}, \mathrm{s})$.

The following compounds $(\mathbf{1 4 g}-\mathbf{i}, \mathbf{1 4} \mathbf{k}-\mathbf{0})$ were prepared from 22 by a method similar to that described for $\mathbf{1 3 e}$.

Methyl 7-\{4-[2-(Butoxy)ethoxy]phenyl\}-1-cyclopropylmethyl-2,3-dihydro-1H-1-benzazepine-4-carboxylate (14g) Yield quant. ${ }^{1} \mathrm{H}-\mathrm{NMR}$ $\left(\mathrm{CDCl}_{3}\right) \delta 0.24-0.32(2 \mathrm{H}, \mathrm{m}), 0.58-0.67(2 \mathrm{H}, \mathrm{m}), 0.93(3 \mathrm{H}, \mathrm{t}, J=7.3 \mathrm{~Hz})$, $1.08-1.15(1 \mathrm{H}, \mathrm{m}), 1.34-1.49(2 \mathrm{H}, \mathrm{m}), 1.55-1.68(2 \mathrm{H}, \mathrm{m}), 2.86(2 \mathrm{H}, \mathrm{t}$, $J=4.4 \mathrm{~Hz}), 3.23(2 \mathrm{H}, \mathrm{d}, J=6.6 \mathrm{~Hz}), 3.39(2 \mathrm{H}, \mathrm{t}, J=4.7 \mathrm{~Hz}), 3.55(2 \mathrm{H}, \mathrm{t}$, $J=6.6 \mathrm{~Hz}), 3.73-3.83(5 \mathrm{H}, \mathrm{m}), 4.11-4.18(2 \mathrm{H}, \mathrm{m}), 6.92-7.01(3 \mathrm{H}, \mathrm{m})$, $7.38-7.53(4 \mathrm{H}, \mathrm{m}), 7.77(1 \mathrm{H}, \mathrm{s})$.

Methyl 7-\{4-[2-(Butoxy)ethoxy]phenyl\}-1-cyclobutylmethyl-2,3-dihydro-1H-1-benzazepine-4-carboxylate (14h) Yield quant. ${ }^{1} \mathrm{H}-\mathrm{NMR}$ $\left(\mathrm{CDCl}_{3}\right) \delta 0.93(3 \mathrm{H}, \mathrm{t}, J=7.3 \mathrm{~Hz}), 1.34-1.45(2 \mathrm{H}, \mathrm{m}), 1.54-2.13(8 \mathrm{H}, \mathrm{m})$, $2.70-2.81(3 \mathrm{H}, \mathrm{m}), 3.26(2 \mathrm{H}, \mathrm{t}, J=4.8 \mathrm{~Hz}), 3.38(2 \mathrm{H}, \mathrm{d}, J=7.4 \mathrm{~Hz}), 3.55$ $(2 \mathrm{H}, \mathrm{t}, J=6.6 \mathrm{~Hz}), 3.78-3.83(5 \mathrm{H}, \mathrm{m}), 4.16(2 \mathrm{H}, \mathrm{t}, J=4.9 \mathrm{~Hz}), 6.87(1 \mathrm{H}, \mathrm{d}$, $J=8.8 \mathrm{~Hz}), 6.97(2 \mathrm{H}, \mathrm{d}, J=8.8 \mathrm{~Hz}), 7.37-7.51(4 \mathrm{H}, \mathrm{m}), 7.75(1 \mathrm{H}, \mathrm{s})$.

Methyl 7-\{4-[2-(Butoxy)ethoxy]phenyl\}-1-cyclohexylmethyl-2,3-dihydro-1H-1-benzazepine-4-carboxylate (14i) Yield quant. ${ }^{1} \mathrm{H}-\mathrm{NMR}$ $\left(\mathrm{CDCl}_{3}\right) \delta 0.89-1.81(18 \mathrm{H}, \mathrm{m}), 2.81(2 \mathrm{H}, \mathrm{t}, J=4.2 \mathrm{~Hz}), 3.19(2 \mathrm{H}, \mathrm{d}$, $J=6.6 \mathrm{~Hz}), 3.29(2 \mathrm{H}, \mathrm{t}, J=4.8 \mathrm{~Hz}), 3.55(2 \mathrm{H}, \mathrm{t}, J=6.6 \mathrm{~Hz}), 3.78-3.82(5 \mathrm{H}$, $\mathrm{m}), 4.15(2 \mathrm{H}, \mathrm{t}, J=4.9 \mathrm{~Hz}), 6.87(\mathrm{H}, \mathrm{d}, J=8.8 \mathrm{~Hz}), 6.97(2 \mathrm{H}, \mathrm{d}, J=8.8 \mathrm{~Hz})$, $7.36-7.51(4 \mathrm{H}, \mathrm{m}), 7.76(1 \mathrm{H}, \mathrm{s})$.

Methyl 1-Benzyl-7-\{4-[2-(butoxy)ethoxy]phenyl\}-2,3-dihydro-1H-1benzazepine-4-carboxylate (14k) Yield quant. ${ }^{1} \mathrm{H}-\mathrm{NMR}\left(\mathrm{CDCl}_{3}\right) \delta 0.93$ $(3 \mathrm{H}, \mathrm{t}, J=7.3 \mathrm{~Hz}), 1.30-1.48(2 \mathrm{H}, \mathrm{m}), 1.54-1.68(2 \mathrm{H}, \mathrm{m}), 2.77(2 \mathrm{H}, \mathrm{t}$, $J=4.7 \mathrm{~Hz}), 3.31(2 \mathrm{H}, \mathrm{t}, J=4.7 \mathrm{~Hz}), 3.55(2 \mathrm{H}, \mathrm{t}, J=6.6 \mathrm{~Hz}), 3.78-3.82(5 \mathrm{H}$, 
m), $4.15(2 \mathrm{H}, \mathrm{t}, J=4.8 \mathrm{~Hz}), 4.59(2 \mathrm{H}, \mathrm{s}), 6.86(1 \mathrm{H}, \mathrm{d}, J=8.8 \mathrm{~Hz}), 6.97(2 \mathrm{H}$ d, $J=8.8 \mathrm{~Hz}), 7.26-7.68(7 \mathrm{H}, \mathrm{m}), 7.82-7.91(3 \mathrm{H}, \mathrm{m})$.

Methyl 7-\{4-[2-(Butoxy)ethoxy]phenyl\}-1-[(thiazol-2-yl)methyl]-2,3dihydro-1H-1-benzazepine-4-carboxylate (14I) Yield 88\%. ${ }^{1} \mathrm{H}-\mathrm{NMR}$ $\left(\mathrm{CDCl}_{3}\right) \delta 0.93(3 \mathrm{H}, \mathrm{t}, J=7.2 \mathrm{~Hz}), 1.34-1.45(2 \mathrm{H}, \mathrm{m}), 1.57-1.70(2 \mathrm{H}, \mathrm{m})$, $2.87(2 \mathrm{H}, \mathrm{t}, J=4.4 \mathrm{~Hz}), 3.42(2 \mathrm{H}, \mathrm{t}, J=4.4 \mathrm{~Hz}), 3.55(2 \mathrm{H}, \mathrm{t}, J=6.6 \mathrm{~Hz})$, $3.78-3.82(5 \mathrm{H}, \mathrm{m}), 4.16(2 \mathrm{H}, \mathrm{t}, J=5.6 \mathrm{~Hz}), 4.86(2 \mathrm{H}, \mathrm{s}), 6.95-7.00(3 \mathrm{H}$, m), $7.30(1 \mathrm{H}, \mathrm{d}, J=3.2 \mathrm{~Hz}), 7.40(1 \mathrm{H}, \mathrm{dd}, J=8.4,2.2 \mathrm{~Hz}), 7.46(2 \mathrm{H}, \mathrm{d}$, $J=8.6 \mathrm{~Hz}), 7.56(1 \mathrm{H}, \mathrm{d}, J=2.6 \mathrm{~Hz}), 7.78-7.81(2 \mathrm{H}, \mathrm{m})$.

Methyl 7-\{4-[2-(Butoxy)ethoxy]phenyl $\}-1-[(1-m e t h y l-1 H$-imidazol-2yl)methyll-2,3-dihydro-1 $H$-1-benzazepine-4-carboxylate $\quad(\mathbf{1 4 m})$ Yield $59 \%$. ${ }^{1} \mathrm{H}-\mathrm{NMR}\left(\mathrm{CDCl}_{3}\right) \delta 0.93(3 \mathrm{H}, \mathrm{t}, J=7.2 \mathrm{~Hz}), 1.38-1.45(2 \mathrm{H}, \mathrm{m})$, $1.54-1.65(2 \mathrm{H}, \mathrm{m}), 2.41(2 \mathrm{H}, \mathrm{t}, J=4.7 \mathrm{~Hz}), 3.30(2 \mathrm{H}, \mathrm{t}, J=4.7 \mathrm{~Hz}), 3.51$ $(3 \mathrm{H}, \mathrm{s}), 3.56(2 \mathrm{H}, \mathrm{t}, J=6.2 \mathrm{~Hz}), 3.79-3.83(5 \mathrm{H}, \mathrm{m}), 4.17(2 \mathrm{H}, \mathrm{t}, J=4.4 \mathrm{~Hz})$, $4.61(2 \mathrm{H}, \mathrm{s}), 6.88(1 \mathrm{H}, \mathrm{d}, J=1.0 \mathrm{~Hz}), 6.97-7.06(4 \mathrm{H}, \mathrm{m}), 7.44-7.50(3 \mathrm{H}$, $\mathrm{m}), 7.56(1 \mathrm{H}, \mathrm{d}, J=2.2 \mathrm{~Hz}), 7.77(1 \mathrm{H}, \mathrm{s})$.

Methyl 7-\{4-[2-(Butoxy)ethoxy]phenyl\}-1-[(1-methyl-1H-pyrazol-5-yl)methyl]-2,3-dihydro-1H-1-benzazepine-4-carboxylate (14n) Yield $67 \%$. ${ }^{1} \mathrm{H}-\mathrm{NMR}\left(\mathrm{CDCl}_{3}\right) \delta 0.93(3 \mathrm{H}, \mathrm{t}, J=7.4 \mathrm{~Hz}), 1.34-1.45(2 \mathrm{H}, \mathrm{m}), 1.55$ $1.70(2 \mathrm{H}, \mathrm{m}), 2.58(2 \mathrm{H}, \mathrm{t}, J=4.8 \mathrm{~Hz}), 3.27(2 \mathrm{H}, \mathrm{t}, J=4.8 \mathrm{~Hz}), 3.56(2 \mathrm{H}, \mathrm{t}$, $J=7.0 \mathrm{~Hz}), 3.79-3.83(8 \mathrm{H}, \mathrm{m}), 4.17(2 \mathrm{H}, \mathrm{t}, J=4.4 \mathrm{~Hz}), 4.52(2 \mathrm{H}, \mathrm{s}), 6.22$ $(1 \mathrm{H}, \mathrm{d}, J=1.8 \mathrm{~Hz}), 6.92(1 \mathrm{H}, \mathrm{d}, J=8.8 \mathrm{~Hz}), 6.99(2 \mathrm{H}, \mathrm{d}, J=8.8 \mathrm{~Hz}), 7.40$ $7.50(4 \mathrm{H}, \mathrm{m}), 7.57(1 \mathrm{H}, \mathrm{d}, J=2.2 \mathrm{~Hz}), 7.79(1 \mathrm{H}, \mathrm{s})$.

Methyl 7-\{4-[2-(Butoxy)ethoxy]phenyl\}-1-[(1-methyl-1H-pyrazol-4-yl)methyll-2,3-dihydro- $1 \mathrm{H}$-1-benzazepine-4-carboxylate (140) Yield $63 \%$ ${ }^{1} \mathrm{H}-\mathrm{NMR}\left(\mathrm{CDCl}_{3}\right) \delta 0.93(3 \mathrm{H}, \mathrm{t}, J=7.4 \mathrm{~Hz}), 1.34-1.45(2 \mathrm{H}, \mathrm{m}), 1.50$ $1.70(2 \mathrm{H}, \mathrm{m}), 2.76(2 \mathrm{H}, \mathrm{t}, J=5.0 \mathrm{~Hz}), 3.27(2 \mathrm{H}, \mathrm{t}, J=5.0 \mathrm{~Hz}), 3.56(2 \mathrm{H}, \mathrm{t}$, $J=7.0 \mathrm{~Hz}), 3.78-3.83(5 \mathrm{H}, \mathrm{m}), 3.89(3 \mathrm{H}, \mathrm{s}), 4.16(2 \mathrm{H}, \mathrm{t}, J=5.2 \mathrm{~Hz}), 4.42$ $(2 \mathrm{H}, \mathrm{s}), 6.92-7.00(3 \mathrm{H}, \mathrm{d}), 7.29(1 \mathrm{H}, \mathrm{s}), 7.40(1 \mathrm{H}, \mathrm{dd}, J=8.4,2.0 \mathrm{~Hz})$, $7.45-7.49(3 \mathrm{H}, \mathrm{m}), 7.54(1 \mathrm{H}, \mathrm{d}, J=2.0 \mathrm{~Hz}), 7.78(1 \mathrm{H}, \mathrm{s})$.

Methyl 7-\{4-[2-(Butoxy)ethoxy]phenyl\}-1-phenyl-2,3-dihydro-1H-1benzazepine-4-carboxylate (14j) To a solution of $\mathbf{2 2}(500 \mathrm{mg}$, $1.26 \mathrm{mmol})$, copper(II) pivalate $(70 \mathrm{mg}, 0.26 \mathrm{mmol})$ in $\mathrm{CH}_{2} \mathrm{Cl}_{2}$ was added triphenylbismuth diacetate $(780 \mathrm{mg}, 1.40 \mathrm{mmol})$ at room temperature. After being stirred at room temperature over night, the reaction mixture was poured into $3 \mathrm{~N} \mathrm{HCl}$. The mixture was neutralized using $1 \mathrm{~N} \mathrm{NaOH}$, and extracted with EtOAc. The organic layer was washed with water and brine, dried over $\mathrm{MgSO}_{4}$, and concentrated in vacuo. The residue was purified by column chromatography (hexane : EtOAc) to give $0.42 \mathrm{~g} \mathrm{(71 \% )} \mathrm{of} \mathbf{1 4} \mathbf{j}$ as yellow crystals, mp $80-82{ }^{\circ} \mathrm{C} .{ }^{1} \mathrm{H}-\mathrm{NMR}\left(\mathrm{CDCl}_{3}\right) \delta 0.94(3 \mathrm{H}, \mathrm{t}, J=7.1 \mathrm{~Hz})$, $1.31-1.49(2 \mathrm{H}, \mathrm{m}), 1.56-1.69(2 \mathrm{H}, \mathrm{m}), 2.85(2 \mathrm{H}, \mathrm{t}, J=4.4 \mathrm{~Hz}), 3.56(2 \mathrm{H}$, $\mathrm{t}, J=6.6 \mathrm{~Hz}), 3.79-3.84(7 \mathrm{H}, \mathrm{m}), 4.17(2 \mathrm{H}, \mathrm{t}, J=4.9 \mathrm{~Hz}), 6.87-7.02(5 \mathrm{H}$, m), $7.16-7.30(3 \mathrm{H}, \mathrm{m}), 7.40(1 \mathrm{H}, \mathrm{dd}, J=8.8,2.2 \mathrm{~Hz}), 7.51(2 \mathrm{H}, \mathrm{d}$, $J=8.4 \mathrm{~Hz}), 7.64(1 \mathrm{H}, \mathrm{d}, J=2.2 \mathrm{~Hz}), 7.80(1 \mathrm{H}, \mathrm{s})$. Anal. Calcd for $\mathrm{C}_{30} \mathrm{H}_{33} \mathrm{NO}_{4}$ : C, 76.41; H, 7.05; N, 2.97. Found: C, 76.30; H, 7.17; N, 2.90.

7-\{4-[2-(Butoxy)etoxy]phenyl\}-1-isobutyl-2,3-dihydro-1 H-1-benzazepine-4-carboxylic Acid (7f) To a solution of $\mathbf{1 4 f}(750 \mathrm{mg}, 1.66 \mathrm{mmol})$ in THF $(15 \mathrm{ml})$ and $\mathrm{MeOH}(15 \mathrm{ml})$ was added $1 \mathrm{~N} \mathrm{NaOH}(7.5 \mathrm{ml}, 7.5 \mathrm{mmol})$ at room temperature. After being stirred at room temperature for $20 \mathrm{~h}$, the reaction mixture was acidified using $1 \mathrm{~N} \mathrm{HCl}$ under ice cooling. The mixture was extracted with EtOAc. The organic layer was washed with brine, dried over $\mathrm{MgSO}_{4}$, and concentrated in vacuo. The precipitated crystals were collected by filtration, washed with hexane : EtOAc $(6: 1)$ to give $610 \mathrm{mg}(84 \%)$ of $7 \mathbf{f}$ as yellow crystals. ${ }^{1} \mathrm{H}-\mathrm{NMR}\left(\mathrm{CDCl}_{3}\right) \delta 0.93(3 \mathrm{H}, \mathrm{t}, J=7.0 \mathrm{~Hz}), 0.96$ $(6 \mathrm{H}, \mathrm{d}, J=6.6 \mathrm{~Hz}), 1.34-1.47(2 \mathrm{H}, \mathrm{m}), 1.54-1.66(2 \mathrm{H}, \mathrm{m}), 1.96-2.18$ $(1 \mathrm{H}, \mathrm{m}), 2.79-2.85(2 \mathrm{H}, \mathrm{m}), 3.19(2 \mathrm{H}, \mathrm{d}, J=6.8 \mathrm{~Hz}), 3.30-3.35(2 \mathrm{H}, \mathrm{m})$, $3.56(2 \mathrm{H}, \mathrm{t}, J=6.6 \mathrm{~Hz}), 3.81(2 \mathrm{H}, \mathrm{t}, J=4.8 \mathrm{~Hz}), 4.16(2 \mathrm{H}, \mathrm{t}, J=4.8 \mathrm{~Hz}), 6.90$ $(1 \mathrm{H}, \mathrm{d}, J=8.8 \mathrm{~Hz}), 6.98(2 \mathrm{H}, \mathrm{d}, J=8.8 \mathrm{~Hz}), 7.38-7.53(4 \mathrm{H}, \mathrm{m}), 7.89(1 \mathrm{H}$, s).

The following compounds $(\mathbf{7 g}-\mathbf{o})$ were prepared from the corresponding esters $(\mathbf{1 4 g}-\mathbf{0})$ by a method similar to that described for $\mathbf{7 f}$.

7-\{4-[2-(Butoxy)ethoxy]phenyl\}-1-cyclopropylmethyl-2,3-dihydro-1 H1-benzazepine-4-carboxylic Acid (7g) Yield 96\%, mp $152-155^{\circ} \mathrm{C} .{ }^{1} \mathrm{H}-$ NMR $\left(\mathrm{CDCl}_{3}\right) \delta 0.25-0.33(2 \mathrm{H}, \mathrm{m}), 0.59-0.68(2 \mathrm{H}, \mathrm{m}), 0.93(3 \mathrm{H}, \mathrm{t}$, $J=7.3 \mathrm{~Hz}), 1.05-1.20(1 \mathrm{H}, \mathrm{m}), 1.30-1.49(2 \mathrm{H}, \mathrm{m}), 1.55-1.69(2 \mathrm{H}, \mathrm{m})$, $2.87(2 \mathrm{H}, \mathrm{t}, J=4.6 \mathrm{~Hz}), 3.25(2 \mathrm{H}, \mathrm{d}, J=6.4 \mathrm{~Hz}), 3.42(2 \mathrm{H}, \mathrm{t}, J=4.6 \mathrm{~Hz}), 3.56$ $(2 \mathrm{H}, \mathrm{t}, J=6.6 \mathrm{~Hz}), 3.81(2 \mathrm{H}, \mathrm{t}, J=5.0 \mathrm{~Hz}), 4.16(2 \mathrm{H}, \mathrm{t}, J=5.0 \mathrm{~Hz}), 6.93-$ $7.00(3 \mathrm{H}, \mathrm{m}), 7.40-7.54(4 \mathrm{H}, \mathrm{m}), 7.89(1 \mathrm{H}, \mathrm{s})$. Anal. Calcd for $\mathrm{C}_{27} \mathrm{H}_{33} \mathrm{NO}_{4}$ : C, 74.45; H, 7.64; N, 3.22. Found: C, 74.27; H, 7.45; N, 3.21

7-\{4-[2-(Butoxy)ethoxy]phenyl\}-1-cyclobutylmethyl-2,3-dihydro-1 H-1benzazepine-4-carboxylic Acid (7h) Yield 87\%, mp $110-112^{\circ} \mathrm{C} .{ }^{1} \mathrm{H}-$ $\operatorname{NMR}\left(\mathrm{CDCl}_{3}\right) \delta 0.93(3 \mathrm{H}, \mathrm{t}, J=7.3 \mathrm{~Hz}), 1.30-2.00(8 \mathrm{H}, \mathrm{m}), 2.00-2.15$ $(2 \mathrm{H}, \mathrm{m}), 2.71-2.80(3 \mathrm{H}, \mathrm{m}), 3.29(2 \mathrm{H}, \mathrm{t}, J=4.8 \mathrm{~Hz}), 3.39(2 \mathrm{H}, \mathrm{d}$, $J=7.0 \mathrm{~Hz}), 3.55(2 \mathrm{H}, \mathrm{t}, J=6.6 \mathrm{~Hz}), 3.80(2 \mathrm{H}, \mathrm{d}, J=5.0 \mathrm{~Hz}), 4.16(2 \mathrm{H}, \mathrm{t}$,
$J=5.0 \mathrm{~Hz}), 6.88(1 \mathrm{H}, \mathrm{d}, J=8.0 \mathrm{~Hz}), 6.98(2 \mathrm{H}, \mathrm{d}, J=8.8 \mathrm{~Hz}), 7.39-7.51(4 \mathrm{H}$, m), $7.85(1 \mathrm{H}, \mathrm{s})$. Anal. Calcd for $\mathrm{C}_{28} \mathrm{H}_{35} \mathrm{NO}_{4}: \mathrm{C}, 74.80 ; \mathrm{H}, 7.85 ; \mathrm{N}, 3.12$. Found: C, 74.51; H, 7.92; N, 2.98 .

7-\{4-[2-(Butoxy)ethoxy]phenyl\}-1-cyclohexylmethyl-2,3-dihydro-1H1-benzazepine-4-carboxylic Acid (7i) Yield $89 \%$, mp $124-125^{\circ} \mathrm{C} .{ }^{1} \mathrm{H}-$ NMR $\left(\mathrm{CDCl}_{3}\right) \delta 0.90-1.85(18 \mathrm{H}, \mathrm{m}), 2.83(3 \mathrm{H}, \mathrm{t}$-like $), 3.22(2 \mathrm{H}, \mathrm{d}$, $J=6.6 \mathrm{~Hz}), 3.32(2 \mathrm{H}, \mathrm{t}-\mathrm{like}), 3.56(2 \mathrm{H}, \mathrm{t}, J=6.6 \mathrm{~Hz}), 3.81(2 \mathrm{H}, \mathrm{d}, J=5.0 \mathrm{~Hz})$, $4.16(2 \mathrm{H}, \mathrm{t}, J=5.0 \mathrm{~Hz}), 6.89(1 \mathrm{H}, \mathrm{d}, J=8.8 \mathrm{~Hz}), 6.98(2 \mathrm{H}, \mathrm{d}, J=8.8 \mathrm{~Hz})$, 7.39-7.53 (4H, m), $7.88(1 \mathrm{H}, \mathrm{s})$. Anal. Calcd for $\mathrm{C}_{30} \mathrm{H}_{39} \mathrm{NO}_{4}: \mathrm{C}, 75.44 ; \mathrm{H}$, 8.23; N, 2.93. Found: C, 75.46; H, 8.23; N, 2.96.

7-\{4-[2-(Butoxy)ethoxy]phenyl\}-1-phenyl-2,3-dihydro-1 $\mathrm{H}$-1-benzazepine-4-carboxylic Acid (7j) Yield 75\%, mp 129-131 ${ }^{\circ} \mathrm{C} .{ }^{1} \mathrm{H}-\mathrm{NMR}$ $\left(\mathrm{CDCl}_{3}\right) \delta 0.94(3 \mathrm{H}, \mathrm{t}, J=7.2 \mathrm{~Hz}), 1.34-1.49(2 \mathrm{H}, \mathrm{m}), 1.55-1.69(2 \mathrm{H}, \mathrm{m})$, $2.86(2 \mathrm{H}, \mathrm{t}, J=4.4 \mathrm{~Hz}), 3.56(2 \mathrm{H}, \mathrm{t}, J=6.6 \mathrm{~Hz}), 3.79-3.84(4 \mathrm{H}, \mathrm{m}), 4.17$ $(2 \mathrm{H}, \mathrm{t}, J=4.8 \mathrm{~Hz}), 6.90-7.04(5 \mathrm{H}, \mathrm{m}), 7.17(1 \mathrm{H}, \mathrm{d}, J=8.6 \mathrm{~Hz}), 7.23-7.31$ $(2 \mathrm{H}, \mathrm{m}), 7.40(1 \mathrm{H}, \mathrm{dd}, J=8.6,2.0 \mathrm{~Hz}), 7.50(2 \mathrm{H}, \mathrm{d}, J=7.2 \mathrm{~Hz}), 7.64(1 \mathrm{H}, \mathrm{d}$, $J=2.0 \mathrm{~Hz}), 7.90(1 \mathrm{H}, \mathrm{s})$. Anal. Calcd for $\mathrm{C}_{29} \mathrm{H}_{31} \mathrm{NO}_{4}: \mathrm{C}, 76.12 ; \mathrm{H}, 6.83 ; \mathrm{N}$, 3.06. Found: C, 76.18; H, 6.85; N, 3.21.

1-Benzyl-7-\{4-[2-(butoxy)ethoxy]phenyl\}-2,3-dihydro-1 H-1-benzazepine-4-carboxylic Acid (7k) Yield 89\%, mp 133-138 ${ }^{\circ} \mathrm{C} .{ }^{1} \mathrm{H}-\mathrm{NMR}$ $\left(\mathrm{CDCl}_{3}\right) \delta 0.93(3 \mathrm{H}, \mathrm{t}, J=7.4 \mathrm{~Hz}), 1.34-1.45(2 \mathrm{H}, \mathrm{m}), 1.54-1.65(2 \mathrm{H}, \mathrm{m})$, $2.80(2 \mathrm{H}, \mathrm{br}), 3.34(2 \mathrm{H}, \mathrm{br}), 3.56(2 \mathrm{H}, \mathrm{t}, J=6.6 \mathrm{~Hz}), 3.80(2 \mathrm{H}, \mathrm{t}, J=5.0 \mathrm{~Hz})$, $4.16(2 \mathrm{H}, \mathrm{t}, J=5.0 \mathrm{~Hz}), 4.61(2 \mathrm{H}, \mathrm{s}), 6.88(1 \mathrm{H}, \mathrm{d}, J=8.8 \mathrm{~Hz}), 6.98(2 \mathrm{H}, \mathrm{d}$ $J=8.8 \mathrm{~Hz}), 7.26-7.49(8 \mathrm{H}, \mathrm{m}), 7.57(1 \mathrm{H}, \mathrm{d}, J=2.2 \mathrm{~Hz}), 7.94(1 \mathrm{H}, \mathrm{s})$. Anal. Calcd for $\mathrm{C}_{30} \mathrm{H}_{33} \mathrm{NO}_{4}$ : C, 76.41; H, 7.05; N, 2.97. Found: C, 76.06; H, 7.15; $\mathrm{N}, 2.68$.

7-\{4-[2-(Butoxy)ethoxy]phenyl\}-1-[(thiazol-2-yl)methyl]-2,3-dihydro1H-1-benzazepine-4-carboxylic Acid (7l) Yield 78\%, mp 105-107 ${ }^{\circ} \mathrm{C}$. ${ }^{1} \mathrm{H}-\mathrm{NMR}\left(\mathrm{CDCl}_{3}\right) \delta 0.93(3 \mathrm{H}, \mathrm{t}, J=7.6 \mathrm{~Hz}), 1.34-1.45(2 \mathrm{H}, \mathrm{m}), 1.54$ $1.65(2 \mathrm{H}, \mathrm{m}), 2.89(2 \mathrm{H}, \mathrm{br}), 3.45(2 \mathrm{H}, \mathrm{br}), 3.55(2 \mathrm{H}, \mathrm{t}, J=6.6 \mathrm{~Hz}), 3.80(2 \mathrm{H}$, $\mathrm{t}, J=5.0 \mathrm{~Hz}), 4.16(2 \mathrm{H}, \mathrm{t}, J=5.0 \mathrm{~Hz}), 4.88(2 \mathrm{H}, \mathrm{s}), 6.96-7.01(3 \mathrm{H}, \mathrm{m}), 7.31$ $(1 \mathrm{H}, \mathrm{d}, J=3.3 \mathrm{~Hz}), 7.46-7.49(3 \mathrm{H}, \mathrm{m}), 7.57(1 \mathrm{H}, \mathrm{d}, J=2.6 \mathrm{~Hz}), 7.80(1 \mathrm{H}, \mathrm{d}$, $J=3.3 \mathrm{~Hz}), 7.91(1 \mathrm{H}, \mathrm{s})$. Anal. Calcd for $\mathrm{C}_{27} \mathrm{H}_{30} \mathrm{~N}_{2} \mathrm{O}_{4} \mathrm{~S}: \mathrm{C}, 67.76 ; \mathrm{H}, 6.32 ; \mathrm{N}$, 5.85. Found: C, 67.76; H, 6.39; N, 5.70

7-\{4-[2-(Butoxy)ethoxy]phenyl\}-1-[(1-methyl-1 H-imidazol-2-yl)methyl]-2,3-dihydro-1 $\mathrm{H}$-1-benzazepine-4-carboxylic Acid $(7 \mathrm{~m})$ Yield $80 \%$. ${ }^{1} \mathrm{H}-\mathrm{NMR}\left(\mathrm{CDCl}_{3}\right) \delta 0.93(3 \mathrm{H}, \mathrm{t}, J=7.4 \mathrm{~Hz}), 1.30-1.50(2 \mathrm{H}, \mathrm{m})$, $1.54-1.70(2 \mathrm{H}, \mathrm{m}), 2.47(2 \mathrm{H}, \mathrm{br}), 3.32(2 \mathrm{H}, \mathrm{br}), 3.54-3.59(5 \mathrm{H}, \mathrm{m}), 3.80$ $(2 \mathrm{H}, \mathrm{t}, J=4.9 \mathrm{~Hz}), 4.16(2 \mathrm{H}, \mathrm{t}, J=4.9 \mathrm{~Hz}), 4.68(2 \mathrm{H}, \mathrm{s}), 6.88(1 \mathrm{H}, \mathrm{s}), 6.98$ $(2 \mathrm{H}, \mathrm{d}, J=8.4 \mathrm{~Hz}), 7.03-7.07(2 \mathrm{H}, \mathrm{m}), 7.45-7.49(3 \mathrm{H}, \mathrm{m}), 7.57(1 \mathrm{H}, \mathrm{d}$, $J=2.2 \mathrm{~Hz}), 7.85(1 \mathrm{H}, \mathrm{s})$

7-\{4-[2-(Butoxy)ethoxy]phenyl\}-1-[(1-methyl-1H-pyrazol-5-yl)methyl|-2,3-dihydro- $1 \boldsymbol{H}$-1-benzazepine-4-carboxylic Acid (7n) Yield $77 \%, \mathrm{mp} 145-148^{\circ} \mathrm{C} .{ }^{1} \mathrm{H}-\mathrm{NMR}\left(\mathrm{CDCl}_{3}\right) \delta 0.93(3 \mathrm{H}, \mathrm{t}, J=7.0 \mathrm{~Hz}), 1.34$ $1.45(2 \mathrm{H}, \mathrm{m}), 1.55-1.65(2 \mathrm{H}, \mathrm{m}), 2.62(2 \mathrm{H}, \mathrm{br} \mathrm{s}), 3.30(2 \mathrm{H}, \mathrm{br} \mathrm{s}), 3.56(2 \mathrm{H}$, $\mathrm{t}, J=7.0 \mathrm{~Hz}), 3.79-3.84(5 \mathrm{H}, \mathrm{m}), 4.17(2 \mathrm{H}, \mathrm{t}, J=5.0 \mathrm{~Hz}), 4.54(2 \mathrm{H}, \mathrm{s}), 6.22$ $(1 \mathrm{H}, \mathrm{d}, J=1.8 \mathrm{~Hz}), 6.93(1 \mathrm{H}, \mathrm{d}, J=8.8 \mathrm{~Hz}), 6.99(2 \mathrm{H}, \mathrm{d}, J=8.8 \mathrm{~Hz}), 7.43-$ $7.50(4 \mathrm{H}, \mathrm{m}), 7.58(1 \mathrm{H}, \mathrm{d}, J=2.2 \mathrm{~Hz}), 7.89(1 \mathrm{H}, \mathrm{s})$. Anal. Calcd for $\mathrm{C}_{28} \mathrm{H}_{33} \mathrm{~N}_{3} \mathrm{O}_{4}$ : C, 70.71; H, 6.99; N, 8.84. Found: C, 70.48; H, 6.90; N, 8.80.

7-\{4-[2-(Butoxy)ethoxy]phenyl\}-1-[(1-methyl-1 H-pyrazol-4-yl)methyl]-2,3-dihydro- $1 \mathrm{H}$-1-benzazepine-4-carboxylic Acid (7o) Yield $69 \%, \mathrm{mp} 131-133{ }^{\circ} \mathrm{C} .{ }^{1} \mathrm{H}-\mathrm{NMR}\left(\mathrm{CDCl}_{3}\right) \delta 0.93(3 \mathrm{H}, \mathrm{t}, J=7.4 \mathrm{~Hz}), 1.34$ $1.49(2 \mathrm{H}, \mathrm{m}), 1.55-1.65(2 \mathrm{H}, \mathrm{m}), 2.79(2 \mathrm{H}, \mathrm{t}, J=4.2 \mathrm{~Hz}), 3.30(2 \mathrm{H}, \mathrm{t}$, $J=4.2 \mathrm{~Hz}), 3.56(2 \mathrm{H}, \mathrm{t}, J=6.6 \mathrm{~Hz}), 3.81(2 \mathrm{H}, \mathrm{t}, J=4.8 \mathrm{~Hz}), 3.90(3 \mathrm{H}, \mathrm{s})$, $4.16(2 \mathrm{H}, \mathrm{t}, J=5.2 \mathrm{~Hz}), 4.44(2 \mathrm{H}, \mathrm{s}), 6.94-7.01(3 \mathrm{H}, \mathrm{m}), 7.30(1 \mathrm{H}, \mathrm{s})$, $7.40-7.50(4 \mathrm{H}, \mathrm{m}), 7.56(1 \mathrm{H}, \mathrm{d}, J=2.0 \mathrm{~Hz}), 7.90(1 \mathrm{H}, \mathrm{s})$. Anal. Calcd for $\mathrm{C}_{28} \mathrm{H}_{33} \mathrm{~N}_{3} \mathrm{O}_{4}$ : C, 70.71; H, 6.99; N, 8.84. Found: $\mathrm{C}, 70.52 ; \mathrm{H}, 6.90 ; \mathrm{N}, 8.70$.

Methyl 1-(tert-Butoxycarbonyl)-7-(4-morpholinophenyl)-2,3-dihydro$\mathbf{1 H}$-1-benzazepine-4-carboxylate (23) This compound was prepared in $82 \%$ yield from 20 by a method similar to that described for $\mathbf{1 4 a}, \mathrm{mp} 183$ $185^{\circ} \mathrm{C} .{ }^{1} \mathrm{H}-\mathrm{NMR}\left(\mathrm{CDCl}_{3}\right) \delta 1.49(9 \mathrm{H}, \mathrm{s}), 2.90(2 \mathrm{H}, \mathrm{t}, J=5.0 \mathrm{~Hz}), 3.19-$ $3.24(4 \mathrm{H}, \mathrm{m}), 3.69(2 \mathrm{H}, \mathrm{t}, J=5.0 \mathrm{~Hz}), 3.83(3 \mathrm{H}, \mathrm{s}), 3.87-3.91(4 \mathrm{H}, \mathrm{m}), 6.98$ $(2 \mathrm{H}, \mathrm{d}, J=9.0 \mathrm{~Hz}), 7.48(2 \mathrm{H}, \mathrm{m}), 7.52(2 \mathrm{H}, \mathrm{d}, J=9.0 \mathrm{~Hz}), 7.58(1 \mathrm{H}, \mathrm{s}), 7.73$ $(1 \mathrm{H}, \mathrm{s})$. Anal. Calcd for $\mathrm{C}_{27} \mathrm{H}_{32} \mathrm{~N}_{2} \mathrm{O}_{5}: \mathrm{C}, 69.81 ; \mathrm{H}, 6.94 ; \mathrm{N}, 6.03$. Found: $\mathrm{C}$, $69.57 ; \mathrm{H}, 6.76 ; \mathrm{N}, 5.76$

Methyl 7-(4-Morpholinophenyl)-2,3-dihydro-1H-1-benzazepine-4-carboxylate (24) This compound was prepared in $93 \%$ yield from 23 by a method similar to that described for $\mathbf{2 1}, \mathrm{mp} 175-182{ }^{\circ} \mathrm{C} .{ }^{1} \mathrm{H}-\mathrm{NMR}\left(\mathrm{CDCl}_{3}\right)$ $\delta 2.89(2 \mathrm{H}, \mathrm{t}, J=4.5 \mathrm{~Hz}), 3.17-3.22(4 \mathrm{H}, \mathrm{m}), 3.41(2 \mathrm{H}, \mathrm{t}, J=4.5 \mathrm{~Hz}), 3.81$ $(3 \mathrm{H}, \mathrm{s}), 3.87-3.91(4 \mathrm{H}, \mathrm{m}), 6.67(1 \mathrm{H}, \mathrm{d}, J=8.3 \mathrm{~Hz}), 6.97(2 \mathrm{H}, \mathrm{d}$, $J=8.8 \mathrm{~Hz}), 7.33(1 \mathrm{H}, \mathrm{dd}, J=8.3,2.0 \mathrm{~Hz}), 7.45-7.50(3 \mathrm{H}, \mathrm{m}), 7.73(1 \mathrm{H}, \mathrm{s})$. Anal. Calcd for $\mathrm{C}_{22} \mathrm{H}_{24} \mathrm{~N}_{2} \mathrm{O}_{3} \cdot 0.2 \mathrm{H}_{2} \mathrm{O}: \mathrm{C}, 71.80 ; \mathrm{H}, 6.68 ; \mathrm{N}, 7.61$. Found: C, $71.51 ; \mathrm{H}, 6.72 ; \mathrm{N}, 7.47$.

Methyl 1-Acetyl-7-(4-morpholinophenyl)-2,3-dihydro-1 $H$-1-benzaze- 
pine-4-carboxylate (14p) To a solution of $24(369 \mathrm{mg}, 1.01 \mathrm{mmol})$ and pyridine $(0.106 \mathrm{ml}, 1.31 \mathrm{mmol})$ in THF $(10 \mathrm{ml})$ was added acetyl chloride $(0.086 \mathrm{ml}, 1.2 \mathrm{mmol})$ under ice cooling. After being stirred at room temperature for $0.5 \mathrm{~h}$, EtOAc was added to the reaction mixture and the mixture was washed with water. The organic layer was dried over $\mathrm{MgSO}_{4}$ and concentrated in vacuo to give $400 \mathrm{mg}(97 \%)$ of $14 \mathrm{p}$ as a pale yellow amorphous. ${ }^{1} \mathrm{H}-\mathrm{NMR}\left(\mathrm{CDCl}_{3}\right) \delta 2.05(3 \mathrm{H}, \mathrm{s}), 2.74-3.19(3 \mathrm{H}, \mathrm{m}), 3.24(4 \mathrm{H}, \mathrm{t}$, $J=4.8 \mathrm{~Hz}), 3.83(3 \mathrm{H}, \mathrm{s}), 3.90(4 \mathrm{H}, \mathrm{t}, J=4.8 \mathrm{~Hz}), 4.73-4.85(1 \mathrm{H}, \mathrm{m}), 7.01$ $(2 \mathrm{H}, \mathrm{d}, J=8.8 \mathrm{~Hz}), 7.23(1 \mathrm{H}, \mathrm{d}, J=8.2 \mathrm{~Hz}), 7.54(2 \mathrm{H}, \mathrm{d}, J=8.8 \mathrm{~Hz}), 7.51-$ $7.56(1 \mathrm{H}, \mathrm{m}), 7.67(1 \mathrm{H}, \mathrm{d}, J=1.8 \mathrm{~Hz}), 7.74(1 \mathrm{H}, \mathrm{s})$.

1-Acetyl-7-(4-morpholinophenyl)-2,3-dihydro-1H-1-benzazepine-4carboxylic Acid (7p) This compound was prepared in $98 \%$ yield from $\mathbf{1 4} \mathbf{p}$ by a method similar to that described for $\mathbf{7 f}$. ${ }^{1} \mathrm{H}-\mathrm{NMR}$ (DMSO- $d_{6}$ ) $1.95(3 \mathrm{H}, \mathrm{s}), 2.75(3 \mathrm{H}, \mathrm{m}), 3.17(4 \mathrm{H}, \mathrm{t}, J=4.8 \mathrm{~Hz}), 3.76(4 \mathrm{H}, \mathrm{t}, J=4.8 \mathrm{~Hz})$, $4.54(1 \mathrm{H}, \mathrm{m}), 7.03(2 \mathrm{H}, \mathrm{d}, J=8.8 \mathrm{~Hz}), 7.46(1 \mathrm{H}, \mathrm{d}, J=8.2 \mathrm{~Hz}), 7.63-7.72$ $(4 \mathrm{H}, \mathrm{m}), 7.88(1 \mathrm{H}, \mathrm{s})$

7-Bromo-2,3-dihydro-1-benzothiepine-4-carboxylic Aicd 1,1-Dioxide (25a) This compound was prepared in $95 \%$ yield from 13a by a method similar to that described for $7 \mathbf{a}, \mathrm{mp} 290-300{ }^{\circ} \mathrm{C}$. ${ }^{1} \mathrm{H}-\mathrm{NMR}$ (DMSO- $d_{6}$ ) $\delta$ $2.91-2.97(2 \mathrm{H}, \mathrm{m}), 3.73-3.80(2 \mathrm{H}, \mathrm{m}), 7.73(1 \mathrm{H}, \mathrm{s}), 7.84(1 \mathrm{H}, \mathrm{dd}, J=8.4$, $2.0 \mathrm{~Hz}), 7.94(1 \mathrm{H}, \mathrm{d}, J=8.4 \mathrm{~Hz}), 8.08(1 \mathrm{H}, \mathrm{d}, J=2.0 \mathrm{~Hz})$. Anal. Calcd for $\mathrm{C}_{11} \mathrm{H}_{9} \mathrm{BrO}_{4} \mathrm{~S}: \mathrm{C}, 41.66 ; \mathrm{H}, 2.86$. Found: $\mathrm{C}, 41.82 ; \mathrm{H}, 3.02$

7-Bromo-1-propyl-2,3-dihydro-1H-1-benzazepine-4-carboxylic Acid (25d) To a solution of $\mathbf{1 3 d}(8.05 \mathrm{~g}, 22.0 \mathrm{mmol})$ in EtOAc $(80 \mathrm{ml})$ was added $4 \mathrm{~N} \mathrm{HCl}$ in EtOAc $(80 \mathrm{ml}, 320 \mathrm{mmol})$ at room temperature. After being stirred at room temperature for $12.5 \mathrm{~h}$, the mixture was adjusted to $\mathrm{pH}=3$ with saturated aqueous $\mathrm{NaHCO}_{3}$. The mixture was extracted with EtOAc. The oraganic layer was washed with water and brine, dried over $\mathrm{MgSO}_{4}$, and concentrated in vacuo. The precipitated yellow crystals were collected by filtration to give $0.98 \mathrm{~g}(14 \%)$ of $\mathbf{2 5 d}$ as yellow crystals, mp $172-173{ }^{\circ} \mathrm{C} .{ }^{1} \mathrm{H}-\mathrm{NMR}\left(\mathrm{CDCl}_{3}\right) \delta 0.95(3 \mathrm{H}, \mathrm{t}, J=7.3 \mathrm{~Hz}), 1.70(2 \mathrm{H}$, sextet, $J=7.3 \mathrm{~Hz}), 2.81(2 \mathrm{H}, \mathrm{t}, J=4.6 \mathrm{~Hz}), 3.22-3.29(4 \mathrm{H}, \mathrm{m}), 6.70(1 \mathrm{H}, \mathrm{d}$ $J=8.8 \mathrm{~Hz}), 7.25(1 \mathrm{H}, \mathrm{dd}, J=8.8,2.3 \mathrm{~Hz}), 7.43(1 \mathrm{H}, \mathrm{d}, J=2.3 \mathrm{~Hz}), 7.69(1 \mathrm{H}$, s). Anal. Calcd for $\mathrm{C}_{14} \mathrm{H}_{16} \mathrm{BrNO}_{2}: \mathrm{C}, 54.21 ; \mathrm{H}, 5.20 ; \mathrm{N}, 4.52$. Found: C, $54.17 ; \mathrm{H}, 5.05 ; \mathrm{N}, 4.42$.

The following compounds $(\mathbf{2 5 b}-\mathbf{c})$ were prepared form the corresponding esters $\left(\mathbf{1 3} \mathbf{b}^{18)}\right.$ - c) by a method similar to that described for $\mathbf{2 5 d}$.

7-Bromo-1-methyl-2,3-dihydro-1H-1-benzazepine-4-carboxylic Acid (25b) Yield quant. ${ }^{1} \mathrm{H}-\mathrm{NMR}\left(\mathrm{CDCl}_{3}\right) \delta 2.85(2 \mathrm{H}, \mathrm{t}, J=4.8 \mathrm{~Hz}), 3.03(3 \mathrm{H}$, s), $3.25(2 \mathrm{H}, \mathrm{t}, J=4.9 \mathrm{~Hz}), 6.67(1 \mathrm{H}, \mathrm{d}, J=9.2 \mathrm{~Hz}), 7.29(1 \mathrm{H}, \mathrm{dd}, J=8.8$, $2.2 \mathrm{~Hz}), 7.44(1 \mathrm{H}, \mathrm{d}, J=2.6 \mathrm{~Hz}), 7.67(1 \mathrm{H}, \mathrm{s})$.

7-Bromo-1-ethyl-2,3-dihydro-1H-1-benzazepine-4-carboxylic Acid (25c) Yield 94\%, mp $198-201{ }^{\circ} \mathrm{C} .{ }^{1} \mathrm{H}-\mathrm{NMR}\left(\mathrm{DMSO}-d_{6}\right) \delta 1.19(3 \mathrm{H}, \mathrm{t}$ $J=6.9 \mathrm{~Hz}), 2.69(2 \mathrm{H}, \mathrm{t}, J=4.4 \mathrm{~Hz}), 3.17(2 \mathrm{H}, \mathrm{t}, J=4.8 \mathrm{~Hz}), 3.34(2 \mathrm{H}, \mathrm{q}$, $J=6.9 \mathrm{~Hz}), 6.81(1 \mathrm{H}, \mathrm{d}, J=9.0 \mathrm{~Hz}), 7.28(1 \mathrm{H}, \mathrm{dd}, J=9.0,2.4 \mathrm{~Hz}), 7.49(1 \mathrm{H}$, s), $7.50(1 \mathrm{H}, \mathrm{d}, J=1.4 \mathrm{~Hz})$. Anal. Calcd for $\mathrm{C}_{13} \mathrm{H}_{14} \mathrm{BrNO}_{2}: \mathrm{C}, 52.72 ; \mathrm{H}, 4.76$; $\mathrm{N}, 4.73$. Found: C, 52.32; H, 4.72; N, 4.54.

7-Bromo-1-(3-methylbutyl)-2,3-dihydro-1H-1-benzazepine-4-carboxylic Acid (25e) This compound was prepared in $91 \%$ yield from $13 \mathrm{f}$ by a method similar to that described for 14f. ${ }^{1} \mathrm{H}-\mathrm{NMR}\left(\mathrm{CDCl}_{3}\right) \delta 0.96(6 \mathrm{H}$, $\mathrm{d}, J=6.2 \mathrm{~Hz}), 1.52-1.71(3 \mathrm{H}, \mathrm{m}), 2.78-2.84(2 \mathrm{H}, \mathrm{m}), 3.21-3.26(2 \mathrm{H}, \mathrm{m})$, $3.32(2 \mathrm{H}, \mathrm{m}), 6.69(1 \mathrm{H}, \mathrm{d}, J=8.8 \mathrm{~Hz}), 7.22-7.29(1 \mathrm{H}, \mathrm{m}), 7.43(1 \mathrm{H}, \mathrm{d}$, $J=2.2 \mathrm{~Hz}), 7.68(1 \mathrm{H}, \mathrm{s})$.

7-Bromo- $N$-(4-\{[methyl(tetrahydro-2H-pyran-4-yl)amino]methyl\}phenyl)-2,3-dihydro-1-benzothiepine-4-carboxamide 1,1-Dioxide (9a) To a solution of $25 \mathbf{a}(4.47 \mathrm{~g}, 14.1 \mathrm{mmol})$ in THF $(90 \mathrm{ml})$ was added $\mathrm{SOCl}_{2}$ $(1.03 \mathrm{ml}, 14.1 \mathrm{mmol})$ and DMF $(1.0 \mathrm{ml})$ at room temperature. The mixture was stirred at room temperature for $2 \mathrm{~h}$. The mixture was added dropwise to a solution of 4-[N-methyl- $N$-(tetrahydropyran-4-yl)-aminomethyl]aniline (8) $(3.41 \mathrm{~g}, 15.5 \mathrm{mmol})$ and $\mathrm{Et}_{3} \mathrm{~N}(7.90 \mathrm{ml}, 56.7 \mathrm{mmol})$ in $\mathrm{THF}(30 \mathrm{ml})$ at room temperature. After being stirred at room temperature for $2 \mathrm{~h}$, the mixture was concentrated in vacuo. To the residue was added water and precipitated colorless crystals were collected by filtration. The crystals were washed with water, $\mathrm{EtOH}, 2$-propanol and $i$ - $\mathrm{Pr}_{2} \mathrm{O}$ to give $4.94 \mathrm{~g}(67 \%)$ of 9a as colorless crystals, mp $232-235^{\circ} \mathrm{C}$. ${ }^{1} \mathrm{H}-\mathrm{NMR}\left(\mathrm{CDCl}_{3}\right) \delta 1.54-1.83(4 \mathrm{H}, \mathrm{m}), 2.21$ $(3 \mathrm{H}, \mathrm{s}), 2.54-2.73(1 \mathrm{H}, \mathrm{m}), 3.11-3.18(2 \mathrm{H}, \mathrm{m}), 3.30-3.44(2 \mathrm{H}, \mathrm{m}), 3.58$ $(2 \mathrm{H}, \mathrm{s}), 3.66-3.73(2 \mathrm{H}, \mathrm{m}), 3.99-4.10(2 \mathrm{H}, \mathrm{m}), 7.19(1 \mathrm{H}, \mathrm{s}), 7.33(2 \mathrm{H}, \mathrm{d}$, $J=8.3 \mathrm{~Hz}), 7.53(2 \mathrm{H}, \mathrm{d}, J=8.3 \mathrm{~Hz}), 7.62-7.71(2 \mathrm{H}, \mathrm{m}), 7.88(1 \mathrm{H}, \mathrm{br} \mathrm{s})$ $8.04(1 \mathrm{H}, \mathrm{d}, J=8.4 \mathrm{~Hz})$. Anal. Calcd for $\mathrm{C}_{24} \mathrm{H}_{27} \mathrm{BrN}_{2} \mathrm{O}_{4} \mathrm{~S}$ : C, 55.49; H, 5.24; N, 5.39. Found: C, 55.56; H, 4.98; N, 5.22.

The following compounds $(\mathbf{9 b}-\mathbf{e})$ were prepared from the corresponding carboxylic acids $(\mathbf{2 5} \mathbf{b}-\mathbf{e})$ by a method similar to that described for $\mathbf{9 a}$.

7-Bromo-1-methyl- $\mathrm{N}-(4-\{[$ methyl(tetrahydro- $2 H$-pyran-4-yl)amino]methyl\}phenyl)-2,3-dihydro-1H-1-benzazepine-4-carboxamide (9b) Yield 75\%, mp 62-64 ${ }^{\circ} \mathrm{C} .{ }^{1} \mathrm{H}-\mathrm{NMR}\left(\mathrm{CDCl}_{3}\right) \delta 1.63-1.79(4 \mathrm{H}, \mathrm{m})$, $2.21(3 \mathrm{H}, \mathrm{s}), 2.57-2.72(1 \mathrm{H}, \mathrm{m}), 2.94(2 \mathrm{H}, \mathrm{t}, J=4.2 \mathrm{~Hz}), 3.03(3 \mathrm{H}, \mathrm{s})$, $3.27-3.44(4 \mathrm{H}, \mathrm{m}), 3.57(2 \mathrm{H}, \mathrm{s}), 4.00-4.07(2 \mathrm{H}, \mathrm{m}), 6.70(1 \mathrm{H}, \mathrm{d}$, $J=8.8 \mathrm{~Hz}), 7.20(1 \mathrm{H}, \mathrm{s}), 7.26-7.30(2 \mathrm{H}, \mathrm{m}), 7.30(1 \mathrm{H}, \mathrm{dd}, J=8.6,2.4 \mathrm{~Hz})$, $7.42(1 \mathrm{H}, \quad \mathrm{d}, \quad J=2.4 \mathrm{~Hz}), \quad 7.50-7.55 \quad(3 \mathrm{H}, \quad \mathrm{m})$. Anal. Calcd. for $\mathrm{C}_{25} \mathrm{H}_{30} \mathrm{BrN}_{3} \mathrm{O}_{2} \cdot 0.25 \mathrm{H}_{2} \mathrm{O}: \mathrm{C}, 61.41 ; \mathrm{H}, 6.29 ; \mathrm{N}, 8.59$. Found: C, 61.45; H, $6.25 ; \mathrm{N}, 8.32$.

7-Bromo-1-ethyl- $N-(4-\{[$ methyl(tetrahydro-2H-pyran-4-yl)amino|methyl\}phenyl)-2,3-dihydro-1 $H$-1-benzazepine-4-carboxamide (9c) Yield $70 \%, \mathrm{mp} 135-137^{\circ} \mathrm{C} .{ }^{1} \mathrm{H}-\mathrm{NMR}\left(\mathrm{CDCl}_{3}\right) \delta 1.28(3 \mathrm{H}, \mathrm{t}$, $J=7.0 \mathrm{~Hz}), 1.63-1.76(4 \mathrm{H}, \mathrm{m}), 2.20(3 \mathrm{H}, \mathrm{s}), 2.56-2.72(1 \mathrm{H}, \mathrm{m}), 2.89(2 \mathrm{H}$ $\mathrm{t}, J=4.4 \mathrm{~Hz}), 3.24-3.43(6 \mathrm{H}, \mathrm{m}), 3.56(2 \mathrm{H}, \mathrm{s}), 4.01-4.07(2 \mathrm{H}, \mathrm{m}), 6.72$ $(1 \mathrm{H}, \mathrm{d}, J=8.8 \mathrm{~Hz}), 7.18(1 \mathrm{H}, \mathrm{s}), 7.24(1 \mathrm{H}, \mathrm{dd}, J=8.8,2.6 \mathrm{~Hz}), 7.29(2 \mathrm{H}, \mathrm{d}$ $J=8.8 \mathrm{~Hz}), 7.39(1 \mathrm{H}, \mathrm{d}, J=2.6 \mathrm{~Hz}), 7.53(2 \mathrm{H}, \mathrm{d}, J=8.8 \mathrm{~Hz}), 7.55(1 \mathrm{H}, \mathrm{s})$. Anal. Calcd for $\mathrm{C}_{26} \mathrm{H}_{32} \mathrm{BrN}_{3} \mathrm{O}_{2}$ : C, 62.65; H, 6.47; N, 8.43. Found: C, 62.44; $\mathrm{H}, 6.57 ; \mathrm{N}, 8.22$.

7-Bromo- $\mathrm{N}$-(4-\{[methyl(tetrahydro-2H-pyran-4-yl)amino]methyl $\}$ phenyl)-1-propyl-2,3-dihydro-1H-1-benzazepine-4-carboxamide (9d) Yield $80 \%$, mp $134-136{ }^{\circ} \mathrm{C} .{ }^{1} \mathrm{H}-\mathrm{NMR}\left(\mathrm{CDCl}_{3}\right) \delta 0.97(3 \mathrm{H}, \mathrm{t}, J=7.5 \mathrm{~Hz})$, $1.60-1.80(6 \mathrm{H}, \mathrm{m}), 2.21(3 \mathrm{H}, \mathrm{s}), 2.57-2.70(1 \mathrm{H}, \mathrm{m}), 2.89(2 \mathrm{H}, \mathrm{t}$, $J=4.6 \mathrm{~Hz}), 3.22-3.30(4 \mathrm{H}, \mathrm{m}), 3.37(2 \mathrm{H}, \mathrm{td}, J=11.1,2.8 \mathrm{~Hz}), 3.57(2 \mathrm{H}, \mathrm{s})$, $4.01-4.07(2 \mathrm{H}, \mathrm{m}), 6.71(1 \mathrm{H}, \mathrm{d}, J=9.0 \mathrm{~Hz}), 7.19(1 \mathrm{H}, \mathrm{s}), 7.24(1 \mathrm{H}, \mathrm{dd}$, $J=9.0,2.6 \mathrm{~Hz}), 7.30(2 \mathrm{H}, \mathrm{d}, J=8.4 \mathrm{~Hz}), 7.41(1 \mathrm{H}, \mathrm{d}, J=2.6 \mathrm{~Hz}), 7.50(1 \mathrm{H}$, s), $7.52(2 \mathrm{H}, \mathrm{d}, J=8.4 \mathrm{~Hz})$. Anal. Calcd for $\mathrm{C}_{27} \mathrm{H}_{34} \mathrm{BrN}_{3} \mathrm{O}_{2}: \mathrm{C}, 63.28 ; \mathrm{H}$, $6.69 ;$ N, 8.20. Found: C, 63.19; H, 6.54; N, 8.05.

7-Bromo-1-(3-methylbutyl)- $\boldsymbol{N}$-(4-\{[methyl(tetrahydro-2H-pyran-4yl)amino|methyl $\}$ phenyl)-2,3-dihydro-1 $\boldsymbol{H}$-1-benzazepine-4-carboxamide (9e) Yield 54\%. ${ }^{1} \mathrm{H}-\mathrm{NMR}\left(\mathrm{CDCl}_{3}\right) \delta 0.96(6 \mathrm{H}, \mathrm{d}, J=6.2 \mathrm{~Hz}), 1.54-1.86$ $(7 \mathrm{H}, \mathrm{m}), 2.21(3 \mathrm{H}, \mathrm{s}), 2.55-2.76(1 \mathrm{H}, \mathrm{m}), 2.84-2.97(2 \mathrm{H}, \mathrm{m}), 3.20-3.42$ $(6 \mathrm{H}, \mathrm{m}) 3.57(2 \mathrm{H}, \mathrm{s}), 3.98-4.11(2 \mathrm{H}, \mathrm{m}), 6.70(1 \mathrm{H}, \mathrm{d}, J=8.8 \mathrm{~Hz}), 7.19$ $7.23(2 \mathrm{H}, \mathrm{m}), 7.30(2 \mathrm{H}, \mathrm{d}, J=8.4 \mathrm{~Hz}), 7.39(1 \mathrm{H}, \mathrm{d}, J=2.2 \mathrm{~Hz}), 7.54(2 \mathrm{H}, \mathrm{d}$, $J=8.4 \mathrm{~Hz}), 7.64(1 \mathrm{H}, \mathrm{s})$

1-Bromo-4-[2-(methoxy)ethoxy]benzene (27a) To a mixture of 26a $(15.0 \mathrm{~g}, 86.7 \mathrm{mmol})$, NaI $(13.0 \mathrm{~g}, 86.7 \mathrm{mmol})$ and $\mathrm{K}_{2} \mathrm{CO}_{3} \quad(14.4 \mathrm{~g}$, $104.2 \mathrm{mmol})$ in DMF $(200 \mathrm{ml})$ was added 2-chloroethyl methyl ether $(9.00 \mathrm{ml}, 98.5 \mathrm{mmol})$ at room temperature. The mixture was stirred at $80^{\circ} \mathrm{C}$ for $3 \mathrm{~d}$. Water was added to the reaction mixture and the mixture was extracted with diethyl ether $\left(\mathrm{Et}_{2} \mathrm{O}\right)$. The organic layer was washed with water and brine, dried over $\mathrm{MgSO}_{4}$, and concentrated in vacuo to give $17.7 \mathrm{~g}$ $(87 \%)$ of $27 \mathbf{a}$ as an orange oil. ${ }^{1} \mathrm{H}-\mathrm{NMR}\left(\mathrm{CDCl}_{3}\right) \delta 3.45(3 \mathrm{H}, \mathrm{s}), 3.72-3.77$ $(2 \mathrm{H}, \mathrm{m}), 4.06-4.11(2 \mathrm{H}, \mathrm{m}), 6.81(2 \mathrm{H}, \mathrm{d}, J=8.9 \mathrm{~Hz}), 7.37(2 \mathrm{H}, \mathrm{d}$, $J=8.9 \mathrm{~Hz}$ ).

The following compounds $(\mathbf{2 7 b}-\mathbf{d}, \mathbf{2 7 f})$ were prepared from $\mathbf{2 6 a}$ by a method similar to that described for $27 \mathbf{a}$.

1-Bromo-4-[2-(ethoxy)ethoxy]benzene (27b) Yield $76 \% .{ }^{1} \mathrm{H}-\mathrm{NMR}$ $\left(\mathrm{CDCl}_{3}\right) \delta 1.24(3 \mathrm{H}, \mathrm{t}, J=7.0 \mathrm{~Hz}), 3.66(2 \mathrm{H}, \mathrm{q}, J=7.0 \mathrm{~Hz}), 3.78(2 \mathrm{H}, \mathrm{t}$, $J=4.8 \mathrm{~Hz}), 4.09(2 \mathrm{H}, \mathrm{t}, J=4.8 \mathrm{~Hz}), 6.77-6.84(2 \mathrm{H}, \mathrm{m}), 7.33-7.39(2 \mathrm{H}$, $\mathrm{m})$.

1-Bromo-4-[2-(propoxy)ethoxy]benzene (27c) Yield 78\%. ${ }^{1} \mathrm{H}-\mathrm{NMR}$ $\left(\mathrm{CDCl}_{3}\right) \delta 0.93(3 \mathrm{H}, \mathrm{t}, J=7.2 \mathrm{~Hz}), 1.55-1.71(2 \mathrm{H}, \mathrm{m}), 3.48(2 \mathrm{H}, \mathrm{t}$, $J=6.8 \mathrm{~Hz}), 3.74-3.79(2 \mathrm{H}, \mathrm{m}), 4.05-4.10(2 \mathrm{H}, \mathrm{m}), 6.77-6.83(2 \mathrm{H}, \mathrm{m})$, $7.33-7.38(2 \mathrm{H}, \mathrm{m})$

1-Bromo-4-[2-(butoxy)ethoxy]benzene (27d) Yield $64 \%$. ${ }^{1} \mathrm{H}-\mathrm{NMR}$ $\left(\mathrm{CDCl}_{3}\right) \delta 0.92(3 \mathrm{H}, \mathrm{t}, J=7.4 \mathrm{~Hz}), 1.27-1.65(4 \mathrm{H}, \mathrm{m}), 3.53(2 \mathrm{H}, \mathrm{t}$, $J=6.6 \mathrm{~Hz}), 3.74-3.79(2 \mathrm{H}, \mathrm{m}), 4.05-4.11(2 \mathrm{H}, \mathrm{m}), 6.81 \quad(2 \mathrm{H}, \mathrm{d}$, $J=9.0 \mathrm{~Hz}), 7.36(2 \mathrm{H}, \mathrm{d}, J=9.0 \mathrm{~Hz})$.

1-Bromo-4-[3-(ethoxy)propoxy]benzene (27f) Yield $43 \% .{ }^{1} \mathrm{H}-\mathrm{NMR}$ $\left(\mathrm{CDCl}_{3}\right) \delta 1.20(3 \mathrm{H}, \mathrm{t}, J=7.0 \mathrm{~Hz}), 1.98-2.08(2 \mathrm{H}, \mathrm{m}), 3.49(2 \mathrm{H}, \mathrm{q}$, $J=7.0 \mathrm{~Hz}), 3.58(2 \mathrm{H}, \mathrm{d}, J=6.0 \mathrm{~Hz}), 4.03(2 \mathrm{H}, \mathrm{d}, J=6.4 \mathrm{~Hz}), 6.79(2 \mathrm{H}, \mathrm{d}$, $J=9.0 \mathrm{~Hz}), 7.36(2 \mathrm{H}, \mathrm{d}, J=9.0 \mathrm{~Hz})$

1-Bromo-4-[2-(pentyloxy)ethoxy]benzene (27e) To a solution of $\mathbf{2 6 \mathbf { b }}$ $(19.5 \mathrm{~g}, 89.8 \mathrm{mmol})$ in DMF $(166 \mathrm{ml})$ was added sodium hydride $(65 \%$ in mineral oil, $5.30 \mathrm{~g}, 143 \mathrm{mmol}$ ) under ice cooling. After being stirred at room temperature for $1.5 \mathrm{~h}, 1$-iodopentane $(17.7 \mathrm{ml}, 135 \mathrm{mmol})$ was added to the reaction mixture at room temperature. The mixture was stirred at room temperature for $2 \mathrm{~h}$, poured into water and extracted with EtOAc. The organic layer was washed with brine, dried over $\mathrm{MgSO}_{4}$, and concentrated in vacuo. The residue was purified by column chromatography (hexane:EtOAc= $10: 1)$ gave $12.0 \mathrm{~g}(57 \%)$ of $27 \mathrm{e}$ as a colorless oil. ${ }^{1} \mathrm{H}-\mathrm{NMR}\left(\mathrm{CDCl}_{3}\right) \delta 0.90$ $(3 \mathrm{H}, \mathrm{t}, J=6.6 \mathrm{~Hz}), 1.25-1.37(4 \mathrm{H}, \mathrm{m}), 1.57-1.68(2 \mathrm{H}, \mathrm{m}), 3.52(2 \mathrm{H}, \mathrm{t}$, $J=6.6 \mathrm{~Hz}), 3.74-3.79(2 \mathrm{H}, \mathrm{m}), 4.05-4.11(2 \mathrm{H}, \mathrm{m}), 6.78-6.83(2 \mathrm{H}, \mathrm{m})$, $7.33-7.39(2 \mathrm{H}, \mathrm{m})$

\{4-[2-(Methoxy)ethoxy]phenyl\}boronic Acid (10a) To a solution of $27 \mathbf{a}(17.0 \mathrm{~g}, 73.6 \mathrm{mmol})$ in THF $(50 \mathrm{ml})$ and $\mathrm{Et}_{2} \mathrm{O}(150 \mathrm{ml})$ was added drop- 
wise a solution of $n$-BuLi in hexane $(1.6 \mathrm{M}, 50.0 \mathrm{ml}, 80.0 \mathrm{mmol})$ at $-78^{\circ} \mathrm{C}$. After being stirred at $-78^{\circ} \mathrm{C}$ for $1 \mathrm{~h}$, a solution of trimethyl borate $(24.8 \mathrm{ml}$, $221 \mathrm{mmol})$ in THF $(25 \mathrm{ml})$ at $-78^{\circ} \mathrm{C}$. The mixture was stirred at room temperature for $2 \mathrm{~h}$. To the reaction mixture was added $10 \%$ aqueous $\mathrm{H}_{2} \mathrm{SO}_{4}$ $(50 \mathrm{ml})$ and the mixture was stirred for $30 \mathrm{~min}$. The mixture was extracted with EtOAc. The organic layer was washed with brine, dried over $\mathrm{MgSO}_{4}$, and concentrated in vacuo. The residue was purified by column chromatography (hexane : EtOAc $=1: 1)$ gave $7.17 \mathrm{~g}(50 \%)$ of $\mathbf{1 0 a}$ as a colorless solid. ${ }^{1} \mathrm{H}-\mathrm{NMR}\left(\mathrm{DMSO}-d_{6}\right) \delta 3.47(3 \mathrm{H}, \mathrm{s}), 3.79(2 \mathrm{H}, \mathrm{t}, J=4.7 \mathrm{~Hz}), 4.19(2 \mathrm{H}, \mathrm{t}$, $J=4.7 \mathrm{~Hz}), 7.00(2 \mathrm{H}, \mathrm{d}, J=8.7 \mathrm{~Hz}), 7.76(2 \mathrm{H}, \mathrm{d}, J=8.7 \mathrm{~Hz})$.

\{4-[2-(Ethoxy)ethoxy]phenyl\}boronic Acid (10b) This compound was prepared in $27 \%$ yield from $\mathbf{2 7 b}$ by a method similar to that described for 10a. ${ }^{1} \mathrm{H}-\mathrm{NMR}$ (DMSO- $\left.d_{6}\right) \delta 1.13(3 \mathrm{H}, \mathrm{t}, J=7.0 \mathrm{~Hz}), 3.50(2 \mathrm{H}, \mathrm{q}, J=7.0 \mathrm{~Hz})$, $3.66-3.71(2 \mathrm{H}, \mathrm{m}), 4.06-4.11(2 \mathrm{H}, \mathrm{m}), 6.89(2 \mathrm{H}, \mathrm{d}, J=8.4 \mathrm{~Hz}), 7.14(2 \mathrm{H}$, d, $J=8.4 \mathrm{~Hz})$.

\{4-[2-(Propoxy)ethoxy]phenyl\}boronic Acid (10c) To a mixture of $\mathrm{Mg}$ $(2.17 \mathrm{~g}, 89.3 \mathrm{mmol})$ and THF $(43 \mathrm{ml})$ was added 1,2-dibromoethane (cat. amount) at room temperature. Then a solution of $27 \mathrm{c}(22.0 \mathrm{~g}, 86.2 \mathrm{mmol})$ in THF $(176 \mathrm{ml})$ was added dropwise to the mixture under reflux. The mixture was refluxed for $15 \mathrm{~min}$. The mixture was cooled to $-78^{\circ} \mathrm{C}$ and a solution of trimethyl borate $(13.2 \mathrm{~g}, 118 \mathrm{mmol})$ in THF $(13 \mathrm{ml})$ at $-78^{\circ} \mathrm{C}$. The mixture was stirred at room temperature for $6 \mathrm{~h}$ and $5 \%$ aqueous $\mathrm{H}_{2} \mathrm{SO}_{4}(5.0 \mathrm{ml})$ was added to the mixture. The mixture was stirred at room temperature for $15 \mathrm{~min}$ and the mixture was extracted with EtOAc. The organic layer was washed with brine, dried over $\mathrm{MgSO}_{4}$, and concentrated in vacuo to give $8.6 \mathrm{~g}(45 \%)$ of $10 \mathrm{c}$ as a colorless solid. ${ }^{1} \mathrm{H}-\mathrm{NMR}\left(\mathrm{DMSO}-d_{6}\right) \delta 0.87(3 \mathrm{H}, \mathrm{t}$, $J=7.4 \mathrm{~Hz}), 1.44-1.62(2 \mathrm{H}, \mathrm{m}), 3.41(2 \mathrm{H}, \mathrm{t}, J=6.6 \mathrm{~Hz}), 3.67-3.72(2 \mathrm{H}$, $\mathrm{m}), 4.07-4.12(2 \mathrm{H}, \mathrm{m}), 6.89(2 \mathrm{H}, \mathrm{d}, J=8.8 \mathrm{~Hz}), 7.73(2 \mathrm{H}, \mathrm{d}, J=8.8 \mathrm{~Hz})$.

The following compounds $(\mathbf{1 0 d}-\mathbf{f})$ were prepared from the corresponding bromides $(\mathbf{2 7} \mathbf{d}-\mathbf{f})$ by a method similar to that described for $\mathbf{1 0 c}$.

\{4-[2-(Butoxy)ethoxy]phenyl\}boronic Acid (10d) Yield 64\%. ${ }^{1} \mathrm{H}-$ $\operatorname{NMR}\left(\mathrm{CDCl}_{3}\right) \delta 0.94(3 \mathrm{H}, \mathrm{t}, J=7.2 \mathrm{~Hz}), 1.29-1.47(2 \mathrm{H}, \mathrm{m}), 1.53-1.66$ $(2 \mathrm{H}, \mathrm{m}), 3.56(2 \mathrm{H}, \mathrm{t}, J=6.6 \mathrm{~Hz}), 3.83(2 \mathrm{H}, \mathrm{t}, J=4.9 \mathrm{~Hz}), 4.21(2 \mathrm{H}, \mathrm{t}$, $J=4.9 \mathrm{~Hz}), 7.03(2 \mathrm{H}, \mathrm{d}, J=8.8 \mathrm{~Hz}), 8.15(1 \mathrm{H}, \mathrm{d}, J=8.8 \mathrm{~Hz})$.

\{4-[2-(Pentyloxy)ethoxy]phenyl\}boronic Acid (10e) Yield 54\%. ${ }^{1} \mathrm{H}$ NMR (DMSO- $\left.d_{6}\right) \delta 0.86(3 \mathrm{H}, \mathrm{t}, J=6.6 \mathrm{~Hz}), 1.22-1.59(6 \mathrm{H}, \mathrm{m}), 3.44(2 \mathrm{H}$, $\mathrm{t}, J=6.6 \mathrm{~Hz}), 3.66-3.71(2 \mathrm{H}, \mathrm{m}), 4.05-4.13(2 \mathrm{H}, \mathrm{m}), 6.88(2 \mathrm{H}, \mathrm{d}$, $J=8.6 \mathrm{~Hz}), 7.72(2 \mathrm{H}, \mathrm{d}, J=8.6 \mathrm{~Hz})$.

\{4-[3-(Ethoxy)propoxy]phenyl\}boronic Acid (10f) Yield 65\%. ${ }^{1} \mathrm{H}$ NMR $\left(\right.$ DMSO- $\left.d_{6}\right) \delta 1.11(3 \mathrm{H}, \mathrm{t}, J=7.0 \mathrm{~Hz}), 1.89-1.98(2 \mathrm{H}, \mathrm{m}), 3.42(2 \mathrm{H}$, $\mathrm{q}, J=7.0 \mathrm{~Hz}), 3.50(2 \mathrm{H}, \mathrm{t}, J=6.2 \mathrm{~Hz}), 4.02(2 \mathrm{H}, \mathrm{t}, J=6.2 \mathrm{~Hz}), 6.84-6.93$ $(2 \mathrm{H}, \mathrm{m}), 7.69-7.81(2 \mathrm{H}, \mathrm{m})$.

7-(4-Ethylphenyl)- $\mathrm{N}$-(4-\{[methyl(tetrahydro-2 $\mathrm{H}$-pyran-4-yl)amino]methyl \}phenyl)-2,3-dihydro-1-benzothiepine-4-carboxamide 1,1-Dioxide (5a) To a solution of $7 \mathbf{a}(180 \mathrm{mg}, 0.53 \mathrm{mmol})$ in THF $(10 \mathrm{ml})$ was added oxalyl chloride $(0.090 \mathrm{ml}, 1.03 \mathrm{mmol})$ and DMF (cat. amount) at room temperature. After being stirred at room temperature for $1 \mathrm{~h}$, the mixture was concentrated in vacuo. A solution of the residue in THF $(15 \mathrm{ml})$ was added dropwise to a solution of $8(128 \mathrm{mg}, 0.58 \mathrm{mmol})$ and $\mathrm{Et}_{3} \mathrm{~N}(0.15 \mathrm{ml}$, $1.08 \mathrm{mmol})$ in THF $(5.0 \mathrm{ml})$ under ice cooling. The reaction mixture was stirred at room temperature for $64 \mathrm{~h}$ under a nitrogen atmosphere. Water was added to the reaction mixture at room temperature and the mixture was extracted with EtOAc. The organic layer was washed with water and brine, dried over $\mathrm{MgSO}_{4}$, and concentrated in vacuo to give crystals. Recrystallization from EtOH gave $174 \mathrm{mg}(60 \%)$ of $\mathbf{5 a}$ as pale yellow crystals. ${ }^{1} \mathrm{H}-\mathrm{NMR}$ $\left(\mathrm{CDCl}_{3}\right) \delta 1.29(3 \mathrm{H}, \mathrm{t}, J=6.7 \mathrm{~Hz}), 1.56-1.83(4 \mathrm{H}, \mathrm{m}), 2.21(3 \mathrm{H}, \mathrm{s}), 2.54$ $2.71(1 \mathrm{H}, \mathrm{m}), 2.72(2 \mathrm{H}, \mathrm{q}, J=6.7 \mathrm{~Hz}), 3.17(2 \mathrm{H}, \mathrm{t}, J=6.7 \mathrm{~Hz}), 3.31-3.44$ $(2 \mathrm{H}, \mathrm{m}), 3.58(2 \mathrm{H}, \mathrm{s}), 3.70-3.76(2 \mathrm{H}, \mathrm{m}), 3.98-4.11(2 \mathrm{H}, \mathrm{m}), 7.31-7.35$ $(5 \mathrm{H}, \mathrm{m}), 7.54(2 \mathrm{H}, \mathrm{d}, J=8.0 \mathrm{~Hz}), 7.55(2 \mathrm{H}, \mathrm{d}, J=8.4 \mathrm{~Hz}), 7.66(1 \mathrm{H}, \mathrm{s}), 7.71$ $(1 \mathrm{H}, \mathrm{dd}, J=8.4,1.8 \mathrm{~Hz}), 7.92(1 \mathrm{H}, \mathrm{br} \mathrm{s}), 8.21(1 \mathrm{H}, \mathrm{d}, J=8.4 \mathrm{~Hz})$. Anal. Calcd for $\mathrm{C}_{32} \mathrm{H}_{36} \mathrm{~N}_{2} \mathrm{O}_{4} \mathrm{~S}: \mathrm{C}, 70.56 ; \mathrm{H}, 6.66 ; \mathrm{N}, 5.14$. Found: C, 70.30; H, 6.73; N, 5.29 .

The following compounds $(\mathbf{5} \mathbf{b}-\mathbf{c})$ were prepared from the corresponding carboxylic acids $(\mathbf{7 b}-\mathbf{c})$ by a method similar to that described for $\mathbf{5 a}$.

$\mathrm{N}$-(4-\{[Methyl(tetrahydro-2H-pyran-4-yl)amino]methyl\}phenyl)-7-(4propylphenyl)-2,3-dihydro-1-benzothiepine-4-carboxamide 1,1-Dioxide (5b) ${ }^{1} \mathrm{H}-\mathrm{NMR}\left(\mathrm{CDCl}_{3}\right) \delta 0.98(3 \mathrm{H}, \mathrm{t}, J=7.3 \mathrm{~Hz}), 1.56-1.83(6 \mathrm{H}, \mathrm{m}), 2.21$ $(3 \mathrm{H}, \mathrm{s}), 2.52-2.74(3 \mathrm{H}, \mathrm{m}), 3.18(2 \mathrm{H}, \mathrm{t}, J=6.6 \mathrm{~Hz}), 3.31-3.44(2 \mathrm{H}, \mathrm{m})$, $3.58(2 \mathrm{H}, \mathrm{s}), 3.70-3.76(2 \mathrm{H}, \mathrm{m}), 3.97-4.10(2 \mathrm{H}, \mathrm{m}), 7.28-7.35(5 \mathrm{H}, \mathrm{m})$, $7.52(2 \mathrm{H}, \mathrm{d}, J=8.4 \mathrm{~Hz}), 7.55(2 \mathrm{H}, \mathrm{d}, J=8.4 \mathrm{~Hz}), 7.66-7.73(2 \mathrm{H}, \mathrm{m}), 7.94$ $\left(1 \mathrm{H}\right.$, br s), $8.21(1 \mathrm{H}, \mathrm{d}, J=8.0 \mathrm{~Hz})$. Anal. Calcd for $\mathrm{C}_{33} \mathrm{H}_{38} \mathrm{~N}_{2} \mathrm{O}_{4} \mathrm{~S}: 70.94 ; \mathrm{H}$, 6.86; N, 5.01. Found: C, 70.99; H, 6.51; N, 5.05.

7-(4-Isopropylphenyl)- $\mathrm{N}$-(4-\{[Methyl(tetrahydro-2H-pyran-4-yl)amino]methyl $\}$ phenyl)-2,3-dihydro-1-benzothiepine-4-carboxamide 1,1-
Dioxide (5c) ${ }^{1} \mathrm{H}-\mathrm{NMR}\left(\mathrm{CDCl}_{3}\right) \delta 1.30(6 \mathrm{H}, \mathrm{d}, J=7.0 \mathrm{~Hz}), 1.52-1.83(4 \mathrm{H}$, $\mathrm{m}), 2.21(3 \mathrm{H}, \mathrm{s}), 2.55-2.77(1 \mathrm{H}, \mathrm{m}), 2.90-3.04(1 \mathrm{H}, \mathrm{m}), 3.17(2 \mathrm{H}, \mathrm{t}$, $J=6.6 \mathrm{~Hz}), 3.37(2 \mathrm{H}, \mathrm{dt}, J=2.8,11.0 \mathrm{~Hz}), 3.58(2 \mathrm{H}, \mathrm{s}), 3.70-3.76(2 \mathrm{H}, \mathrm{m})$, $3.98-4.09(2 \mathrm{H}, \mathrm{m}), 7.31-7.38(5 \mathrm{H}, \mathrm{m}), 7.52-7.58(4 \mathrm{H}, \mathrm{m}), 7.66-7.73$ $(2 \mathrm{H}, \mathrm{m}), 7.98(1 \mathrm{H}$, br s), $8.21(1 \mathrm{H}, \mathrm{d}, J=8.4 \mathrm{~Hz})$. Anal. Calcd for $\mathrm{C}_{33} \mathrm{H}_{38} \mathrm{~N}_{2} \mathrm{O}_{4} \mathrm{~S}: \mathrm{C}, 70.94 ; \mathrm{H}, 6.86 ; \mathrm{N}, 5.01$. Found: C, 70.89; H, 6.61; N, 7.75.

$\mathrm{N}$-(4-\{[Methyl(tetrahydro-2H-pyran-4-yl)amino]methyl\}phenyl)-7-(4propoxyphenyl)-2,3-dihydro-1-benzothiepine-4-carboxamide 1,1-Dioxide (5d) To a suspension of $7 \mathbf{d}(170 \mathrm{mg}, 0.456 \mathrm{mmol})$ in THF $(5.0 \mathrm{ml})$ was added $\mathrm{SOCl}_{2}(0.070 \mathrm{ml}, 0.96 \mathrm{mmol})$ and DMF (cat. amount) at room temperature. After being stirred at room temperature for $1 \mathrm{~h}$, the mixture was concentrated in vacuo. A solution of the residue in THF $(10 \mathrm{ml})$ was added dropwise to a solution of $8(111 \mathrm{mg}, 0.50 \mathrm{mmol})$ and $\mathrm{Et}_{3} \mathrm{~N}(0.18 \mathrm{ml}$, $1.29 \mathrm{mmol})$ in THF $(2.0 \mathrm{ml})$ at room temperature. The reaction mixture was stirred at room temperature for $21 \mathrm{~h}$ under a nitrogen atmosphere. Water was added to the reaction mixture at room temperature, and the mixture was extracted with EtOAc. The organic layer was washed with water and brine, dried over $\mathrm{MgSO}_{4}$, and concentrated in vacuo. The residue was purified by column chromatography (EtOAc: $\mathrm{EtOH}=3: 1)$ and recrystallization from EtOH gave $148 \mathrm{mg}(56 \%)$ of $\mathbf{5 d}$ as pale yellow crystals. ${ }^{1} \mathrm{H}-\mathrm{NMR}\left(\mathrm{CDCl}_{3}\right) \delta$ $1.06(3 \mathrm{H}, \mathrm{t}, J=7.4 \mathrm{~Hz}), 1.57-1.90(6 \mathrm{H}, \mathrm{m}), 2.21(3 \mathrm{H}, \mathrm{s}), 2.54-2.75(1 \mathrm{H}$, $\mathrm{m}), 3.13-3.20(2 \mathrm{H}, \mathrm{m}), 3.31-3.44(2 \mathrm{H}, \mathrm{m}), 3.58(2 \mathrm{H}, \mathrm{s}), 3.69-3.76(2 \mathrm{H}$, $\mathrm{m}), 3.98(2 \mathrm{H}, \mathrm{t}, J=6.6 \mathrm{~Hz}), 3.99-4.11(2 \mathrm{H}, \mathrm{m}), 7.01(2 \mathrm{H}, \mathrm{d}, J=8.8 \mathrm{~Hz})$, $7.31-7.35(3 \mathrm{H}, \mathrm{m}), 7.52-7.56(4 \mathrm{H}, \mathrm{m}), 7.62(1 \mathrm{H}, \mathrm{d}, J=1.8 \mathrm{~Hz}), 7.67(1 \mathrm{H}$, $\mathrm{dd}, J=8.0,1.8 \mathrm{~Hz}), 7.92(1 \mathrm{H}, \mathrm{brs}), 8.19(1 \mathrm{H}, \mathrm{d}, J=8.0 \mathrm{~Hz})$. Anal. Calcd for $\mathrm{C}_{33} \mathrm{H}_{38} \mathrm{~N}_{2} \mathrm{O}_{5} \mathrm{~S}$ : C, 68.96; H, 6.66; N, 4.87. Found: C, 68.72; H, 6.70; N, 4.88 .

The following compounds $(\mathbf{6 e}, \mathbf{6 i}, \mathbf{6 k}, \mathbf{6 m -})$ ) were prepared from the corresponding carboxylic acids $(\mathbf{7 f}-\mathbf{g}, \mathbf{7 i - \mathbf { i }}-\mathbf{7 p})$ by a method similar to that described for $\mathbf{5 d}$.

1-Acetyl-7-(4-morpholinophenyl)- $N-(4-\{[$ methyl(tetrahydro-2Hpyran-4-yl)amino]methyl $\}$ phenyl)-2,3-dihydro-1H-1-benzazepine-4-carboxamide (6e) ${ }^{1} \mathrm{H}-\mathrm{NMR}\left(\mathrm{CDCl}_{3}\right) \delta 1.65-1.87(4 \mathrm{H}, \mathrm{m}), 2.09(3 \mathrm{H}, \mathrm{s}), 2.23$ $(3 \mathrm{H}, \mathrm{s}), 2.61-2.78(1 \mathrm{H}, \mathrm{m}), 2.81-3.05(3 \mathrm{H}, \mathrm{m}), 3.24(4 \mathrm{H}, \mathrm{t}, J=4.7 \mathrm{~Hz})$, $3.37(2 \mathrm{H}, \mathrm{td}, J=11.4,2.7 \mathrm{~Hz}), 3.60(2 \mathrm{H}, \mathrm{s}), 3.90(4 \mathrm{H}, \mathrm{t}, J=4.8 \mathrm{~Hz}), 4.02$ $4.07(2 \mathrm{H}, \mathrm{m}), 4.75-4.91(1 \mathrm{H}, \mathrm{m}), 7.01(2 \mathrm{H}, \mathrm{d}, J=8.8 \mathrm{~Hz}), 7.23-7.27(1 \mathrm{H}$, $\mathrm{m}), 7.34(2 \mathrm{H}, \mathrm{d}, J=8.4 \mathrm{~Hz}), 7.52-7.69(8 \mathrm{H}, \mathrm{m})$. Anal. Calcd for $\mathrm{C}_{36} \mathrm{H}_{42} \mathrm{~N}_{4} \mathrm{O}_{4}: \mathrm{C}, 72.70 ; \mathrm{H}, 7.12 ; \mathrm{N}, 9.42$. Found: C, 72.79; H, 7.07; N, 9.38.

7-\{4-[2-(Butoxy)ethoxy]phenyl\}-1-isobutyl- $N$-(4-\{[methyl(tetrahydro2H-pyran-4-yl)amino]methyl $\}$ phenyl)-2,3-dihydro-1 $H$-1-benzazepine-4carboxamide (6i) ${ }^{1} \mathrm{H}-\mathrm{NMR}\left(\mathrm{CDCl}_{3}\right) \delta 0.93(3 \mathrm{H}, \mathrm{t}, J=7.2 \mathrm{~Hz}), 0.97(6 \mathrm{H}$, $\mathrm{d}, J=6.6 \mathrm{~Hz}), 1.33-1.46(2 \mathrm{H}, \mathrm{m}), 1.54-1.77(6 \mathrm{H}, \mathrm{m}), 1.95-2.16(1 \mathrm{H}, \mathrm{m})$, $2.20(3 \mathrm{H}, \mathrm{s}), 2.64(1 \mathrm{H}, \mathrm{m}), 2.88-2.95(2 \mathrm{H}, \mathrm{m}), 3.18(2 \mathrm{H}, \mathrm{d}, J=7.4 \mathrm{~Hz})$, $3.30-3.43(4 \mathrm{H}, \mathrm{m}), 3.55(2 \mathrm{H}, \mathrm{t}, J=6.6 \mathrm{~Hz}), 3.56(2 \mathrm{H}, \mathrm{s}), 3.77-3.83(2 \mathrm{H}$, $\mathrm{m}), 3.98-4.07(2 \mathrm{H}, \mathrm{m}), 4.12-4.18(2 \mathrm{H}, \mathrm{m}), 6.91(1 \mathrm{H}, \mathrm{d}, J=8.8 \mathrm{~Hz}), 6.99$ $(2 \mathrm{H}, \mathrm{d}, J=8.4 \mathrm{~Hz}), 7.29(2 \mathrm{H}, \mathrm{d}, J=8.4 \mathrm{~Hz}), 7.36-7.58(8 \mathrm{H}, \mathrm{m})$. Anal. Calcd for $\mathrm{C}_{40} \mathrm{H}_{53} \mathrm{~N}_{3} \mathrm{O}_{4}$ : C, 75.08; H, 8.35; N, 6.57. Found: C, 74.99; H, 8.16; N, 6.69 .

7-\{4-[2-(Butoxy)ethoxy]phenyl\}-1-cyclopropylmethyl- $N$-(4-\{[methyl(tetrahydro-2H-pyran-4-yl)amino]methyl $\}$ phenyl)-2,3-dihydro-1H-1benzazepine-4-carboxamide (6k) ${ }^{1} \mathrm{H}-\mathrm{NMR}\left(\mathrm{CDCl}_{3}\right) \delta 0.26-0.33(2 \mathrm{H}$, $\mathrm{m}), 0.60-0.69(2 \mathrm{H}, \mathrm{m}), 0.93(3 \mathrm{H}, \mathrm{t}, J=7.4 \mathrm{~Hz}), 1.05-1.18(1 \mathrm{H}, \mathrm{m}), 1.22-$ $2.05(8 \mathrm{H}, \mathrm{m}), 2.21(3 \mathrm{H}, \mathrm{s}), 2.59-2.67(1 \mathrm{H}, \mathrm{m}), 2.95(2 \mathrm{H}, \mathrm{t}-\mathrm{like}), 3.25(2 \mathrm{H}$, d, $J=6.2 \mathrm{~Hz}), 3.32-3.58(8 \mathrm{H}, \mathrm{m}), 3.80(2 \mathrm{H}, \mathrm{t}, J=5.0 \mathrm{~Hz}), 3.93-4.18(4 \mathrm{H}$, m), 6.95-7.00 (3H, m), $7.29(2 \mathrm{H}, \mathrm{d}, J=8.8 \mathrm{~Hz}), 7.41-7.58(8 \mathrm{H}, \mathrm{m})$. Anal. Calcd for $\mathrm{C}_{40} \mathrm{H}_{51} \mathrm{~N}_{3} \mathrm{O}_{4}$ : C, 75.32; H, 8.06; N, 6.59. Found: C, 75.21; H, 8.12; N, 6.49 .

7-\{4-[2-(Butoxy)ethoxy]phenyl\}-1-cyclohexylmethyl- $N$-(4-\{[methyl(tetrahydro-2H-pyran-4-yl)aminolmethyl\}phenyl)-2,3-dihydro-1H-1benzazepine-4-carboxamide $(\mathbf{6 m}){ }^{1} \mathrm{H}-\mathrm{NMR} \quad\left(\mathrm{CDCl}_{3}\right) \quad \delta \quad 0.93 \quad(3 \mathrm{H}, \mathrm{t}$, $J=7.3 \mathrm{~Hz}), 0.93-1.84(19 \mathrm{H}, \mathrm{m}) 2.21(3 \mathrm{H}, \mathrm{s}), 2.58-2.66(1 \mathrm{H}, \mathrm{m}), 2.91$ (2H, t-like), $3.22(2 \mathrm{H}, \mathrm{d}, J=6.6 \mathrm{~Hz}), 3.30-3.46(4 \mathrm{H}, \mathrm{m}), 3.50-3.58(4 \mathrm{H}$, $\mathrm{m}), 3.80(2 \mathrm{H}, \mathrm{t}, J=4.9 \mathrm{~Hz}), 4.01-4.06(2 \mathrm{H}, \mathrm{m}), 4.16(2 \mathrm{H}, \mathrm{t}, J=4.9 \mathrm{~Hz})$, $6.91(1 \mathrm{H}, \mathrm{d}, J=8.8 \mathrm{~Hz}), 6.98(2 \mathrm{H}, \mathrm{d}, J=8.8 \mathrm{~Hz}), 7.30(2 \mathrm{H}, \mathrm{d}, J=8.4 \mathrm{~Hz})$, 7.37-7.56 (8H, m). Anal. Calcd for $\mathrm{C}_{43} \mathrm{H}_{57} \mathrm{~N}_{3} \mathrm{O}_{4}: \mathrm{C}, 75.96 ; \mathrm{H}, 8.45 ; \mathrm{N}$, 6.18. Found: C, 75.93; H, 8.58; N, 6.21.

7-\{4-[2-(Butoxy)ethoxy]phenyl $\}-N-(4-\{[$ methyl(tetrahydro-2H-pyran4-yl)amino]methyl $\}$ phenyl)-1-phenyl-2,3-dihydro-1 $H$-1-benzazepine-4carboxamide (6n) ${ }^{1} \mathrm{H}-\mathrm{NMR}\left(\mathrm{CDCl}_{3}\right) \delta 0.93(3 \mathrm{H}, \mathrm{t}, J=7.3 \mathrm{~Hz}), 1.27$ $1.49(2 \mathrm{H}, \mathrm{m}), 1.55-1.74(6 \mathrm{H}, \mathrm{m}), 2.19(3 \mathrm{H}, \mathrm{s}), 2.58-2.66(1 \mathrm{H}, \mathrm{m}), 2.93$ $(2 \mathrm{H}, \mathrm{t}, J=4.8 \mathrm{~Hz}), 3.36(2 \mathrm{H}, \mathrm{dt}, J=3.2,10.8 \mathrm{~Hz}), 3.52-3.59(4 \mathrm{H}, \mathrm{m}), 3.81$ $(2 \mathrm{H}, \mathrm{t}, J=5.0 \mathrm{~Hz}), 3.89(2 \mathrm{H}, \mathrm{t}, J=4.8 \mathrm{~Hz}), 4.00-4.06(2 \mathrm{H}, \mathrm{m}), 4.17(2 \mathrm{H}, \mathrm{t}$, $J=5.0 \mathrm{~Hz}), 6.88-7.02(5 \mathrm{H}, \mathrm{m}), 7.21-7.30(4 \mathrm{H}, \mathrm{m}), 7.41(1 \mathrm{H}, \mathrm{dd}, J=8.6$, $2.2 \mathrm{~Hz}), 7.48-7.53(7 \mathrm{H}, \mathrm{m}), 7.64(1 \mathrm{H}, \mathrm{d}, J=2.2 \mathrm{~Hz})$. Anal. Calcd for $\mathrm{C}_{42} \mathrm{H}_{49} \mathrm{~N}_{3} \mathrm{O}_{4} \cdot 0.25 \mathrm{H}_{2} \mathrm{O}: \mathrm{C}, 75.93 ; \mathrm{H}, 7.51 ; \mathrm{N}, 6.32$. Found: C, 75.80; H, 7.40; 
$\mathrm{N}, 6.30$.

1-Benzyl-7-\{4-[2-(butoxy)ethoxy]phenyl $\}-N-(4-\{[$ methyl(tetrahydro2H-pyran-4-yl)amino]methyl $\}$ phenyl)-2,3-dihydro-1H-1-benzazepine-4carboxamide (6o) ${ }^{1} \mathrm{H}-\mathrm{NMR}\left(\mathrm{CDCl}_{3}\right) \delta 0.93(3 \mathrm{H}, \mathrm{t}, J=7.1 \mathrm{~Hz}), 1.30$ $1.75(8 \mathrm{H}, \mathrm{m}), 2.21(3 \mathrm{H}, \mathrm{s}), 2.55-2.70(1 \mathrm{H}, \mathrm{m}), 2.85(2 \mathrm{H}, \mathrm{t}-\mathrm{like}), 3.31-$ $3.38(4 \mathrm{H}, \mathrm{m}), 3.52-3.58(4 \mathrm{H}, \mathrm{m}), 3.80(2 \mathrm{H}, \mathrm{t}, J=4.9 \mathrm{~Hz}), 4.01-4.05(2 \mathrm{H}$, $\mathrm{m}), 4.16(2 \mathrm{H}, \mathrm{t}, J=4.9 \mathrm{~Hz}), 4.61(2 \mathrm{H}, \mathrm{s}), 6.90(1 \mathrm{H}, \mathrm{d}, J=8.4 \mathrm{~Hz}), 6.98(2 \mathrm{H}$, d, $J=8.8 \mathrm{~Hz}), 7.26-7.56(15 \mathrm{H}, \mathrm{m})$. Anal. Calcd for $\mathrm{C}_{43} \mathrm{H}_{51} \mathrm{~N}_{3} \mathrm{O}_{4} \cdot 0.25 \mathrm{H}_{2} \mathrm{O}$ : C, 76.13; H, 7.65; N, 6.19. Found: C, 76.19; H, 7.55; N, 6.19.

7-\{4-[2-(Butoxy)ethoxy]phenyl\}-1-[(thiazol-2-yl)methyl]- N-(4\{[methyl(tetrahydro-2H-pyran-4-yl)amino]methyl\}phenyl)-2,3-dihydro$\mathbf{1 H}$-1-benzazepine-4-carboxamide (6p) ${ }^{1} \mathrm{H}-\mathrm{NMR}\left(\mathrm{CDCl}_{3}\right) \delta 0.93(3 \mathrm{H}, \mathrm{t}$, $J=7.3 \mathrm{~Hz}), 1.33-1.45(2 \mathrm{H}, \mathrm{m}), 1.58-1.80(6 \mathrm{H}, \mathrm{m}), 2.21(3 \mathrm{H}, \mathrm{s}), 2.51-$ $2.73(1 \mathrm{H}, \mathrm{m}), 2.88-2.99(2 \mathrm{H}, \mathrm{m}), 3.30-3.57(8 \mathrm{H}, \mathrm{m}), 3.80(2 \mathrm{H}, \mathrm{t}$, $J=4.8 \mathrm{~Hz}), 3.96-4.10(2 \mathrm{H}, \mathrm{m}), 4.16(2 \mathrm{H}, \mathrm{t}, J=4.8 \mathrm{~Hz}), 4.88(2 \mathrm{H}, \mathrm{s}), 6.96$ $7.03(3 \mathrm{H}, \mathrm{m}), 7.26-7.60(11 \mathrm{H}, \mathrm{m}), 7.80(1 \mathrm{H}, \mathrm{d}, J=3.2 \mathrm{~Hz})$. Anal. Calcd for $\mathrm{C}_{40} \mathrm{H}_{48} \mathrm{~N}_{4} \mathrm{O}_{4} \mathrm{~S}: \mathrm{C}, 70.56 ; \mathrm{H}, 7.11 ; \mathrm{N}, 8.23$. Found: C, 70.38; H, 7.12; N, 8.18.

7-\{4-[2-(Butoxy)ethoxy]phenyl $\}-1-[(1-m e t h y l-1 H$-imidazol-2-yl)methyl $]-N-(4-\{[$ methyl(tetrahydro-2H-pyran-4-yl)amino]methyl $\}-$ phenyl)-2,3-dihydro-1 $\boldsymbol{H}$-1-benzazepine-4-carboxamide (6q) ${ }^{1} \mathrm{H}-\mathrm{NMR}$ $\left(\mathrm{CDCl}_{3}\right) \delta 0.93(3 \mathrm{H}, \mathrm{t}, J=7.2 \mathrm{~Hz}), 1.30-1.45(2 \mathrm{H}, \mathrm{m}), 1.55-1.80(6 \mathrm{H}, \mathrm{m})$, $2.20(3 \mathrm{H}, \mathrm{s}), 2.43-2.70(3 \mathrm{H}, \mathrm{m}), 3.30-3.45(4 \mathrm{H}, \mathrm{m}), 3.52-3.59(7 \mathrm{H}, \mathrm{m})$, $3.81(2 \mathrm{H}, \mathrm{t}, J=5.0 \mathrm{~Hz}), 3.97-4.08(2 \mathrm{H}, \mathrm{m}), 4.17(2 \mathrm{H}, \mathrm{t}, J=5.0 \mathrm{~Hz}), 4.62$ $(2 \mathrm{H}, \mathrm{s}), 6.90(1 \mathrm{H}, \mathrm{d}, J=1.2 \mathrm{~Hz}), 6.97-7.01(3 \mathrm{H}, \mathrm{m}), 7.07(1 \mathrm{H}, \mathrm{d}$, $J=8.0 \mathrm{~Hz}), 7.27-7.32(2 \mathrm{H}, \mathrm{m}), 7.46-7.57(8 \mathrm{H}, \mathrm{m})$. Anal. Calcd for $\mathrm{C}_{41} \mathrm{H}_{51} \mathrm{~N}_{5} \mathrm{O}_{4} \cdot 0.5 \mathrm{H}_{2} \mathrm{O}: \mathrm{C}, 71.69 ; \mathrm{H}, 7.63 ; \mathrm{N}, 10.30$. Found: C, 71.80; H, 7.75; $\mathrm{N}, 10.38$.

7-\{4-[2-(Butoxy)ethoxy]phenyl $\}-1-[(1-$ methyl-1H-pyrazol-5-yl)methyl $]-N-(4-\{[$ methyl(tetrahydro-2 $H$-pyran-4-yl)amino]methyl $\}-$ phenyl)-2,3-dihydro-1 $\boldsymbol{H}$-1-benzazepine-4-carboxamide (6r) ${ }^{1} \mathrm{H}-\mathrm{NMR}$ $\left(\mathrm{CDCl}_{3}\right) \delta 0.93(3 \mathrm{H}, \mathrm{t}, J=7.2 \mathrm{~Hz}), 1.34-1.45(2 \mathrm{H}, \mathrm{m}), 1.50-1.80(6 \mathrm{H}, \mathrm{m})$, $2.21(3 \mathrm{H}, \mathrm{s}), 2.40-2.70(3 \mathrm{H}, \mathrm{m}), 3.30-3.45(4 \mathrm{H}, \mathrm{m}), 3.55(2 \mathrm{H}, \mathrm{t}$, $J=6.6 \mathrm{~Hz}), 3.57(2 \mathrm{H}, \mathrm{s}), 3.79-3.84(5 \mathrm{H}, \mathrm{m}), 3.97-4.09(2 \mathrm{H}, \mathrm{m}), 4.17(2 \mathrm{H}$, $\mathrm{t}, J=5.0 \mathrm{~Hz}), 4.55(2 \mathrm{H}, \mathrm{s}), 6.25(1 \mathrm{H}, \mathrm{d}, J=1.8 \mathrm{~Hz}), 6.95(1 \mathrm{H}, \mathrm{d}, J=8.4 \mathrm{~Hz})$, $6.99(2 \mathrm{H}, \mathrm{d}, J=8.8 \mathrm{~Hz}), 7.30(2 \mathrm{H}, \mathrm{d}, J=8.4 \mathrm{~Hz}), 7.42-7.57(9 \mathrm{H}, \mathrm{m})$. Anal. Calcd for $\mathrm{C}_{41} \mathrm{H}_{51} \mathrm{~N}_{5} \mathrm{O}_{4} \cdot 0.25 \mathrm{H}_{2} \mathrm{O}: \mathrm{C}, 72.17 ; \mathrm{H}, 7.61 ; \mathrm{N}, 10.26$. Found: C, $72.02 ; \mathrm{H}, 7.46 ; \mathrm{N}, 10.03$.

7-[4-[2-(Butoxy)ethoxy]phenyl]-1-[(1-methyl-1H-pyrazol-4-yl)methyl]$\mathrm{N}$-[4-[[methyl(tetrahydro-2H-pyran-4-yl)amino]methyl]phenyl]-2,3-dihydro-1 $\boldsymbol{H}$-1-benzazepine-4-carboxamide $(6 \mathbf{s}){ }^{1} \mathrm{H}-\mathrm{NMR}\left(\mathrm{CDCl}_{3}\right) \boldsymbol{\delta} 0.93$ $(3 \mathrm{H}, \mathrm{t}, J=7.2 \mathrm{~Hz}), 1.34-1.45(2 \mathrm{H}, \mathrm{m}), 1.50-1.80(6 \mathrm{H}, \mathrm{m}), 2.21(3 \mathrm{H}, \mathrm{s})$, $2.51-2.72(3 \mathrm{H}, \mathrm{m}), 2.79-2.88(2 \mathrm{H}, \mathrm{m}), 3.28-3.45(4 \mathrm{H}, \mathrm{m}), 3.55(2 \mathrm{H}, \mathrm{t}$, $J=6.4 \mathrm{~Hz}), 3.57(2 \mathrm{H}, \mathrm{s}), 3.80(2 \mathrm{H}, \mathrm{d}, J=4.9 \mathrm{~Hz}), 3.90(3 \mathrm{H}, \mathrm{s}), 3.97-4.09$ $(2 \mathrm{H}, \mathrm{m}), 4.16(2 \mathrm{H}, \mathrm{t}, J=4.9 \mathrm{~Hz}), 4.44(2 \mathrm{H}, \mathrm{s}), 6.96-7.01(3 \mathrm{H}, \mathrm{m}), 7.26$ $7.39(3 \mathrm{H}, \mathrm{m}), 7.45-7.55(9 \mathrm{H}, \mathrm{m})$. Anal. Calcd for $\mathrm{C}_{41} \mathrm{H}_{51} \mathrm{~N}_{5} \mathrm{O}_{4}: \mathrm{C}, 72.64 ; \mathrm{H}$, $758 ;$ N, 10.33. Found: C, 72.34; H, 7.59; N, 10.34 .

7-\{4-[2-(Butoxy)ethoxy]phenyl $\}$-1-cyclobutylmethyl- $N$-(4-\{[methyl(tetrahydro-2H-pyran-4-yl)amino]methyl $\}$ phenyl)-2,3-dihydro-1H-1benzazepine-4-carboxamide Dihydrochloride (61) The free amine was prepared from $\mathbf{7 h}$ by a method similar to that described for $\mathbf{5 d}$. To a solution of the free amine in EtOAc and $\mathrm{EtOH}$ was added $6 \mathrm{~N} \mathrm{HCl}$ and the mixture was concentrated in vacuo. To the residue was added $\mathrm{Et}_{2} \mathrm{O}$ and the pale yellow amorphous solid was collected by filtration to give 6l. ${ }^{1} \mathrm{H}-\mathrm{NMR}$ $\left(\mathrm{DMSO}-d_{6}\right) \delta 0.89(3 \mathrm{H}, \mathrm{t}, J=7.1 \mathrm{~Hz}), 1.24-1.58(4 \mathrm{H}, \mathrm{m}), 1.73-2.15(1 \mathrm{H}$, m), $2.57(2 \mathrm{H}, \mathrm{d}, J=4.8 \mathrm{~Hz}), 2.60-2.85(3 \mathrm{H}, \mathrm{m}), 3.20-3.49(10 \mathrm{H}, \mathrm{m})$, $3.96-4.13(5 \mathrm{H}, \mathrm{m}), 4.38-4.44(1 \mathrm{H}, \mathrm{m}), 6.97-7.02(3 \mathrm{H}, \mathrm{m}), 7.40-7.63$ $(7 \mathrm{H}, \mathrm{m}), 7.80(2 \mathrm{H}, \mathrm{d}, J=8.8 \mathrm{~Hz}), 10.02(1 \mathrm{H}, \mathrm{s}), 10.41(1 \mathrm{H}, \mathrm{s})$. Anal. Calcd for $\mathrm{C}_{41} \mathrm{H}_{53} \mathrm{~N}_{3} \mathrm{O}_{4} \cdot 2 \mathrm{HCl} \cdot 1.5 \mathrm{H}_{2} \mathrm{O}: \mathrm{C}, 65.50 ; \mathrm{H}, 7.78 ; \mathrm{N}, 5.59$. Found: $\mathrm{C}, 65.51$; $\mathrm{H}, 7.77 ; \mathrm{N}, 5.24$.

$\mathrm{N}$-(4-\{[Methyl(tetrahydro-2H-pyran-4-yl)amino]methyl\}phenyl)-7-(4morpholinophenyl)-2,3-dihydro-1-benzothiepine-4-carboxamide 1,1Dioxide (5e) A mixture of 7 e $(177 \mathrm{mg}, 0.44 \mathrm{mmol})$ and $\mathrm{HOBt}(90 \mathrm{mg}$, $0.67 \mathrm{mmol})$ in DMF $(5.0 \mathrm{ml})$ was added EDC $(127 \mathrm{mg}, 0.66 \mathrm{mmol})$ at room temperature. After being stirred for $1 \mathrm{~h}$ at room temperature, a solution of $\mathbf{8}$ $(107 \mathrm{mg}, 0.49 \mathrm{mmol})$ and $\mathrm{Et}_{3} \mathrm{~N}(0.12 \mathrm{ml}, 0.86 \mathrm{mmol})$ in DMF $(5.0 \mathrm{ml})$ and DMAP (cat. amount) was added to the reaction mixture at room temperature. The mixture was stirred at room temperature for $64 \mathrm{~h}$. The mixture was evaporated in vacuo, and water was added to the residue. The mixture was extracted with $\mathrm{CH}_{2} \mathrm{Cl}_{2}$. The organic layer was washed with brine, dried over $\mathrm{MgSO}_{4}$, and concentrated in vacuo. The residue was purified by column chromatography $(\mathrm{EtOAc}: \mathrm{EtOH}=1: 1)$ gave $31.6 \mathrm{mg}(12 \%)$ of $5 \mathbf{e}$ as pale yellow crystals. ${ }^{1} \mathrm{H}-\mathrm{NMR}\left(\mathrm{CDCl}_{3}\right) \delta 1.38-1.84(4 \mathrm{H}, \mathrm{m}), 2.23(3 \mathrm{H}, \mathrm{s})$, $2.58-2.80(1 \mathrm{H}, \mathrm{m}), 3.10-3.45(8 \mathrm{H}, \mathrm{m}), 3.61(2 \mathrm{H}, \mathrm{s}), 3.67-3.78(2 \mathrm{H}, \mathrm{m})$, $3.83-3.94(4 \mathrm{H}, \mathrm{m}), 3.99-4.09(2 \mathrm{H}, \mathrm{m}), 7.00(2 \mathrm{H}, \mathrm{d}, J=8.8 \mathrm{~Hz}), 7.19-$
$7.38(3 \mathrm{H}, \mathrm{m}), 7.49-7.60(4 \mathrm{H}, \mathrm{m}), 7.62-7.71(2 \mathrm{H}, \mathrm{m}), 7.89-7.95(1 \mathrm{H}, \mathrm{m})$, $8.19(1 \mathrm{H}, \mathrm{d}, J=8.4 \mathrm{~Hz})$. Anal. Calcd for $\mathrm{C}_{34} \mathrm{H}_{39} \mathrm{~N}_{3} \mathrm{O}_{5} \mathrm{~S} \cdot 1.5 \mathrm{H}_{2} \mathrm{O}: \mathrm{C}, 64.95 ; \mathrm{H}$, $6.73 ; \mathrm{N}, 6.68$. Found: C, 64.74; H, 6.57; N, 6.43. The hydrochloride salts were prepared by mixing 5e with an excess of conc. $\mathrm{HCl}$ in $\mathrm{EtOH}$ and $\mathrm{MeOH}$, followed by evaporation of the solvent and crystallization. ${ }^{1} \mathrm{H}-\mathrm{NMR}$ $\left(\mathrm{DMSO}-d_{6}\right) \delta 1.65-2.18(4 \mathrm{H}, \mathrm{m}), 2.60(3 \mathrm{H}, \mathrm{s}), 3.01-3.12(2 \mathrm{H}, \mathrm{m}), 3.16$ $3.51(7 \mathrm{H}, \mathrm{m}), 3.62-3.87(6 \mathrm{H}, \mathrm{m}), 3.93-4.07(2 \mathrm{H}, \mathrm{m}), 4.10-4.22(1 \mathrm{H}, \mathrm{m})$, $4.39-4.51(1 \mathrm{H}, \mathrm{m}), 7.08(2 \mathrm{H}, \mathrm{d}, J=8.8 \mathrm{~Hz}), 7.53-7.58(3 \mathrm{H}, \mathrm{m}), 7.72(2 \mathrm{H}$, d, $J=8.8 \mathrm{~Hz}), 7.80-7.92(3 \mathrm{H}, \mathrm{m}), 8.02-8.10(2 \mathrm{H}, \mathrm{m}), 10.42(1 \mathrm{H}, \mathrm{br} \mathrm{s})$.

7-\{4-[2-(Methoxy)ethoxy]phenyl $\}-N-(4-\{[$ methyl(tetrahydro- $H$ pyran-4-yl)amino]methyl $\}$ phenyl)-2,3-dihydro-1-benzothiepine-4-carboxamide 1,1-Dioxide (5f) A mixture of 9a $(300 \mathrm{mg}, 0.578 \mathrm{mmol}), 10 a$ $(124 \mathrm{mg}, 0.633 \mathrm{mmol})$ and $\mathrm{K}_{2} \mathrm{CO}_{3}(160 \mathrm{mg}, 1.16 \mathrm{mmol})$ in toluene $(10 \mathrm{ml})$, $\mathrm{EtOH}(1.0 \mathrm{ml})$ and water $(1.0 \mathrm{ml})$ was stirred at room temperature for $1 \mathrm{~h}$ under an argon atmosphere. $\mathrm{Pd}\left(\mathrm{PP}_{3}\right)_{4}(44.0 \mathrm{mg}, 0.038 \mathrm{mmol})$ was added, and the mixture was refluxed for $6 \mathrm{~h}$ under an argon atmosphere. The reaction mixture was extracted with EtOAc. The organic layer was washed with brine, dried over $\mathrm{MgSO}_{4}$, and concentrated in vacuo. The residue was purified by recrystallization from EtOH to give $246 \mathrm{mg}(72 \%)$ of $\mathbf{5 f}$ as colorless crystals. ${ }^{1} \mathrm{H}-\mathrm{NMR}\left(\mathrm{CDCl}_{3}\right) \delta 1.64-1.84(4 \mathrm{H}, \mathrm{m}), 2.21(3 \mathrm{H}, \mathrm{s}), 2.55-2.74$ $(1 \mathrm{H}, \mathrm{m}), 3.13-3.19(2 \mathrm{H}, \mathrm{m}), 3.32-3.44(2 \mathrm{H}, \mathrm{m}), 3.47(3 \mathrm{H}, \mathrm{s}), 3.58(2 \mathrm{H}$, s), $3.69-3.81(4 \mathrm{H}, \mathrm{m}), 3.99-4.09(2 \mathrm{H}, \mathrm{m}), 4.16-4.21(2 \mathrm{H}, \mathrm{m}), 7.04(2 \mathrm{H}$, $\mathrm{d}, J=8.8 \mathrm{~Hz}), 7.30-7.35(3 \mathrm{H}, \mathrm{m}), 7.52-7.56(4 \mathrm{H}, \mathrm{m}), 7.62-7.69(2 \mathrm{H}, \mathrm{m})$, $7.92(1 \mathrm{H}, \mathrm{s}), 8.19(1 \mathrm{H}, \mathrm{d}, J=8.4 \mathrm{~Hz})$. Anal. Calcd for $\mathrm{C}_{33} \mathrm{H}_{38} \mathrm{~N}_{2} \mathrm{O}_{6} \mathrm{~S}: \mathrm{C}$, 67.10; H, 6.48; N, 4.74. Found: C, 66.85; H, 6.40; N, 4.62.

The following compounds $(\mathbf{5 g}-\mathbf{k}, \mathbf{6} \mathbf{a}-\mathbf{d}, \mathbf{6} \mathbf{f}-\mathbf{h}, \mathbf{6 j})$ were prepared form the corresponding bromides $(9 \mathbf{a}-\mathbf{e})$ by a method similar to that described for $\mathbf{5 f}$.

7-\{4-[2-(Ethoxy)ethoxy]phenyl $\}-N-(4-\{[$ methyl(tetrahydro-2H-pyran4-yl)amino]methyl\}phenyl)-2,3-dihydro-1-benzothiepine-4-carboxamide 1,1-Dioxide (5g) ${ }^{1} \mathrm{H}-\mathrm{NMR}\left(\mathrm{CDCl}_{3}\right) \delta 1.26(3 \mathrm{H}, \mathrm{t}, J=7.0 \mathrm{~Hz}), 1.60-1.81$ $(4 \mathrm{H}, \mathrm{m}), 2.21(3 \mathrm{H}, \mathrm{s}), 2.65(1 \mathrm{H}, \mathrm{m}), 3.13-3.21(2 \mathrm{H}, \mathrm{m}), 3.31-3.44(2 \mathrm{H}$, m), $3.57(2 \mathrm{H}, \mathrm{s}), 3.63(2 \mathrm{H}, \mathrm{q}, J=7.0 \mathrm{~Hz}), 3.67-3.75(2 \mathrm{H}, \mathrm{m}), 3.83(2 \mathrm{H}, \mathrm{t}$, $J=5.0 \mathrm{~Hz}), 3.98-4.09(2 \mathrm{H}, \mathrm{m}), 4.19(2 \mathrm{H}, \mathrm{t}, J=5.0 \mathrm{~Hz}), 7.24(2 \mathrm{H}, \mathrm{d}$, $J=8.8 \mathrm{~Hz}), 7.30(1 \mathrm{H}, \mathrm{s}), 7.35(1 \mathrm{H}, \mathrm{s}), 7.51-7.69(6 \mathrm{H}, \mathrm{m}), 7.81(1 \mathrm{H}, \mathrm{s}), 8.19$ $(1 \mathrm{H}, \mathrm{d}, J=8.4 \mathrm{~Hz})$. Anal. Calcd for $\mathrm{C}_{34} \mathrm{H}_{40} \mathrm{~N}_{2} \mathrm{O}_{6} \mathrm{~S}: \mathrm{C}, 67.53 ; \mathrm{H}, 6.67 ; \mathrm{N}, 4.63$. Found: C, 67.55; H, 6.58; N, 4.71

$\mathrm{N}$-(4-\{[Methyl(tetrahydro-2H-pyran-4-yl)amino]methyl\}phenyl)-7-\{4[2-(propoxy)ethoxy]phenyl\}-2,3-dihydro-1-benzothiepine-4-carboxamide 1,1-Dioxide (5h) ${ }^{1} \mathrm{H}-\mathrm{NMR}\left(\mathrm{CDCl}_{3}\right) \delta 0.95(3 \mathrm{H}, \mathrm{t}, J=7.2 \mathrm{~Hz}), 1.60-1.80$ $(6 \mathrm{H}, \mathrm{m}), 2.21(3 \mathrm{H}, \mathrm{s}), 2.65(1 \mathrm{H}, \mathrm{m}), 3.13-3.20(2 \mathrm{H}, \mathrm{m}), 3.31-3.44(2 \mathrm{H}$, $\mathrm{m}), 3.52(2 \mathrm{H}, \mathrm{t}, J=6.8 \mathrm{~Hz}), 3.57(2 \mathrm{H}, \mathrm{s}), 3.68-3.75(2 \mathrm{H}, \mathrm{m}), 3.82(2 \mathrm{H}, \mathrm{t}$, $J=4.8 \mathrm{~Hz}), 4.10-4.20(2 \mathrm{H}, \mathrm{m}), 4.19(2 \mathrm{H}, \mathrm{t}, J=4.8 \mathrm{~Hz}), 7.04(2 \mathrm{H}, \mathrm{d}$, $J=8.8 \mathrm{~Hz}), 7.30-7.35(3 \mathrm{H}, \mathrm{m}), 7.51-7.68(6 \mathrm{H}, \mathrm{m}), 7.83(1 \mathrm{H}, \mathrm{s}), 8.19(1 \mathrm{H}$, d, $J=8.0 \mathrm{~Hz}$ ). Anal. Calcd for $\mathrm{C}_{35} \mathrm{H}_{42} \mathrm{~N}_{2} \mathrm{O}_{6} \mathrm{~S}: \mathrm{C}, 67.94 ; \mathrm{H}, 6.84 ; \mathrm{N}, 4.53$. Found: C, 67.87; H, 6.98; N, 4.45

7-\{4-[2-(Butoxy)ethoxy]phenyl\}- $\mathrm{N}-(4-\{[$ Methyl(tetrahydro-2H-pyran4-yl)amino]methyl phenyl)-2,3-dihydro-1-benzothiepine-4-carboxamide 1,1-Dioxide (5i) ${ }^{1} \mathrm{H}-\mathrm{NMR}\left(\mathrm{CDCl}_{3}\right) \delta 0.93(3 \mathrm{H}, \mathrm{t}, J=7.2 \mathrm{~Hz}), 1.33-1.55$ $(2 \mathrm{H}, \mathrm{m}), 1.57-1.77(6 \mathrm{H}, \mathrm{m}), 2.21(3 \mathrm{H}, \mathrm{s}), 2.65(1 \mathrm{H}, \mathrm{m}), 3.16(2 \mathrm{H}, \mathrm{t}$, $J=6.4 \mathrm{~Hz}), 3.31-3.44(2 \mathrm{H}, \mathrm{m}), 3.52-3.59(2 \mathrm{H}, \mathrm{m}), 3.57(2 \mathrm{H}, \mathrm{s}), 3.67-$ $3.74(2 \mathrm{H}, \mathrm{m}), 3.79-3.84(2 \mathrm{H}, \mathrm{m}), 3.98-4.08(2 \mathrm{H}, \mathrm{m}), 4.18(2 \mathrm{H}, \mathrm{t}$, $J=4.8 \mathrm{~Hz}), 7.03(2 \mathrm{H}, \mathrm{d}, J=8.8 \mathrm{~Hz}), 7.30-7.35(3 \mathrm{H}, \mathrm{m}), 7.50-7.66(6 \mathrm{H}$, m), $7.88(1 \mathrm{H}, \mathrm{s}), 8.18(1 \mathrm{H}, \mathrm{d}, J=8.0 \mathrm{~Hz})$. Anal. Calcd for $\mathrm{C}_{36} \mathrm{H}_{44} \mathrm{~N}_{2} \mathrm{O}_{6} \mathrm{~S}: \mathrm{C}$, $68.33 ; \mathrm{H}, 7.01 ; \mathrm{N}, 4.43$. Found: C, 68.33; H, 6.85; N, 4.39.

$\mathrm{N}$-(4-\{[Methyl(tetrahydro-2H-pyran-4-yl)amino]methyl\}phenyl)-7-\{4[2-(pentyloxy)ethoxy]phenyl\}-2,3-dihydro-1-benzothiepine-4-carboxamide 1,1-Dioxide (5j) ${ }^{1} \mathrm{H}-\mathrm{NMR}\left(\mathrm{CDCl}_{3}\right) \delta 0.90(3 \mathrm{H}, \mathrm{t}, J=6.6 \mathrm{~Hz}), 1.38$ $1.40(4 \mathrm{H}, \mathrm{m}), 1.56-1.77(6 \mathrm{H}, \mathrm{m}), 2.20(3 \mathrm{H}, \mathrm{s}), 2.64(1 \mathrm{H}, \mathrm{m}), 3.10-3.19$ $(2 \mathrm{H}, \mathrm{m}), 3.30-3.44(2 \mathrm{H}, \mathrm{m}), 3.55(2 \mathrm{H}, \mathrm{t}, J=6.6 \mathrm{~Hz}), 3.56(2 \mathrm{H}, \mathrm{s}), 3.65-$ $3.73(2 \mathrm{H}, \mathrm{m}), 3.79-3.85(2 \mathrm{H}, \mathrm{m}), 3.98-4.10(2 \mathrm{H}, \mathrm{m}), 4.15-4.21(2 \mathrm{H}, \mathrm{m})$, $7.00-7.06(2 \mathrm{H}, \mathrm{m}), 7.29-7.34(2 \mathrm{H}, \mathrm{m}), 7.47-7.66(7 \mathrm{H}, \mathrm{m}), 7.95(1 \mathrm{H}, \mathrm{s})$, $8.17(1 \mathrm{H}, \mathrm{d}, J=8.4 \mathrm{~Hz})$. Anal. Calcd for $\mathrm{C}_{37} \mathrm{H}_{46} \mathrm{~N}_{2} \mathrm{O}_{6} \mathrm{~S}: \mathrm{C}, 68.70 ; \mathrm{H}, 7.17 ; \mathrm{N}$, 4.33. Found: C, 68.64; H, 7.03; N, 4.31.

7-\{4-[3-(Ethoxy)propoxy]phenyl $\}-N-(4-\{[$ Methyl(tetrahydro-2Hpyran-4-yl)amino]methyl $\}$ phenyl)-2,3-dihydro-1-benzothiepine-4-carboxamide 1,1-Dioxide (5k) ${ }^{1} \mathrm{H}$-NMR $\left(\mathrm{CDCl}_{3}\right) \delta 1.21(3 \mathrm{H}, \mathrm{t}, J=7.0 \mathrm{~Hz})$, $1.69-1.77(4 \mathrm{H}, \mathrm{m}), 2.05-2.13(2 \mathrm{H}, \mathrm{m}), 2.21(3 \mathrm{H}, \mathrm{s}), 2.65(1 \mathrm{H}, \mathrm{m}), 3.16$ $(2 \mathrm{H}, \mathrm{t}, J=6.6 \mathrm{~Hz}), 3.31-3.44(2 \mathrm{H}, \mathrm{m}), 3.51(2 \mathrm{H}, \mathrm{q}, J=7.0 \mathrm{~Hz}), 3.57(2 \mathrm{H}, \mathrm{s})$, $3.62(2 \mathrm{H}, \mathrm{t}, J=6.2 \mathrm{~Hz}), 3.67-3.75(2 \mathrm{H}, \mathrm{m}), 3.98-4.16(4 \mathrm{H}, \mathrm{m}), 7.01(2 \mathrm{H}$, d, $J=8.8 \mathrm{~Hz}), 7.29-7.35(3 \mathrm{H}, \mathrm{m}), 7.50-7.67(6 \mathrm{H}, \mathrm{m}), 7.86(1 \mathrm{H}, \mathrm{s}), 8.18$ $(1 \mathrm{H}, \mathrm{d}, J=8.0 \mathrm{~Hz})$. Anal. Calcd for $\mathrm{C}_{35} \mathrm{H}_{42} \mathrm{~N}_{2} \mathrm{O}_{6} \mathrm{~S}: \mathrm{C}, 67.94 ; \mathrm{H}, 6.84 ; \mathrm{N}, 4.53$. Found: C, 67.67; H, 6.77; N, 4.54.

1-Methyl- $N$-(4-\{[methyl(tetrahydro-2H-pyran-4-yl)amino]methyl\}- 
phenyl)-7-(4-morpholinophenyl)-2,3-dihydro-1 $H$-1-benzazepine-4-carboxamide (6a) ${ }^{1} \mathrm{H}-\mathrm{NMR}\left(\mathrm{CDCl}_{3}\right) \delta 1.64-1.77(4 \mathrm{H}, \mathrm{m}), 2.21(3 \mathrm{H}, \mathrm{s})$, $2.57-2.75(1 \mathrm{H}, \mathrm{m}), 2.96(2 \mathrm{H}, \mathrm{t}, J=5.2 \mathrm{~Hz}), 3.09(3 \mathrm{H}, \mathrm{s}), 3.20(2 \mathrm{H}, \mathrm{t}$, $J=4.8 \mathrm{~Hz}), 3.18-3.22(2 \mathrm{H}, \mathrm{m}), 3.33-3.43(4 \mathrm{H}, \mathrm{m}), 3.58(2 \mathrm{H}, \mathrm{s}), 3.89(4 \mathrm{H}$, $\mathrm{t}, J=4.8 \mathrm{~Hz}), 4.01-4.06(2 \mathrm{H}, \mathrm{m}), 6.88(1 \mathrm{H}, \mathrm{d}, J=8.4 \mathrm{~Hz}), 6.97(2 \mathrm{H}, \mathrm{d}$, $J=8.8 \mathrm{~Hz}), 7.30(2 \mathrm{H}, \mathrm{d}, J=8.8 \mathrm{~Hz}), 7.41-7.56(8 \mathrm{H}, \mathrm{m})$. Anal. Calcd for $\mathrm{C}_{35} \mathrm{H}_{42} \mathrm{~N}_{4} \mathrm{O}_{3}$ : C, 74.18; H, 7.47; N, 9.89. Found: C, 73.92; H, 7.36; N, 9.95.

1-Methyl- $\mathrm{N}$-(4-\{[methyl(tetrahydro-2H-pyran-4-yl)amino]methyl $\}$ phenyl)-7-\{4-[2-(propoxy)ethoxy]phenyl\}-2,3-dihydro-1H-1-benzazepine4-carboxamide (6b) ${ }^{1} \mathrm{H}-\mathrm{NMR}\left(\mathrm{CDCl}_{3}\right) \delta 0.94(3 \mathrm{H}, \mathrm{t}, J=7.3 \mathrm{~Hz}), 1.65$ $(2 \mathrm{H}$, sextet, $J=7.2 \mathrm{~Hz}), 1.69-1.76(4 \mathrm{H}, \mathrm{m}), 2.21(3 \mathrm{H}, \mathrm{s}), 2.57-2.72(1 \mathrm{H}$, m), $2.96(2 \mathrm{H}, \mathrm{t}, J=4.4 \mathrm{~Hz}), 3.09(3 \mathrm{H}, \mathrm{s}), 3.32-3.43(4 \mathrm{H}, \mathrm{m}), 3.51(2 \mathrm{H}, \mathrm{t}$, $J=6.8 \mathrm{~Hz}), 3.56(2 \mathrm{H}, \mathrm{s}), 3.81(2 \mathrm{H}, \mathrm{t}, J=5.0 \mathrm{~Hz}), 4.01-4.06(2 \mathrm{H}, \mathrm{m}), 4.16$ $(2 \mathrm{H}, \mathrm{t}, J=5.0 \mathrm{~Hz}), 6.88(1 \mathrm{H}, \mathrm{d}, J=8.4 \mathrm{~Hz}), 6.98(2 \mathrm{H}, \mathrm{d}, J=8.8 \mathrm{~Hz}), 7.30(2 \mathrm{H}$, d, $J=8.6 \mathrm{~Hz}), 7.40-7.56(8 \mathrm{H}, \mathrm{m})$. Anal. Calcd for $\mathrm{C}_{36} \mathrm{H}_{45} \mathrm{~N}_{3} \mathrm{O}_{4} \cdot 0.25 \mathrm{H}_{2} \mathrm{O}: \mathrm{C}$, 73.50; H, 7.80; N, 7.14. Found: C, 73.12; H, 7.67; N, 7.08.

7-\{4-[2-(Butoxy)ethoxy]phenyl\}-1-methyl- $N$-(4-\{[methyl(tetrahydro2H-pyran-4-yl)amino]methyl\}phenyl)-2,3-dihydro-1 $H$-1-benzazepine-4carboxamide (6c) ${ }^{1} \mathrm{H}-\mathrm{NMR}\left(\mathrm{CDCl}_{3}\right) \delta 0.93(3 \mathrm{H}, \mathrm{t}, J=7.2 \mathrm{~Hz}), 1.39(2 \mathrm{H}$, sextet, $J=7.3 \mathrm{~Hz}), 1.55-1.79(6 \mathrm{H}, \mathrm{m}), 2.21(3 \mathrm{H}, \mathrm{s}), 2.57-2.75(1 \mathrm{H}, \mathrm{m})$, $2.96(2 \mathrm{H}, \mathrm{t}, J=4.4 \mathrm{~Hz}), 3.09(3 \mathrm{H}, \mathrm{s}), 3.31-3.38(2 \mathrm{H}, \mathrm{m}), 3.37(2 \mathrm{H}, \mathrm{td}$, $J=11.6,2.7 \mathrm{~Hz}), 3.55(2 \mathrm{H}, \mathrm{t}, J=6.6 \mathrm{~Hz}), 3.57(2 \mathrm{H}, \mathrm{s}), 3.81(2 \mathrm{H}, \mathrm{t}$, $J=5.0 \mathrm{~Hz}), 4.00-4.08(2 \mathrm{H}, \mathrm{m}), 4.16(2 \mathrm{H}, \mathrm{t}, J=5.0 \mathrm{~Hz}), 6.88(1 \mathrm{H}, \mathrm{d}$, $J=8.6 \mathrm{~Hz}), 6.96-7.01(2 \mathrm{H}, \mathrm{m}), 7.30(2 \mathrm{H}, \mathrm{d}, J=8.4 \mathrm{~Hz}), 7.40-7.56(4 \mathrm{H}$, $\mathrm{m}), 7.48(2 \mathrm{H}, \mathrm{d}, J=9.0 \mathrm{~Hz}), 7.54(2 \mathrm{H}, \mathrm{d}, J=8.6 \mathrm{~Hz})$. Anal. Calcd for $\mathrm{C}_{37} \mathrm{H}_{47} \mathrm{~N}_{3} \mathrm{O}_{4} \cdot 0.1 \mathrm{H}_{2} \mathrm{O}: \mathrm{C}, 74.12 ; \mathrm{H}, 7.93 ; \mathrm{N}, 7.01$. Found: C, 73.90; H, 7.82; $\mathrm{N}, 7.12$.

1-Ethyl- $N$-(4-\{[methyl(tetrahydro-2H-pyran-4-yl)amino]methyl $\}$ phenyl)-7-(4-morpholinophenyl)-2,3-dihydro-1 $H$-1-benzazepine-4-carboxamide (6d) ${ }^{1} \mathrm{H}-\mathrm{NMR}\left(\mathrm{CDCl}_{3}\right) \delta 1.32(3 \mathrm{H}, \mathrm{t}, J=7.1 \mathrm{~Hz}), 1.65-1.77$ $(4 \mathrm{H}, \mathrm{m}), 2.21(3 \mathrm{H}, \mathrm{s}), 2.57-2.72(1 \mathrm{H}, \mathrm{m}), 2.92(2 \mathrm{H}, \mathrm{t}, J=4.2 \mathrm{~Hz}), 3.20(4 \mathrm{H}$, $\mathrm{t}, J=4.9 \mathrm{~Hz}), 3.31-3.38(4 \mathrm{H}, \mathrm{m}), 3.44(2 \mathrm{H}, \mathrm{q}, J=6.9 \mathrm{~Hz}), 3.57(2 \mathrm{H}, \mathrm{s}), 3.89$ $(4 \mathrm{H}, \mathrm{t}, J=4.8 \mathrm{~Hz}), 4.01-4.07(2 \mathrm{H}, \mathrm{m}), 6.92(1 \mathrm{H}, \mathrm{d}, J=8.6 \mathrm{~Hz}), 6.97(2 \mathrm{H}, \mathrm{d}$, $J=8.8 \mathrm{~Hz}), 7.30(2 \mathrm{H}, \mathrm{d}, J=8.4 \mathrm{~Hz}), 7.40-7.56(8 \mathrm{H}, \mathrm{m})$. Anal. Calcd for $\mathrm{C}_{36} \mathrm{H}_{44} \mathrm{~N}_{4} \mathrm{O}_{3}: \mathrm{C}, 74.45 ; \mathrm{H}, 7.64 ; \mathrm{N}, 9.65$. Found: $\mathrm{C}, 74.34 ; \mathrm{H}, 7.54 ; \mathrm{N}, 9.61$.

1-Ethyl- $\mathrm{N}$-(4-\{[methyl(tetrahydro- $2 \mathrm{H}$-pyran-4-yl)amino]methyl\}phenyl)-7-\{4-[2-(propoxy)ethoxy]phenyl\}-2,3-dihydro-1H-1-benzazepine-4-carboxamide (6f) ${ }^{1} \mathrm{H}-\mathrm{NMR}\left(\mathrm{CDCl}_{3}\right) \delta 0.94(3 \mathrm{H}, \mathrm{t}, J=7.5 \mathrm{~Hz})$, $1.32(3 \mathrm{H}, \mathrm{t}, J=6.9 \mathrm{~Hz}), 1.65(2 \mathrm{H}$, sextet, $J=7.1 \mathrm{~Hz}), 1.70-1.76(4 \mathrm{H}, \mathrm{m})$, $2.21(3 \mathrm{H}, \mathrm{s}), 2.56-2.69(1 \mathrm{H}, \mathrm{m}), 2.92(2 \mathrm{H}, \mathrm{t}, J=4.0 \mathrm{~Hz}), 3.31-3.46(6 \mathrm{H}$, $\mathrm{m}), 3.51(2 \mathrm{H}, \mathrm{t}, J=6.8 \mathrm{~Hz}), 3.56(2 \mathrm{H}, \mathrm{s}), 3.81(2 \mathrm{H}, \mathrm{t}, J=4.9 \mathrm{~Hz}), 4.01-4.06$ $(2 \mathrm{H}, \mathrm{m}), 4.16(2 \mathrm{H}, \mathrm{t}, J=5.0 \mathrm{~Hz}), 6.92(1 \mathrm{H}, \mathrm{d}, J=8.4 \mathrm{~Hz}), 6.98(2 \mathrm{H}, \mathrm{d}$, $J=8.8 \mathrm{~Hz}), 7.30(2 \mathrm{H}, \mathrm{d}, J=8.8 \mathrm{~Hz}), 7.40(1 \mathrm{H}, \mathrm{s}), 7.47(2 \mathrm{H}, \mathrm{d}, J=8.8 \mathrm{~Hz})$, $7.54(2 \mathrm{H}, \quad \mathrm{d}, \quad J=8.8 \mathrm{~Hz}), \quad 7.40-7.56 \quad(3 \mathrm{H}, \quad \mathrm{m})$. Anal. Calcd for $\mathrm{C}_{37} \mathrm{H}_{47} \mathrm{~N}_{3} \mathrm{O}_{4} \cdot 0.25 \mathrm{H}_{2} \mathrm{O}: \mathrm{C}, 73.78 ; \mathrm{H}, 7.95 ; \mathrm{N}, 6.98$. Found: $\mathrm{C}, 73.52 ; \mathrm{H}, 7.76$; $\mathrm{N}, 6.95$

7-\{4-[2-(Butoxy)ethoxy]phenyl\}-1-ethyl- $\mathrm{N}$-(4-\{[methyl(tetrahydro-2Hpyran-4-yl)amino]methyl $\}$ phenyl)-2,3-dihydro- $1 \mathrm{H}$-1-benzazepine-4-carboxamide $(6 \mathbf{g g}){ }^{1} \mathrm{H}-\mathrm{NMR}\left(\mathrm{CDCl}_{3}\right) \delta 0.93(3 \mathrm{H}, \mathrm{t}, J=7.1 \mathrm{~Hz}), 1.32(3 \mathrm{H}, \mathrm{t}$, $J=7.0 \mathrm{~Hz}), 1.39(2 \mathrm{H}$, sextet, $J=7.4 \mathrm{~Hz}), 1.54-1.76(6 \mathrm{H}, \mathrm{m}), 2.21(3 \mathrm{H}, \mathrm{s})$, $2.54-2.72(1 \mathrm{H}, \mathrm{m}), 2.92(2 \mathrm{H}, \mathrm{t}, J=4.6 \mathrm{~Hz}), 3.31-3.50(6 \mathrm{H}, \mathrm{m}), 3.55(2 \mathrm{H}$, $\mathrm{t}, J=6.6 \mathrm{~Hz}), 3.57(2 \mathrm{H}, \mathrm{s}), 3.81(2 \mathrm{H}, \mathrm{t}, J=4.9 \mathrm{~Hz}), 4.01-4.07(2 \mathrm{H}, \mathrm{m}), 4.16$ $(2 \mathrm{H}, \mathrm{t}, J=5.0 \mathrm{~Hz}), 6.92(1 \mathrm{H}, \mathrm{d}, J=8.6 \mathrm{~Hz}), 6.98(2 \mathrm{H}, \mathrm{d}, J=8.8 \mathrm{~Hz}), 7.30(2 \mathrm{H}$, d, $J=8.4 \mathrm{~Hz}), 7.40(1 \mathrm{H}, \mathrm{s}), 7.44-7.56(3 \mathrm{H}, \mathrm{m}), 7.47(2 \mathrm{H}, \mathrm{d}, J=9.0 \mathrm{~Hz})$ $7.54(2 \mathrm{H}, \mathrm{d}, J=8.4 \mathrm{~Hz})$. Anal. Calcd for $\mathrm{C}_{38} \mathrm{H}_{49} \mathrm{~N}_{3} \mathrm{O}_{4} \cdot 0.2 \mathrm{H}_{2} \mathrm{O}: \mathrm{C}, 74.16 ; \mathrm{H}$, 8.09 ; N, 6.83. Found: C, 73.92; H, 8.19; N, 6.59.

7-\{4-[2-(Butoxy)ethoxy]phenyl\}- $\mathrm{N}$-(4-\{[methyl(tetrahydro-2 $\mathrm{H}$-pyran4-yl)amino]methyl $\}$ phenyl)-1-propyl-2,3-dihydro- $1 \mathrm{H}$-1-benzazepine-4carboxamide (6h) ${ }^{1} \mathrm{H}-\mathrm{NMR}\left(\mathrm{CDCl}_{3}\right) \delta 0.93(3 \mathrm{H}, \mathrm{t}, J=7.1 \mathrm{~Hz}), 0.99(3 \mathrm{H}$, $\mathrm{t}, J=7.3 \mathrm{~Hz}), 1.39(2 \mathrm{H}$, sextet, $J=7.2 \mathrm{~Hz}), 1.54-1.80(8 \mathrm{H}, \mathrm{m}), 2.20(3 \mathrm{H}, \mathrm{s})$, $2.53-2.71(1 \mathrm{H}, \mathrm{m}), 2.91(2 \mathrm{H}, \mathrm{t}, J=4.0 \mathrm{~Hz}), 3.27-3.43(6 \mathrm{H}, \mathrm{m}), 3.52-$ $3.58(4 \mathrm{H}, \mathrm{m}), 3.80(2 \mathrm{H}, \mathrm{t}, J=4.8 \mathrm{~Hz}), 4.01-4.06(2 \mathrm{H}, \mathrm{m}), 4.15(2 \mathrm{H}, \mathrm{t}$, $J=4.8 \mathrm{~Hz}), 6.89(1 \mathrm{H}, \mathrm{d}, J=8.8 \mathrm{~Hz}), 6.97(2 \mathrm{H}, \mathrm{d}, J=8.8 \mathrm{~Hz}), 7.29(2 \mathrm{H}, \mathrm{d}$, $J=8.4 \mathrm{~Hz}), 7.37-7.59(8 \mathrm{H}, \mathrm{m})$. Anal. Calcd for $\mathrm{C}_{39} \mathrm{H}_{51} \mathrm{~N}_{3} \mathrm{O}_{4}: \mathrm{C}, 74.85 ; \mathrm{H}$, 8.21 ; N, 6.71. Found: C, 74.64; H, 8.36; N, 6.93 .

7-\{4-[2-(Butoxy)ethoxy]phenyl\}-1-(3-methylbutyl)- $N$-(4-\{[methyl(tetrahydro-2H-pyran-4-yl)amino]methyl $\}$ phenyl)-2,3-dihydro- $1 \boldsymbol{H}$-1benzazepine-4-carboxamide (6j) ${ }^{1} \mathrm{H}-\mathrm{NMR}\left(\mathrm{CDCl}_{3}\right) \quad \delta \quad 0.93 \quad(3 \mathrm{H}, \quad \mathrm{t}$, $J=7.4 \mathrm{~Hz}), 0.99(3 \mathrm{H}, \mathrm{t}, J=6.2 \mathrm{~Hz}), 1.30-1.46(2 \mathrm{H}, \mathrm{m}), 1.49-1.81(9 \mathrm{H}$, $\mathrm{m}), 2.21(3 \mathrm{H}, \mathrm{s}), 2.52-2.71(1 \mathrm{H}, \mathrm{m}), 2.86-2.98(2 \mathrm{H}, \mathrm{m}), 3.27-3.46(6 \mathrm{H}$, $\mathrm{m}), 3.55(2 \mathrm{H}, \mathrm{t}, J=6.6 \mathrm{~Hz}), 3.56(2 \mathrm{H}, \mathrm{s}), 3.80(2 \mathrm{H}, \mathrm{t}, J=5.0 \mathrm{~Hz}), 3.96-4.07$ $(2 \mathrm{H}, \mathrm{m}), 4.16(2 \mathrm{H}, \mathrm{t}, J=5.0 \mathrm{~Hz}), 6.89(1 \mathrm{H}, \mathrm{d}, J=8.8 \mathrm{~Hz}), 6.98(2 \mathrm{H}, \mathrm{d}$, $J=8.8 \mathrm{~Hz}), 7.30(2 \mathrm{H}, \mathrm{d}, J=8.8 \mathrm{~Hz}), 7.39-7.55(8 \mathrm{H}, \mathrm{m})$. Anal. Calcd for $\mathrm{C}_{41} \mathrm{H}_{55} \mathrm{~N}_{3} \mathrm{O}_{4}: \mathrm{C}, 75.31 ; \mathrm{H}, 8.48 ; \mathrm{N}, 6.43$. Found: $\mathrm{C}, 74.94 ; \mathrm{H}, 8.70 ; \mathrm{N}, 6.50$.
Receptor Binding Assays CHO-K1 and CCR5-expressing CHO cells ${ }^{16)}$ were incubated with various concentrations of test compound in the binding buffer (Ham's F-12 medium containing $20 \mathrm{~mm}$ HEPES and $0.5 \%$ bovine serum albumin, $\mathrm{pH} 7.2$ ) containing $200 \mathrm{pm}\left[{ }^{125} \mathrm{I}\right] \mathrm{RANTES}$. Binding reactions were performed at room temperature for $40 \mathrm{~min}$. The binding reaction was terminated by washing out the free ligand with cold phosphate-buffered saline, and the cell-associated radioactivity was counted using a TopCount scintillation counter (Packard).

HIV-1 Envelope-Mediated Membrane Fusion Assay COS-7 cells were maintained in Dulbecco's modified Eagle medium (D-MEM) supplemented with $10 \% \mathrm{FBS}, 100 \mathrm{U} / \mathrm{ml}$ penicillin, and $100 \mu \mathrm{g} / \mathrm{ml}$ streptomycin. MOLT-4/CCR5/Luc ${ }^{+}$cells, a lymphoblastoid cell line that expresses human CCR5 and that has an integrated copy of the HIV-1 long terminal repeat-driven luciferase reporter gene, were maintained in RPMI 1640 medium supplemented with $10 \% \mathrm{FBS}, 100 \mathrm{U} / \mathrm{ml}$ penicillin, $100 \mu \mathrm{g} / \mathrm{ml}$ streptomycin, and $500 \mu \mathrm{g} / \mathrm{ml}$ geneticin. Tat, rev, and envelope cDNA were amplified from total RNA of R5 HIV-1 (JR-FL)-infected cells and cloned into an expression vector for mammalian cells. Those expression vectors were mixed at a ratio of $3: 1: 5$ and co-transfected into COS-7 cells using Lipofectamine 2000 (Invitrogen). After $2 \mathrm{~d}$ incubation, transfected COS-7 cells and MOLT$4 / \mathrm{CCR} 5 / \mathrm{Luc}^{+}$cells were seeded in a $96-$ well plate at $10^{4}$ cells each per well, and various concentrations of the test compounds were added to the wells. The cell suspension was incubated at $37^{\circ} \mathrm{C}$. The mixture of D-MEM and RPMI 1640 medium supplemented with $10 \% \mathrm{FBS}, 100 \mathrm{U} / \mathrm{ml}$ penicillin, and $100 \mu \mathrm{g} / \mathrm{ml}$ streptomycin was used as medium for membrane fusion. After an overnight incubation, Luc-Screen (Tropix) was added to each well, and the mixtures were incubated at room temperature for $10 \mathrm{~min}$. The luciferase activity was measured with a luminometer (Wallac 1420 ARVOsx).

Preliminary pharmacokinetic Analysis Compounds $(10 \mathrm{mg} / \mathrm{kg})$ suspended in $0.5 \%$ methylcellulose were orally administered to SD (IGS) rats (male, 8 weeks old). Blood samples were collected at different time points (pre, 15, $30 \mathrm{~min}, 1,2,4,8,24 \mathrm{~h}$ ) from the tail vein. Acetonitrile $(200 \mu \mathrm{l})$ was added to each plasma sample $(100 \mu \mathrm{l})$, and the precipitated plasma proteins were removed by centrifugation. The compound concentrations in the supernatant were measured by HPLC (column; Inertsil ODS-3, 4.6 $\times 150 \mathrm{~mm}$, $5 \mathrm{~mm}$ particle size, GL Science: mobile phase; acetonitrile- $0.01 \mathrm{~mol} / 1 \mathrm{am}-$ monium acetate or acetonitrile $-0.01 \mathrm{~mol} / 1$ phosphate buffer $(\mathrm{pH} 7)$ at a flow rate of $1.0 \mathrm{ml} / \mathrm{min}$ at $40^{\circ} \mathrm{C}$ : UV detection; 280 or $285 \mathrm{~nm}$ ).

Acknowledgment We thank Mr. Kenichi Kuroshima for the CCR5 binding assay; Mr. Katsunori Takashima, Dr. Hiroshi Miyake, and Ms. Shikiko Shiki for the membrane fusion assay.

\section{References}

1) Deng H., Liu R., Ellmeier W., Choe S., Unutmaz D., Burkhart M., Di Marzio P., Marmon S., Sutton R. E., Hill C. M., Davis C. B., Peiper S. C., Schall T. J., Littman D. R., Landau N. R., Nature (London), 381, 661-666 (1996).

2) Dragic T., Litwin V., Allaway G. P., Martin S. R., Huang Y., Nagashima K. A., Cayanan C., Maddon P. J., Koup R. A., Moore J. P., Paxton W. A., Nature (London), 381, 667—673 (1996).

3) Alkhatib G., Combadiere C., Broder C. C., Feng Y., Kennedy P. E., Murphy P. M., Berger E. A., Science, 272, 1955-1958 (1996).

4) Choe H., Farzan M., Sun Y., Sullivan N., Rollins B., Ponath P. D., Wu L., Mackay C. R., LaRosa G., Newman W., Gerard N., Gerard C., Sodroski J., Cell, 85, 1135-1148 (1996).

5) Doranz B. J., Rucker J., Yi Y., Smyth R. J., Samson M., Peiper S. C., Parmentier M., Collman R. G., Doms R. W., Cell, 85, 1149-1159 (1996).

6) Cocchi F., DeVico A. L., Garzino-Demo A., Arya S. K., Gallo R. C., Lusso P., Science, 270, 1811-1815 (1995).

7) Liu R., Paxton W. A., Choe S., Ceradini D., Martin S. R., Horuk R., MacDonald M. E., Stuhlmann H., Koup R. A., Landau N. R., Cell, 86, 367-377 (1996).

8) Samson M., Libert F., Doranz B. J., Rucker J., Liesnard C., Farber C. M., Saragosti S., Lapoumeroulie C., Cognaux J., Forceille C., Muyldermans G., Verhofstede C., Burtonboy G., Georges M., Imai T., Rana S., Yi Y., Smyth R. J., Collman R. G., Doms R. W., Vassart G., Parmentier M., Nature (London), 382, 722 -725 (1996).

9) Dean M., Carrington M., Winkler C., Huttley G. A., Smith M. W., Allikmets R., Goedert J. J., Buchbinder S. P., Vittinghoff E., Gomperts E., Donfield S., Vlahov D., Kaslow R., Saah A., Rinaldo C., Detels R., O’Brien S. J., Science, 273, 1856-1862 (1996).

10) Carpenter C. C., Fischl M. A., Hammer S. M., Hirsch M. S., Jacobsen 
D. M., Katzenstein D. A., Montaner J. S., Richman D. D., Saag M. S., Schooley R. T., Thompson M. A., Vella S., Yeni P. G., Volberding P. A., J. Am. Med. Assoc., 280, 78-86 (1998).

11) Finzi D., Blankson J., Siliciano J. D., Margolick J. B., Chadwick K., Pierson T., Smith K., Lisziewicz J., Lori F., Flexner C., Quinn T. C., Chaisson R. E., Rosenberg E., Walker B., Gange S., Gallant J., Siliciano R. F., Nat. Med., 5, 512-517 (1999).

12) Pomerantz R. J., J. Am. Med. Assoc., 282, 1177-1178 (1999).

13) Deeks S. G., Smith M., Holodniy M., Kahn J. O., J. Am. Med. Assoc., 277, 145-153 (1997).

14) Saunders J., Tarby C. M., Drug Discov. Today, 4, 80—92 (1999).

15) Schwarz M. K., Wells T. N., Nat. Rev. Drug. Disc., 1, 347-358 (2002).

16) Baba M., Nishimura O., Kanzaki N., Okamoto M., Sawada H., Iizawa Y., Shiraishi M., Aramaki Y., Okonogi K., Ogawa Y., Meguro K., Fujino M., Proc. Natl. Acad. Sci. U.S.A., 96, 5698- 6703 (1999).
17) Shiraishi M., Aramaki Y., Seto M., Imoto H., Nishikawa Y., Kanzaki N., Okamoto M., Sawada H., Nishimura O., Baba M., Fujino M., J. Med. Chem., 43, 2049-2063 (2000).

18) Aramaki Y., Seto M., Okawa T., Oda T., Kanzaki N., Shiraishi M., Chem. Pharm. Bull., 52, 254-258 (2004).

19) Takeda K., Akiyama A., Nakamura H., Takizawa S., Mizuno Y., Takayanagi H., Harigaya Y., Synthesis., 1994, 1063 (1994).

20) Hewson A. T., Hughes K, Richardson S. K., Sharpe D. A., Wadsworth A. H., J. Chem. Soc. Perkin Trans. 1, 1991, 1565-1569 (1991).

21) Booker-Milburn K. I., Dunkin I. R., Kelly F. C., Khalaf A. I., Learmonth D. A., Proctor G. R., Scopes D. I., J. Chem. Soc. Perkin Trans. 1, 1997, 3261-3274 (1997).

22) Abdel-Mggid A. F., Carson K. G., Harris B. D., Maryanoff C. A., Shah R. D., J. Org. Chem., 61, 3849-4862 (1996).

23) Arnauld T., Barton D. H. R., Doris E., Tetrahedron, 53, 4137-4144 (1997). 